



\title{
RE-ARCHITECTURE: MEANS-ORIENTED DESIGN
}

By:

\author{
Arkadiusz Zjawin \\ Bachelor of Architectural Science, Ryerson University, Toronto, 2011
}

\author{
A design thesis|project \\ presented to Ryerson University \\ In partial fulfillment of the \\ requirements for the degree of \\ Master of Architecture
}

Toronto, Ontario, Canada, 2013

CArkadiusz Zjawin 2013 

Ryerson University

Master of Architecture 2013

Arkadiusz Zjawin

Re-Architecture: means oriented design

\section{Abstract}

Depleting fossil fuels and heavy reliance on such energy sources for production of construction materials can render a great deal of disorder in the near future for the architectural, engineering and construction industries. The ideal resource management methods are currently in trial stage, and as much as 'cradle to cradle' or 'closed cycle loop' are achievable they will have to be accompanied by a different mindset from the designer's standpoint. Design with reused or superused materials requires a means-oriented approach. With such high levels of residential post construction and demolition waste lies a great opportunity for their direct application (with minor processing), which is currently highly underutilized. Shortcircuiting the material flow and its possibilities for reuse or superuse may lead to a different kind of aesthetics that this thesis seeks to explore. 



\section{Acknowledgements}

My first and sincere appreciation goes to my thesis supervisor Dr. Mark Gorgolewski, whose passion for the topic, shared with me a few years earlier, lead to this investigation. His encouragement throughout the process, his vast knowledge and insightful feedback helped me to maintain the enthusiasm during past months. I am truly grateful for his time and support.

I am thankful to my second advisor, Professor Taymoore Balbaa, for sharing his different perspective on the topic. I am grateful for his expertise and advice.

I am also grateful to my Ryerson colleagues for support and help.

Finally, I would like to thank my wife and son, Bogumiła and Alexander, for their love and understanding. Without the support of my family the completion of this thesis would not be possible. 



\section{Author's declaration}

I hereby declare that I am the sole author of this thesis|project.

I authorize Ryerson University to lend this thesis|project to other institutions or individuals for the purpose of scholarly research. 



\section{Table of Contents}

$\begin{array}{lll} & \text { Abstract } & \text { V } \\ \text { 1. Introduction } & 1\end{array}$

1.1. Diminishing resources

1.2. Construction and environment

1.3. Waste Stream

1.4. Current policy and restrictions

2. Unchartered territories of reuse

2.1. From Rome to Motor City

2.2. Altering the material flow

2.3. Building as a living organism

2.4. Reuse vs. Superuse

2.5. Urban harvest in local context

2.6. Condition of reuse market

2.7. Reused material retinal locations

2.8. Means-oriented design

3. Case Studies 28

3.1. Case $1 \mathrm{Re}-$ Use: The Big Dig House

3.2. Case 2 Superuse: Miele Space Station

3.3. Case 3 Re-Use: MEC Winnipeg

4. Embodied Energy 36

5. Experimentation 42

5.1. House 1

5.2. House 2

5.3. Wasted elevation

5.4. Local Superuse opportunities

6. The design exploration 52

$\begin{array}{lll}\text { 7. Conclusion } & 87\end{array}$

$\begin{array}{ll}\text { List of figures } & 92\end{array}$

$\begin{array}{lr}\text { References } & 98\end{array}$ 



\section{Introduction}

The construction industry is one of the main waste generators and its function as such is yet to be adequately addressed by the 'green building' industry. Materials that make up the built environment and ultimately end up on landfills are only considered at design stage and only from the perspective of resource management (rapidly renewable, sustainable in harvest and level of recycled content). Reuse is an approach, that despite being present since ancient Egypt and written about in Vitruvius' The ten books on Architecture, is not a part of the main stream in architecture. In the United States between 25\% (Ogbu L., 2010) and 27\% (EPA, 2012) of the building stock existing in 2000 will be decommissioned by 2030 . There is a great opportunity for architects and industry leaders to utilize the materials that are temporarily being part of those structures. The social stigma attached to preowned seems to leave its mark on architecture, as the designers rarely challenge themselves with alternative sources of building materials.

\section{Research objective}

My intention is to identify the opportunities and challenges working with material in a closed loop. The focus will be on material reuse and its application within a limited distance from materials origin. The investigation will not be limited to construction material but products from other industries with a potential use in construction. 



\section{ALUMINUM}

abundant

IRON ORE

114 years

URANIUM

67 years

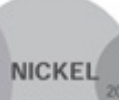

\section{$>$}

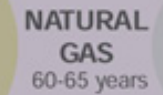

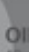

\subsection{Diminishing resources}

The definition of the term, sustainable development, first appeared in a Report of the Wold Commission on Environment and Development entitled Our Common Future.

'Sustainable development seeks to meet the needs and aspirations of the present without compromising the ability to meet those of the future. Far from requiring the cessation of economic growth, (Brundtland, 1987)

The current rate of consumption that has been steadily increasing since industrialization is unsustainable. Constant growth economies that we base our financial stability on rely heavily on extraction of resources and consumption at unprecedented rates. Since the 1960s the usage of resources such as minerals, metals and wood increased more than threefold and the use of petroleum based plastics increased $560 \%$. Humanity is exploiting the earth at a rate that surpasses its ability to regenerate by $30 \%$. (Bums, B. 2008)

Sustainable development similar to reused material consideration is an example of 'finale world thinking'. It's juxtaposed to a 'notion of an infinite world, where waste creation and resource consumption would be perceived to have little consequence'. (Bums, B. 2008)

The 1973 Oil Crisis served as a wake-up call, exposing the dependence that human civilization has on this finite resource. Considering that the current core of manufacturing is oil that is found in everything from baby oil to upholstery to diapers, the fact that this resource is running out, should alert society to modify its consumption habits. Currently, about $37 \%$ of the world's energy supply is generated from burning oil or petroleum, which one of the most harmful greenhouse gas and toxin emitting processes. (Botkin, 2010). This dependence on one resource that is projected to last for another 20 to 40 years (depending on current or projected demand) is worrisome.

Fig 1.1 Diminishing Resources, years remaining at rate of current use 
With increasing cost of fossil fuel comes increasing cost of manufacturing of construction materials, however, the relationship of these two is not linear. China, once considered as a haven of cheap labour, is undergoing a change in terms of manufacturing cost. Forecasts predicting $300 \%$ growth of the middle class over next ten years (Hongbin L. 2012) present a challenge for salary increases. The cost of 'cheap' manufacturing has been steadily increasing, due to a combined accumulation of higher land and raw material costs, but above all, an increase in manufacturing wages in urban areas, which have increased over $200 \%$ from 2003 to 2010 (Hongbin L. 2012). This clearly is an end of inexpensive production and supply of cheap goods to the west.

It is not uncommon for local developers to use materials manufactured in China in order to maximize their profit, with Toronto's Trump Tower and its cladding system serving as an example. With increasing transportation costs, these practices have an expiry date and in the future, more emphasis will be made on local material suppliers. 


\subsection{Construction and environment}

In order to reduce the environmental impact of construction projects, designers ought to follow Trias Ecologica principles; these seek reduction in GHG and energy use on new construction:

1. Avoid the need for building materials

2. Apply Renewable sources;

3. Select materials with the lowest environmental impact. (Rovers R., 2008)

The order reflects the burden on the environment as avoiding the need for materials results in minimal impact. Eliminating the need for raw materials can be accomplished by designing for longevity of flexible buildings. This permits adaptive reuse at a later date, once the original function can no longer be housed in the building. The following steps are suggested during addressing the need for materials:

Step 1. Look for an existing building that can be used

Step 2. Investigate whether an existing building can be transformed to fit the purpose

Step 3. If steps 1 and 2 fail, a new building can be designed made from existing building products (reuse)

Step 4. If steps 1, 2 and 3 fail, a new building can be designed made from new building products, following the principles of Trias Ecologica. (Rovers R., 2008)

This thesis will focus on Step 3 - use of existing building products in construction and its implications on the design process and construction. This methodology diverts the materials from landfills as well as reduces the need for extraction of raw materials used for production of building materials. 


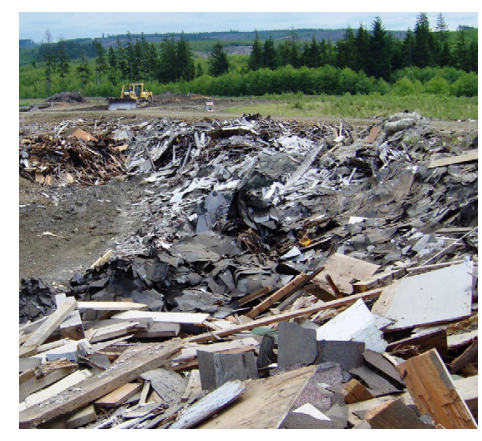

Fig 1.2 Construction and demolition waste landfill.

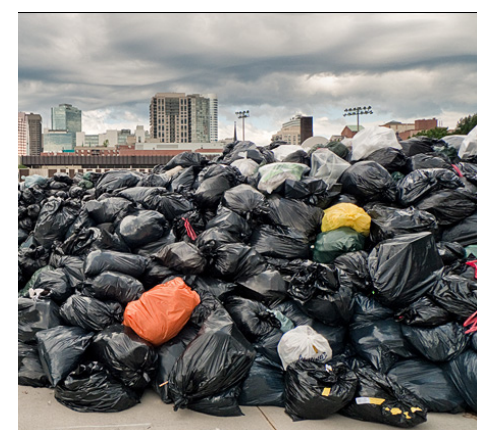

Fig 1.3 2009 Toronto Garbage Collection Srike.

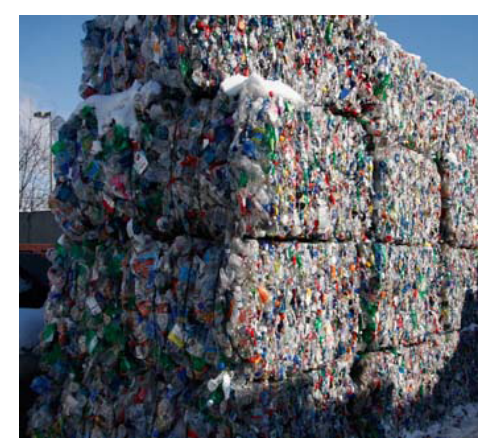

Fig 1.4 Recycling material prepared for processing

\subsection{Waste Stream}

In 2002, there were 30.45 million tonnes of solid waste generated in Canada, out of which $11 \%$ is a result of construction, renovation and demolition (C\&D) (Stats Can). Ontario had its share of the score, by producing 12 million tonnes, with each sector contributing respectively:

- $\quad 1.2$ million tonnes derived from C\&D

- $\quad 6.5$ million tonnes from the commercial and institutional sector

- $\quad 4.4$ million tonnes from the residential

The waste such as concrete, asphalt and steel is recycled at a high rate. On the other hand materials such wood and gypsum recycled at lower rates.

Despite of waste management being a subject of interest in Ontario, inexpensive landfills and lack of fees and taxation still prevents from larger reuse of construction 'waste' and post construction material. The province's government has set a goal of $60 \%$ of waste to be diverted from waste streams by the end of 2008 , by means of the $3 R$ principle (Reduce, Reuse and Recycle) to minimise the degradation of the natural environment caused by disposal. (Saotome, 2007)

Ontario's Environmental Protection Act speaks of the 3Rs. Ontario Regulation $102 / 94$ and 103/94 are applied to building projects and strongly relate to C\&D waste management. Mentioned below are two regulations for C\&D waste management from projects that generate these wastes: 
Ontario Regulation 102/94 applies to C\&D projects characterized by at least 2,000 square meters in total floor area and it requires owners to assess the project conducting a waste audit followed by a waste reduction plan that is to be updated annually. (Saotome, 2007)

Ontario Regulation 103/94, on the other, hand talks about C\&D projects at least 2,000 square meters in total floor area and it requires owners to execute source separation and recycling of waste. The construction materials that are designated for recycling are cardboard, brick, concrete, unpainted gypsum wall board, steel and untreated wood. Demolition materials designated for recycling include all of the above with the exception of gypsum wall board. (Saotome, 2007) The regulations, however, barely touch on reuse or the salvage approach to materials and no recommendations are found regarding diversion of waste using those methods.

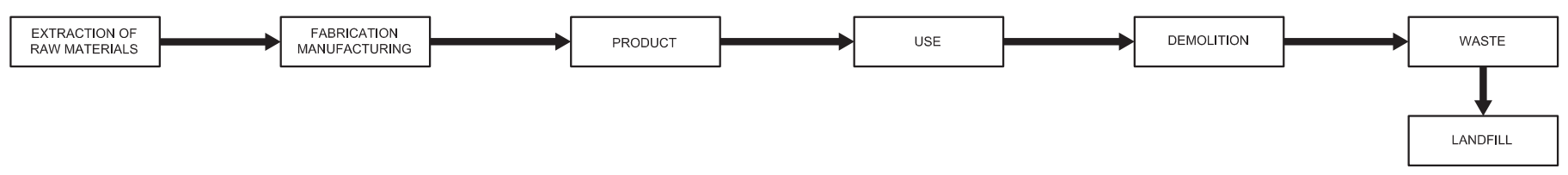

Fig 1.5 Current linear flow "cradle to grave" 


\subsection{Current Policy and restrictions}

\section{Ontario Building Code}

Application of reused material in new construction is governed by local codes and bylaws. In Ontario the Ontario Building Code does permit for material reuse

\section{"1.2.2.2. Used Materials, Appliances and Equipment}

(1) Unless otherwise specified, recycled materials in building products may be used and used materials, appliances and equipment may be reused when they meet the requirements of this Code for new materials and are satisfactory for their intended use" (OBC, 2006)

When considering reused lumber for structural design, it is important to ensure that it is graded. Not certified or ungraded lumber cannot be used in structural applications in residential buildings. It is permitted, however, for the material to be evaluated by a licenced grader or an engineer who could render the material to be to standards and therefore used as a structural component. It is especially important factor as some older buildings that can serve as material donors are not constructed with graded lumber. In such a scenario, it is important to properly assess the potential material and its structural abilities prior to design stage.

Graded lumber means lumber that has been graded and stamped to indicate its grade, as determined by the NLGA "Standard Grading Rules for Canadian Lumber". (OBC, 2006)

The Ontario Building Code does, however, permit the use of ungraded and uncertified lumber in farm buildings for posts, common rafters, lintels, beams and wall studs. "More critical structural components (roof trusses, floor joists, etc.) require the use of graded lumber." (McDonald, 2010)

Another permitted application of ungraded lumber can occur in OBC Part 11 buildings (renovation). The compliance alternative provision states: 


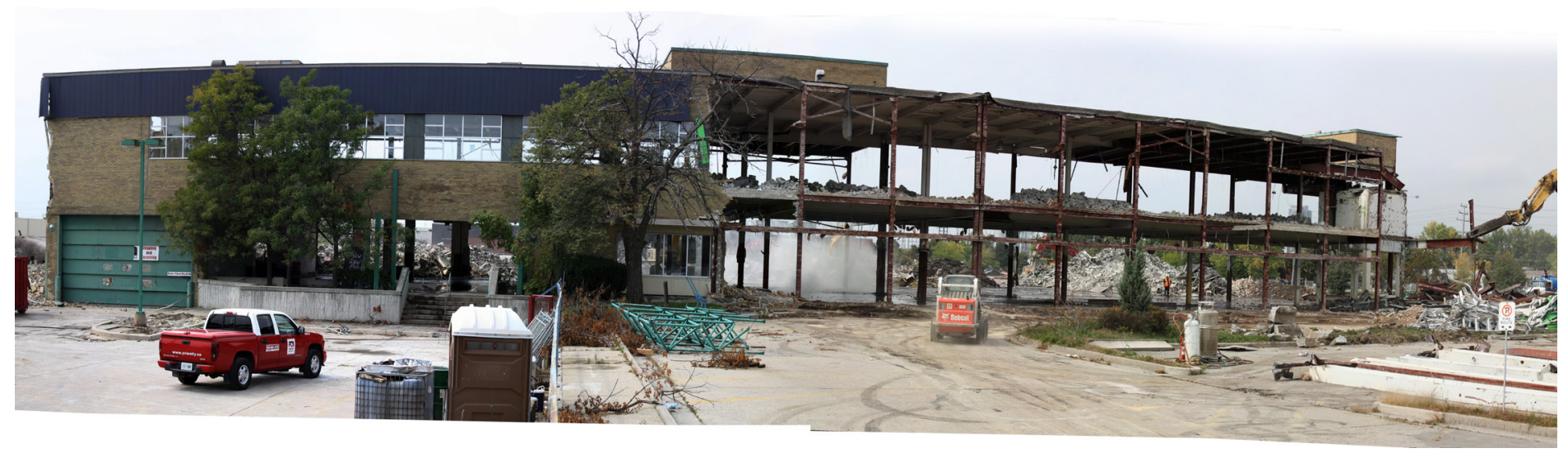

"Sound used lumber may be acceptable for reuse without a grade stamp provided that:

(a) visual examination shows no excessive weakening by holes, notches, nail splits or other damage,

(b) where the grade or species is unknown, the minimum grade shall apply for span table use, and

(c) lumber has not been subjected to termite infestation." (OBC, 2006)

Reuse of Structural Steel is permitted by the code as the steel structure is designed and sealed by a professional engineer. It is, however, important for the involved engineer to assess the quality of the material sourced from a demolished building. It also require care in salvaged material handling and storage, as steel members to be reused cannot be damaged.

Ontario Building Code in Part 9 Section 9.20.2.1 lists a number of standards that unit masonry shall comply with. The code clearly allows the use of used brick in section 9.20.2.2 Sentence 1 "Used bricks shall be free of old mortar, soot or other surface coating and shall conform to (...)" the current standards. (OBC, 2006) Material that does not meet the requirement can still be utilized as the code permits its application for parching and filling of existing work to match adjacent finishes.

Similarly the sanitary equipment is permitted to be reused as long as it meets the current standards.

Any potential material that is to be reused would need to undergo an assessment and be tested against current regulations and standards. This can impact the cost of the materials. It is noteworthy that some US reused material brokers provide specifications and testing of their stock to ensure local code compliance. A similar service in Ontario could encourage material reuse, as it would assure Ontario Code compliance of the offered materials.
Fig 1.6 Etobicoke building demolished, with steel components segregated for recycling - reuse opportunity 


\section{Reused material and tax credits}

Building with reused materials is only possible if there is a material supply from deconstruction process. Due to higher time and labor requirements deconstruction seems not as attractive for the property owners as demolition. According to National Association of Home Builders case studies the immediate cost is about $17 \%$ higher when compared to traditional demolition process (NAHBRC, 2000) and Dantata et al (2004) concluded the difference to be $17 \%-25 \%$. The increased cost of deconstruction can be justified by the labor required to disassemble and process the material which also impacts the scheduling as deconstruction is twice to 10 times longer to complete (Chini \& Breuning, 2003).

There are multiple contract structures currently used when contracting deconstruction. The for-profit deconstruction models vary depending on the initial cost incurred and ownership of the acquired material and include: Deconstruct Service (owner Retains materials), Deconstruct (split material ownership), and Deconstruct (contractor retains materials). Because of increased cost, for-profit options, the only options available in Canada, do not work to the advantage of material Reuse.

One of the powerful tools encouraging deconstruction (thus reuse) among homeowners in United States are tax credits. In order to take advantage of this option the building owner should be a taxable entity, generated through contracting a non-profit organization with education and traning focus and donating the deconstructed material to that organization both of which are recognized in the 526 Publication from the Department of the Treasury's Internal Revenue Service for Charitable Contributions (IRS, 2010). The tax deduction benefit from donation of the material is based on an appraisal of the structures prior to deconstruction and it is calculated as Value of the donation (appraisal) multiplied by the tax bracket the owner is in. In example if the building to be deconstructed and donated is appraised at $\$ 54,600$ and the tax bracket is $35 \%$, the deduction is $\$ 19,1100$ ((or $0.35 \times \$ 54,600$ ) (McLear, 2011). A tax credit derived from contracting a non-profit organization with education and training focus is calculated based on the contract amount and equals the contract price multiplied by the tax bracket. In example 
if the work was contracted at $\$ 35,000$ and the tax bracket of the owner is $35 \%$," the cash donation tax deduction \$12,250 (or \$35,000 x 0.35)" (McLear, 2011). In addition there are also other tax credits available depending on state or region. In example in Colorado State Enterprise Zone additional tax incentives are offered if deconstruction is conducted by an organization that uses the donation (deconstructed building) to generate jobs, or for job preservation, or for homeless persons programs. If the non-profit organization contracted for work conducts deconstruction trenning programs on the donated building "the credit can be used as a tax incentive" (McLear, 2011).

The table below is a calculation from a case study conducted by Kyle McLear and MaryEllen C. Nobe, and represents tax incentives when deconstruction was conducted by a The National Center for Craftsmanship a non-profit organization with a training focus located in a special Colorado State Enterprise Zone.

\section{Table 2}

The Property Owner Benefit Using The NCC Deconstruct Model

Owner Income Tax Bracket* $35 \%$

Competing Demolition Bid* $\$ 20,000$

Cost of Deconstruct Contract* $\$ 35,000$

Appraised Value of In-kind Material Donation* $\$ 54,600$

Tax Incentives

Cash Contribution Deduction Value

In-kind Materials Deduction Value $\$ 19,110$

Enterprise Zone Tax Credit

$\$ 22,400$

Subtotal: Deductions \& Credit Benefits

$\$ 53,760$

Benefit to Deconstruct

$\$ 18,760$

Net Benefit to Deconstruct

$\$ 38,760$

Return on Investment

$53.6 \%$

* Input variables received from The National Center for Craftsmanship Source (McLear, 2011). 


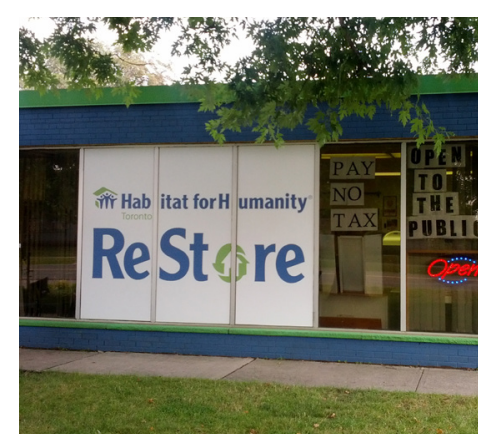

Fig 1.7 Reused material retailer in Ontario

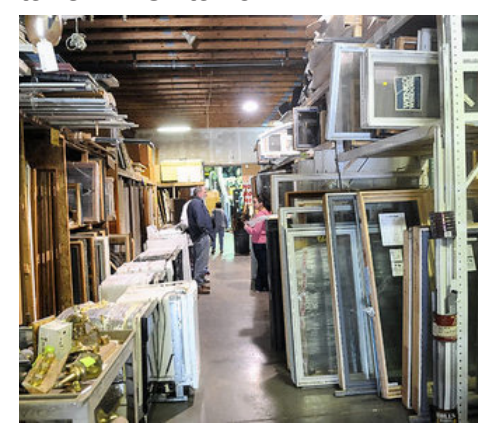

Fig 1.8 Salvaged and overstock materials offered at restores at fraction of the retail price

\section{Restore}

In Province of Ontario Habitat for Humanity accepts donation of construction material that in turn is sold in its ReStore retail outlets. The organization accepts donations that according to their experience have a potential of being in demand and such donations qualify for a charitable tax receipt (Habitat, 2012). According to Mike Bennett of ReStore the price thus value of the donation is based on guidelines which take into consideration the brand, condition (fair, good, excellent) and quality of materials it is made with (in case of millwork: pressed board, melamine, solid wood). The sale price of donated items, thus the value of the charitable tax receipt is usually set at $50 \%$ of the retail price of the same or similar new item. The values are set by the salvage crew or office sAtaff.

Canada Revenue Agency stipulates that all gifts in kind (non-cash gifts) receive a receipt to the amount that reflects a fair market value.

Fair market value is normally the highest price, expressed in dollars that property would bring in an open and unrestricted market, between a willing buyer and a willing seller who are knowledgeable, informed, and prudent, and who are acting independently of each other. (RCA 2011)

It is however recommended by RCA that any donation of more than $\$ 1,000$ to be apprised by a third party professional associated with neither the donor nor the charity. (RCA, 2013) This reduces a possibility of reassessment of a value of the donation.

Habitat for humanity does not provide tax receipts for deconstruction services as legally charities cannot issue such for any services. From administrative standpoint, however, there are tools that permit such operation. The charity compensates the contractor in full for the service, following which he or she issues a cheque donation of a similar amount thus (also referred to as cheque exchange). As a result the contractor receives a tax receipt. 
Below is a simulation of potential tax credit using Canada Revenue Agency Charitable donation tax credit calculator based on a material donation of $\$ 10,000$.

Province: Ontario

Tax Year: 2013

Total Donation: $\quad \$ 10,000.00$

Federal tax credit: $\quad \$ 2,872.00$

Provincial tax credit: $\quad \$ 1,103.78$

Total tax credits: $\quad \$ 3,975.78$

Source RCA 2013

The process of gentrification of some Toronto neighbourhoods is a generator of a large amount of demolition waste. It is a great opportunity for a donation of an entire building for deconstruction. However, according to Bruce Johnston (CFO of Habitat for Humanity Toronto) there is no record of anyone ever attempting it. 



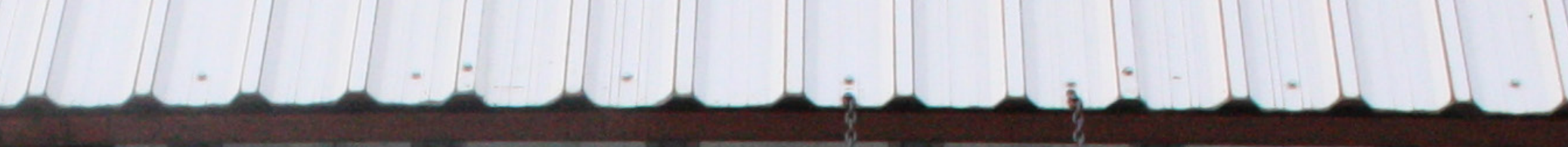

2. Unchartered territories of reuse 


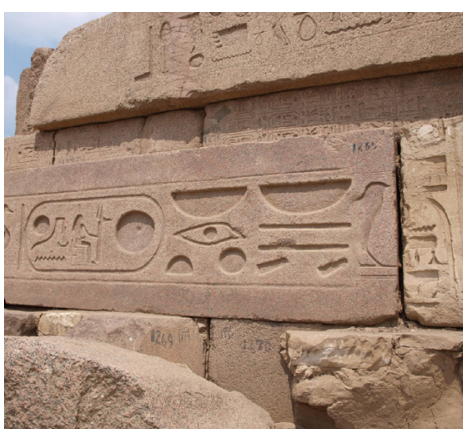

Fig 2.1 Reused architectural elements from Pi-Ramesses

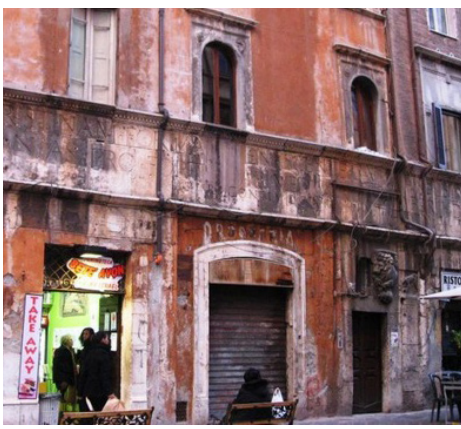

Fig 2.2 Ancient Rome stone reuse in later construction

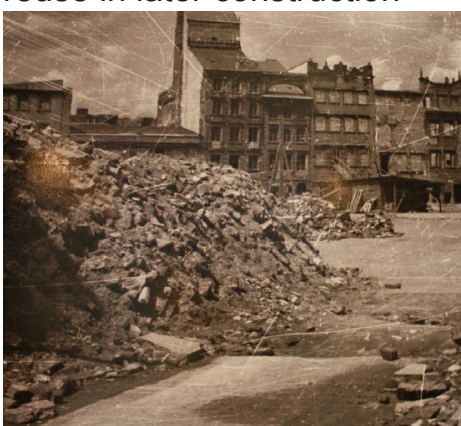

Fig 2.3 Rebuilding Warsaw 1945 , reuse all materials

\subsection{From Rome to Motor City}

When hardship strikes many innovative or radical solutions become acceptable. In post-WWII Europe, it was a common trend to grow fruits and vegetables in the urban environment on every accessible scrap of soil, however, once the economy picked up, such agriculture was frown upon and slowly phased out. It was not until Patric Blanc and his 1988 green wall at the Museum of Science and Industry in Paris, when the concept regained grip in the urban setting.

Similarly, material reuse is a common movement in times of hardship, and was practiced to accelerate construction, as reuse of existing temple components reduced time required for raw stone quarrying. It was also practiced in scenarios of cities in decline. The shrinking cities leave abandoned stock and due to claimants to the properties it is often impossible to take possession of an existing building until it falls into disrepair and adaptive reuse is no longer possible. At that point, the owners show disinterest to keep/maintain the building and it becomes a donor. A Donor is a building that is exposed to scavengers who salvage the materials in the order of their market value or reusability. Since scavengers usually work without sophisticated equipment, their extraction efforts are limited in accordance to manpower.

The results of this activity are still visible in Rome (ancient temple elements reused as lintels or headers) and can be currently observed in any large US city that is in the process of shrinking with Detroit being the best example. 


\subsection{Altering the material flow}

Recycling is the most common method of diverting materials from rapidly filling wastelands. High recycling rates of materials such as concrete, asphalt or steel are associated with reduction in $\mathrm{GHG}$ emissions as a result or reduced raw material extraction. Recycling also reduces the energy use and waste generation linked to the processing of raw materials.

A step further from recycling is the practice of reusing or reclaiming also referred to as salvaging. For the purpose of this thesis I classified the above as Reuse. It is the extraction materials from waste and repurposing them with minimal processing that does not impact the material's nature. Similarly to recycling, reuse involves waste material, with a difference being, that it does not involve extensive and energy consuming processing associated with production of new material from recycled content.

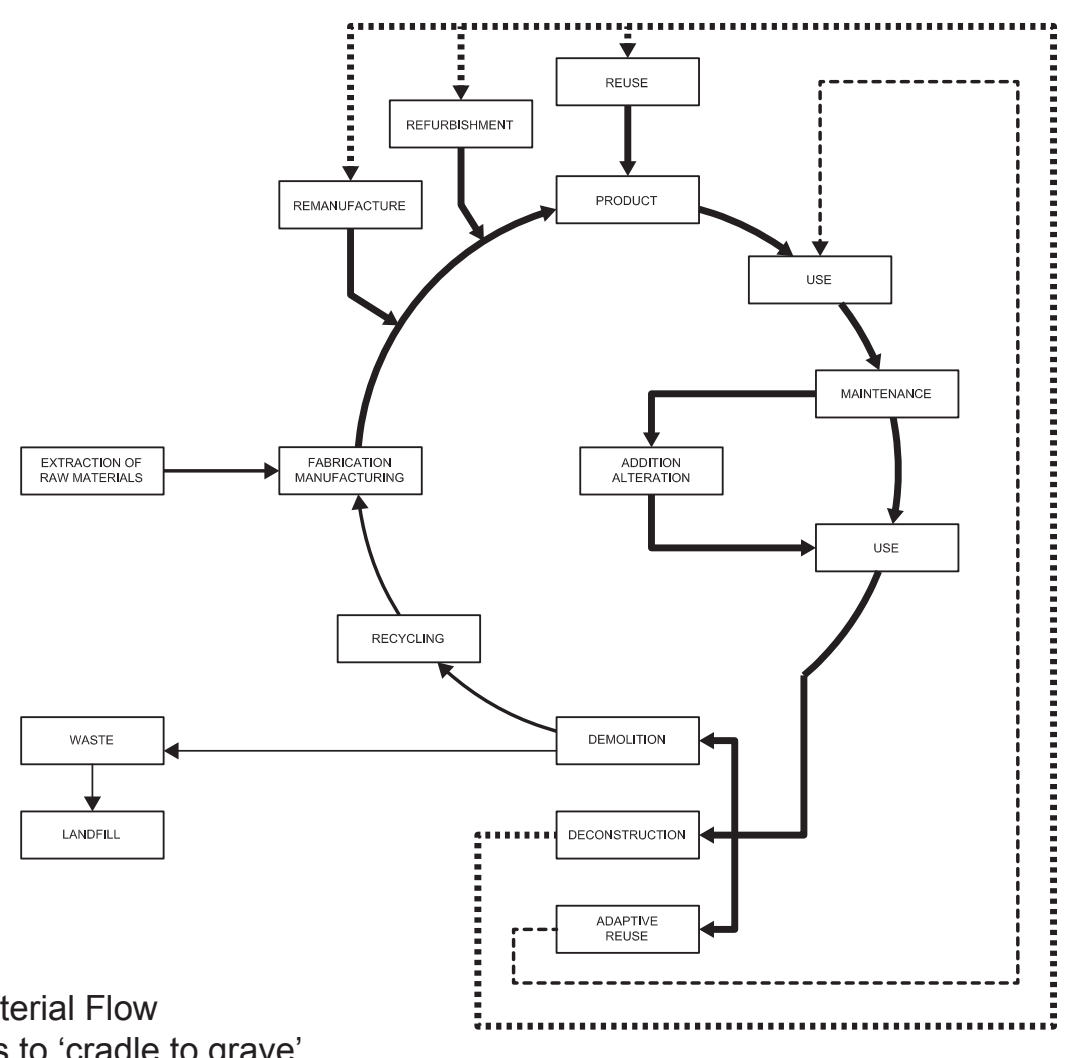

alternatives to 'cradle to grave' 


\subsection{Building as a living organism}

Wilfried Wang, in Sustainability is a Cultural Problem, criticizes the current dogma of building perception, stating that,

“...orthodox architectural historiography is focused on buildings as they first came into being and more often than not as free standing, that is to say de-contextualized objects. The inclusion of a building in the canon is based on its status as a new object."

Wang notes that buildings are not judged by their ability adapt over time or change in accordance to new condition. As time and weatherization impact the performance and appearance of architecture and at times drastically alter the original architect's vision, buildings are hardly ever designed with change in mind. Designing for deconstruction is a trend present in the profession but not commonly practiced and never mentioned in academic discourse.

Architecture, by nature, is susceptible to time, and buildings should never be considered as a single frame, but in continues movement through time facing its forces. Césare Peeren shares this stand point in saying,

“I don't really believe in current process, defined as they seem to be by economic. It can be seen as a leftover of modernism (...) I'm interested in building as a living thing/organism, constantly changing, growing, and degenerating, absorbing the superfluous that they find in their surrounds and setting free what is no longer needed" (E. Hinte et al, 2007)

From that perspective, replacements (addition or removal) of entire components or parts of buildings can be seen as an ultimate transplant. The reuse methodology acknowledges different stages of the building's life, and does not seek its eternal preservation but rather opportunities for a structure to be 'served' or 'serving others'. Therefore, even though deconstruction is the end of life for any building in its original form, it allows building components to live on in other projects.

High profile buildings containing quality components, that require replacing to maintain buildings performance, can serve as a great material source for other 
structures of no high profile or performance requirement. Large scale material reuse could then create interrelationships between different building typologies with material/energy flows similar to biological ecosystems.

\subsection{Reuse vs. Superuse}

Reusing results in the reduction of environmental impact of a project, assuming that the refurbishing of reused components is not highly energy consuming and the material is not transported a great distance. It may be, however, limiting in its nature as it considers an object only in the same function as it had in its original setting. Jan Jongret of 2012 Architecten finds the greatest potential in a different approach to reuse as he states that:

"It's not very interesting to restore the former state of things. At best they will look like they did before. The most interesting buildings are those that are in motion, that evolve over time." (E. Hinte et al, 2007)

Superuse is creating architecture by 'shortcutting a flow of products and elements from their state of maximum added value to stage which value has (...) been dissipated' (E. Hinte et al, 2007) and it seeks to create a new narrative for an existing object through attempts to design from existing stock of already made stuff. To superuse, is to take an object that is considered waste and generate its new function, by placing it in a new context and associating with it a whole new meaning. It not only serves as an extension of the life cycle of an object that is to be decommissioned but it gives that object a second life - life after death.

Potential sources of superuse projects are not limited to building materials, but extend beyond that, into automotive, aerospace or energy sector objects. It can involve dead stock of over-manufactured product with no demand and, therefore, no market value, or objects decommissioned due to regulation change (otherwise operational). 2012 Architecten is a firm which adopted the term superuse. In their practice they seek potential sources of materials in post-production waste, short lifespan objects or items commonly referred to as temporary that support making or fabrication (i.e. formwork). 


\subsection{Urban harvest in local context}

A Harvest Map is a concept investigated by 2012 Architecten, which maps available material of no value or waste available for redesign. The map is closely connected with the superuse design approach and helps to graphically represent the distance from the source of material to its destination. This is important data, as the transportation impacts the embodied energy. The fathers of superuse went further in their analysis, mapping energy and waste flow in the urban setting and layering all data to extract possible material generators.

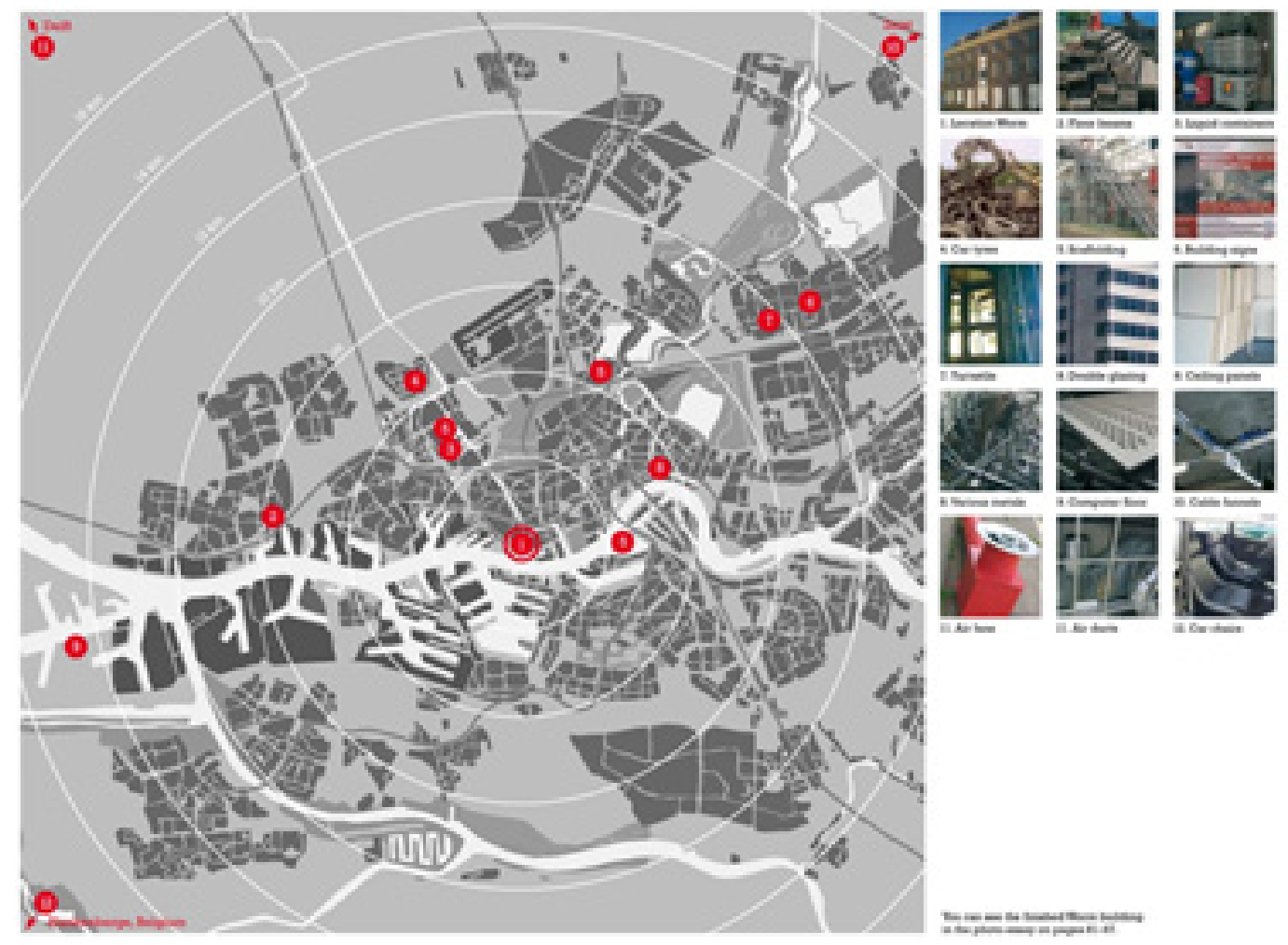

Fig. 2.5 Example Harvest Map Warm 


\subsection{Condition of Reuse market}

Detroit Renailed Market Development Summit (Sept 20-22, 2012) organized by The Building Materials Reuse Association (BMRA) and the Detroit Area Deconstruction Steering Committee gave me an insight to the current state of the industry that specializes in resource extraction from existing house stock bound for demolition. Deconstruction was a term used by most of those gathered in the Next Energy Center in Detroit, whereas I would prefer to use the term, salvage. The industry leaders exchanged their views on disassembling wooden structures with focus on individual consumer and his/her small volume needs. A fresh view on the potential of the market was presented by Nathan Benjamin, founder and principal of Planet Reuse. With his experience as a consultant to multiple architectural projects, he sees a future of reuse as a market for building material parallel to big box construction stores. In his efforts to make the stock information available to consumers (architects included) he developed a system that provides information on the product, stock availability, and photographs of the material, as well the option to purchase it online. Planet Reuse recognizes that in order to incorporate reused materials in new projects, architects need to have information about materials available, as well as the volume at which particular materials can be accessed. Benjamin hopes that his efforts in making all that information available on his service will boost the popularity of reuse and increase the number or projects giving materials a second life.

One of the main challenges of the reused market lies in having the knowledge of what can be salvaged and what materials will be available at the end of the deconstruction project. Considering that current building stock is not designed for disassembly poses a challenge to develop methodologies to extract, analyse, assess (code compliance, structural properties), store and provide information about salvaged material. It is also burdensome architects to take the path of reusing materials, as they expose themselves to greater risk, due to the unpredictability of reused materials (unknowns at the start of the project). Design for deconstruction allows for the data pertaining to the potential reuse, be made available beforehand as the components are designed with repeated application in mind. 
It seems that there are three stages to the reuse implementation. Currently, we are in a stage which has a lot of variables and unknowns, due to building stock that was designed on a cradle to grave ideology. Through material reuse we transition into the future that is based on Design for Deconstruction. Over time, the waste stream will be reduced in the attempts to fully close the cycle.
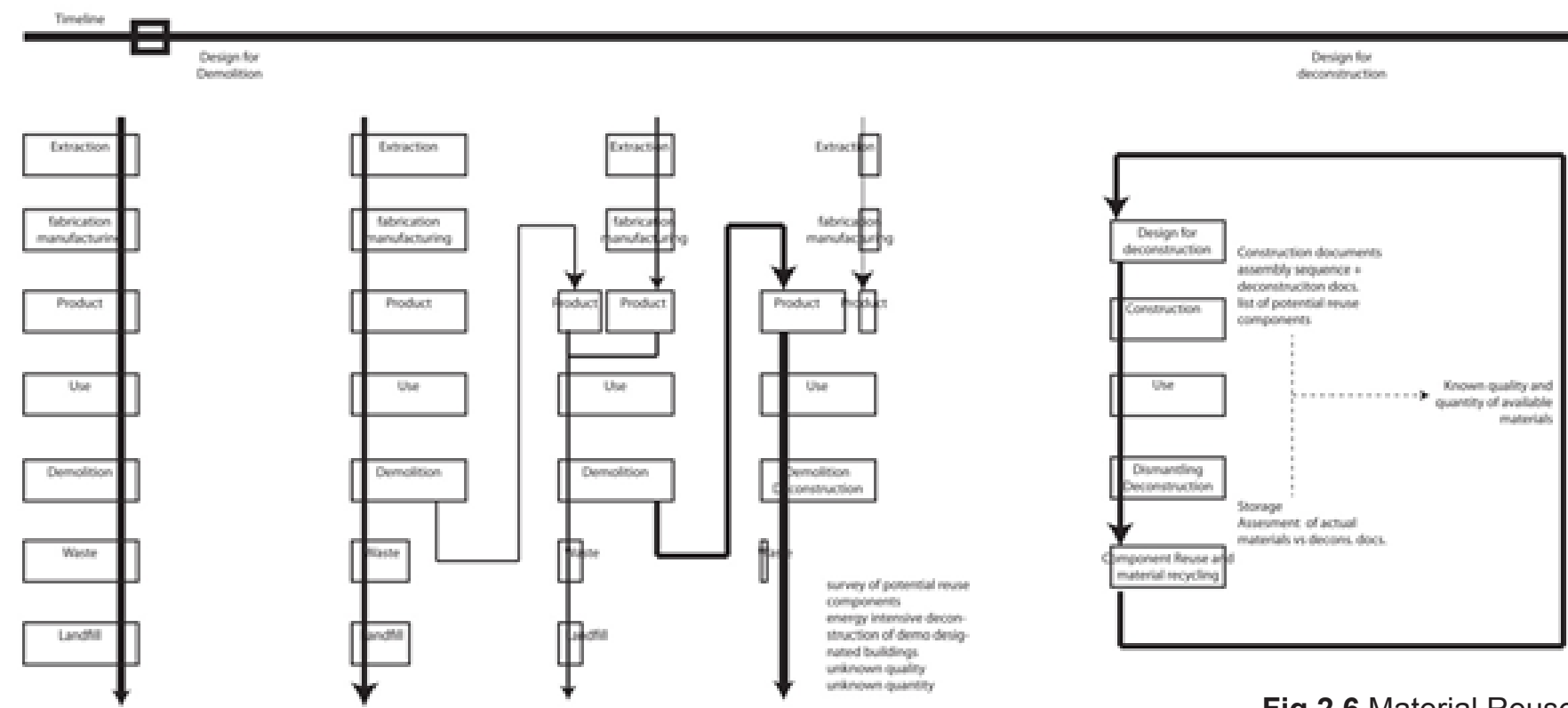

Fig 2.6 Material Reuse Stages 


\subsection{Reused material retail locations}

ReStore is a retail outlet owned and operated by Habitat for Humanity, a non-profit organization. The stores sell new (overstock) and used construction materials that were previously donated to the organization. Property owners and contractors donate carefully dismantled building parts (i.e. doors, windows, cabinetry, fixtures etc.) that are later processed and sold for profit. The profits help to offset administrative cost of Habitat for Humanity and permits large or entire sun of cash donations to be designated for construction of adequate living for families in substandard housing. Currently there are four ReStore locations in Toronto. Each retail location is staffed with volunteers, this arrangement allows for salary savings of $\$ 420,000$ a year. With net profits of $\$ 1,316$ million in $2008, \$ 1,386$ million in 2009 (Borrow, 2010), \$1,51 million in 2010 and \$1,141 million in 2011 (Thorton, 2012) the retail locations help to cover the administrative cost in case of Toronto division. As ReStore sells items typically at $20 \%-50 \%$ of original retail value it promotes material reuse while diverting waste from landfill, which in 2010 accounted for over $3,279,482$ lbs or 1,488 metric tonnes (Habitat, 2012).

As Toronto ReStores do not provide any workshops, other reused material retail locations are built around just that. Rebuilding Exchange in Chicago Illinois focuses on creating the market for their products by organizing studios, do-it-yourself seminars, allow small scale fabrication in their workshops and support deconstruction and reuse through 100 different workshops in a year (rebuilding exchange, 2013). This promotes community engagement and empowerment as local residents can purchase, modify and create without a need for private workshop. Rebuilding Exchange also offers a number of original products designed and built in their facility. 


\subsection{Means-oriented design}

Reuse challenges:

Getting the entire team, from the owners to the contractor, on board early in the stage of the project is an essential move to ensure the project's success. The architects involved in reuse projects noted that enthusiasm and devotion promoting reuse made it possible to convince the parties involved. (Ogbu L., 2010)

Early insight into material availability is another challenge, therefore, building networks of material distributors and brokers is essential. The latter can find desired material outside of the local market, secure stock and provide specifications or samples. This is where the reuse industry is still lacking. Most of the retailers focus on small scale clients, and do not want to invest in stock systems or databases which are essential to provide architects with information for the design process such as the amount of available material. This, in turn, is an obstacle for the implementation of reuse on a larger scale or even a larger project.

During the documentation stage, it is difficult to specify reused products as they may be uncertain in their performance, which is why performance focused specifications that clearly describe the functioning and task of the material in-situ seem to be a choice (Ogbu L., 2010).

The time required in obtaining an alternative source of material can be an issue as well. The materials are not off the shelf and ordering them may render difficulties if not strategically planned. If deconstruction materials are used on the same site for a new structure, additional time ought to be accounted for the salvaging process as it is more energy and labour consuming than typical demolition. Harvested materials, however, may be of higher quality, with lesser VOC emissions and with lower environmental impact than new materials. Experimentation with reused materials, in some cases, permits quality and aesthetics otherwise unaffordable.

One of the greatest both challenges and opportunities to look beyond the original material designation as defined by superuse, which 2012 Architecten specifically 


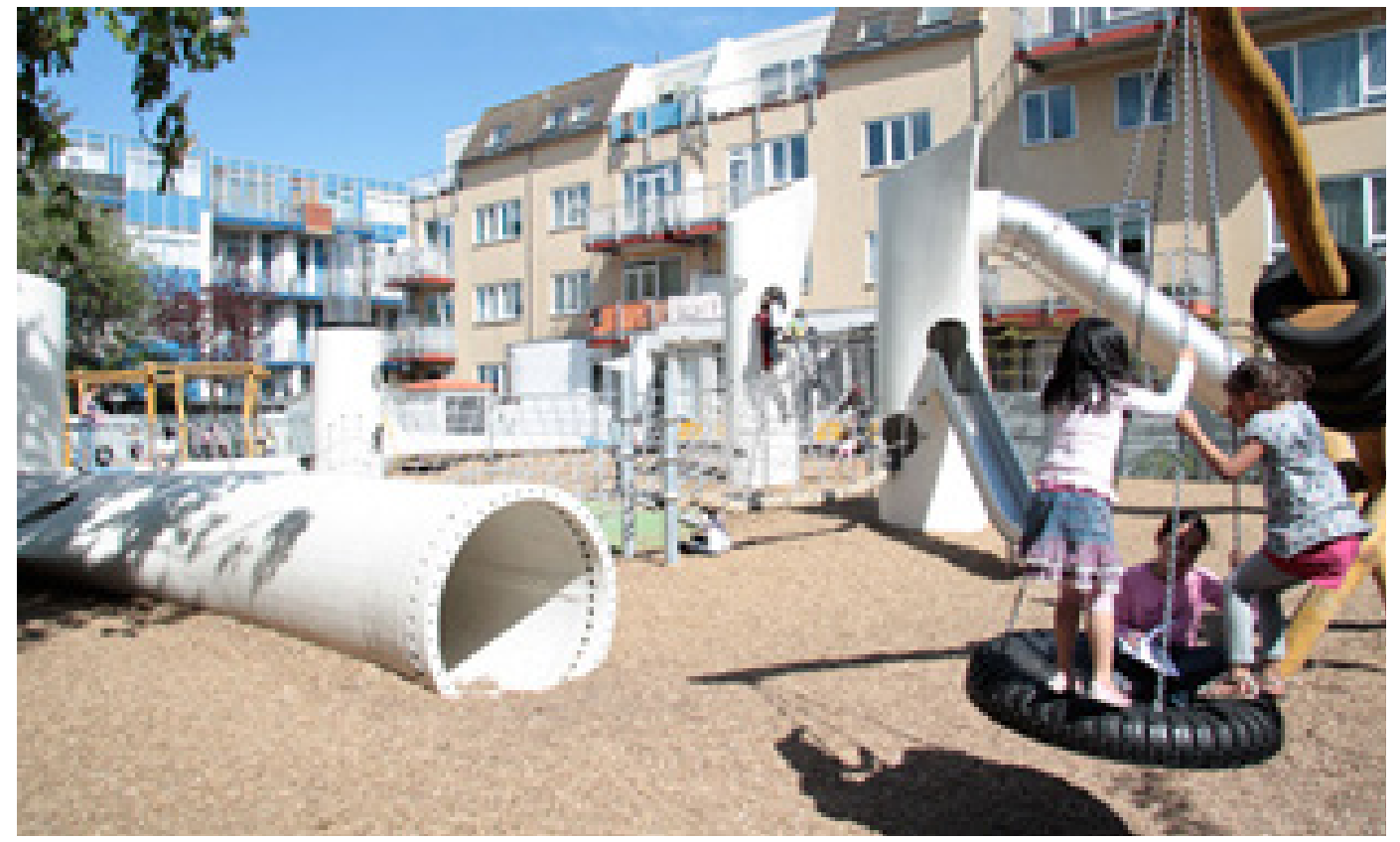

focuses on, developing an alternative type of aesthetics, that is ought to be judged through the perspective of the material state at the starting point.

There is, however, an expiry date on Reuse. Its current form relies on waste as a source of material. What was doomed to be a part of landfill is carefully disassembled by reuse crews and made available back on the market. Therefore, if waste is considered a product that can generate income, an undesirable flow of waste for the sake of generating profit may become a secondary side effect. Such a scenario is only possible in the case of highly successful superuse design, utilizing waste as its basis.

Due to improvements in wind turbine blade design or damage about 8,000 blades are replaced around the world each year due to their wear and/or improvements in design (more efficient profiles). (Brigitte Franzen et al. 2010). Wikado Playground (Fig.2.7) uses decommissioned wind turbine blades that are otherwise regarded to as trash. The blades are no longer suitable for application in a wind turbine but they are still structurally sound, waterproof, high quality material that can be used in design of streetscape objects. In case of Wikado a combination of five blades provided surfaces for climbing, tunnels for crawling through and structural sup-
Fig 2.7 Wikado Playground 2012 Architecten, Rotterdam, The Netherlands 
ports for other elements such as climbing nets. The blades due to their finish and shape are an interesting and intriguing form and a highly diverse building material that allowed completion of the project at a similar cost as a typical playground at $2 \%$ global footprint. (Brigitte Franzen et al. 2010)

If, however, a higher demand for such playgrounds is generated, the used blades due to their demand would increase in value, jeopardizing the future financial feasibility of such projects.

Reuse has also its share of sceptics criticizing its narrow application and the small part that it plays in the process of creating a built environment and the building's life cycle. Mark Goedkoop a co-founder of Pre Consultants in Amersfoort NL states that "Measures such as insulation and decisions about the way the sun can determine climate quality are far more important than reuse of materials. (...) air conditioning systems that need to be replaced should not be reused due to their inefficiency." (E. Hinte et al, 2007)

Goedkoop goes further to state that the transportation distances are only relevant in the larger life cycle calculations when transporting bulk material. Curtain walls, concrete brick as well as sand and gravel hauled from miles away alters the equation but materials such as window frames due to their weight, do not matter. It seems that adaptive reuse is a far more superior solution than reuse of building material, but at the same time Goedkoop looks at reuse from a different perspective saying that "It's possible that you get more value with reduced environmental impact. Creating architecture provides an expression of reuse that may compensate for inefficiency."

In the case of lighter structures such as wood frame buildings, the scenario is much different. With bulk materials being used only at below ground applications, they make a great case for reuse. If the overall weight of the building is taken into account and cross-referenced with reused or recycled content a Material-Neutral Building Index can be calculated (Rovers R., 2010). Material-Neutral Building Index goes beyond the life-cycle analysis as it attempts to assess the building's performance in a material closed loop scenario. If ultimate resource management is a closed loop approach, reusing is its core element. 

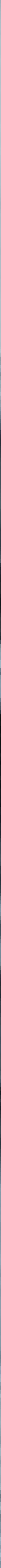


\section{Case Studies}




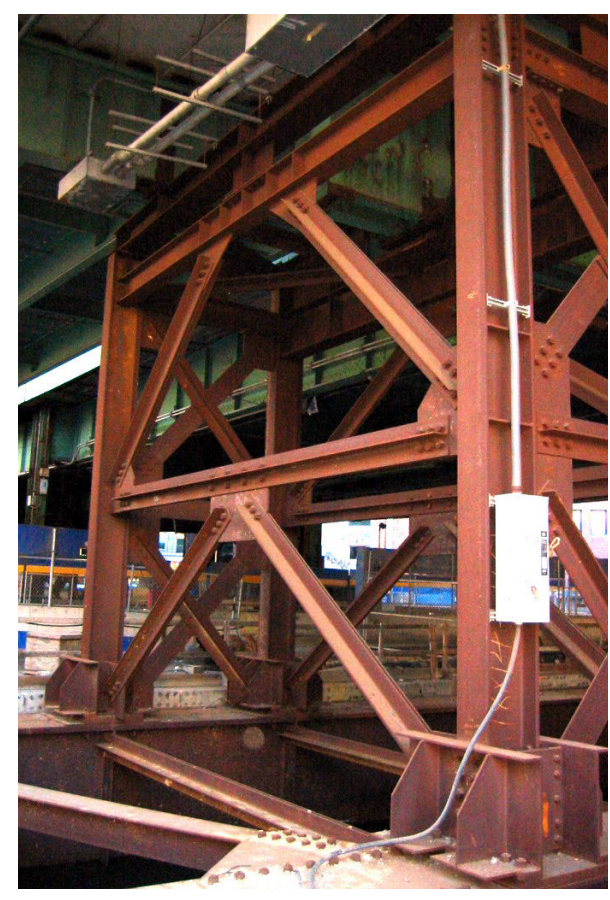

From Left:

Fig 3.1 Structural elements from Central Artery/Tunnel Project in Boston (The Big Dig)

Fig 3.2 Salvaged structural steel Central Artery/Tunnel Project in Boston

Fig 3.3 Salvaged invertset panels: Initially part of temporary highway structure, later structural slabs at Big Dig House
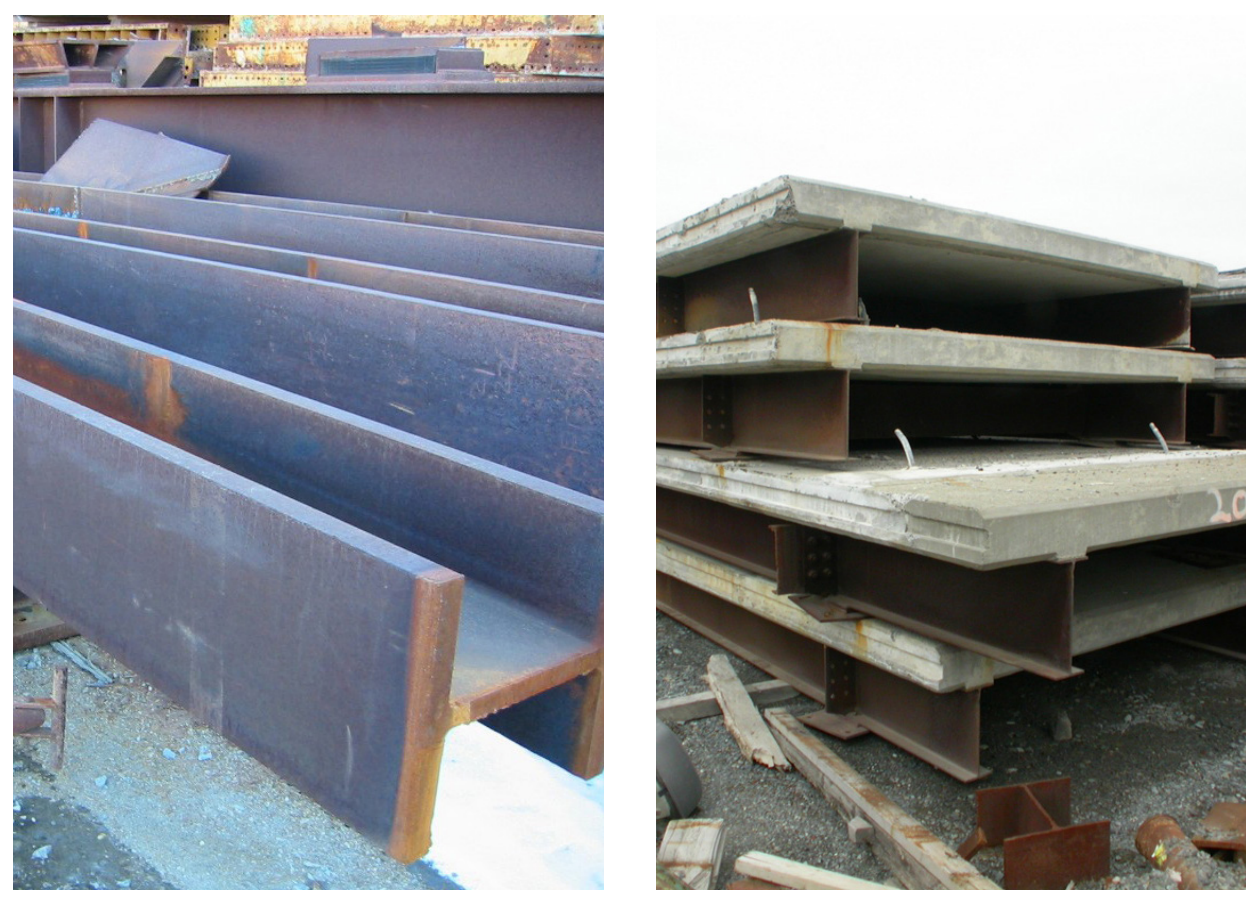

\section{Case Studies}

\subsection{Big Dig House, Lexington, MA - Reuse}

The Big Dig House is set in Six Moon Hill, a suburban neighbourhood west of Boston that was built as a modern model of ideal development by Walter Gropius's TAC. The house was conceived by Paul Pedini and designed by Single Speed Design. Pedini who worked for 11 years on the Big Dig project in Boston, asked the state officials for some of the material from the project's temporary ramp structures to be salvaged by his company instead of being crushed. This resulted in the state saving of $\$ 20,000$, since it did not have to pay for disposal, as well as benefiting Pedini. The salvaged material was initially designed to form part of a temporary highway which was moving traffic in and out of the city during underground work was conducted (Fitzgerald, M. 2006). Federally funded projects require structural steel as well as concrete slabs to meet high quality standards of public transportation guidelines. Considering that the lifecycle of those elements surpasses the temporary nature of the overpass it was a great opportunity for the materials to be reused. The design of the Big Dig House utilized 600,000 pounds of steel and invertset panels (40 feet long), which were used with little to no modification, allowing for a rapid one day steel frame erection and two day slab installation (SSD, 2006) (Bahamon A. 2008). 

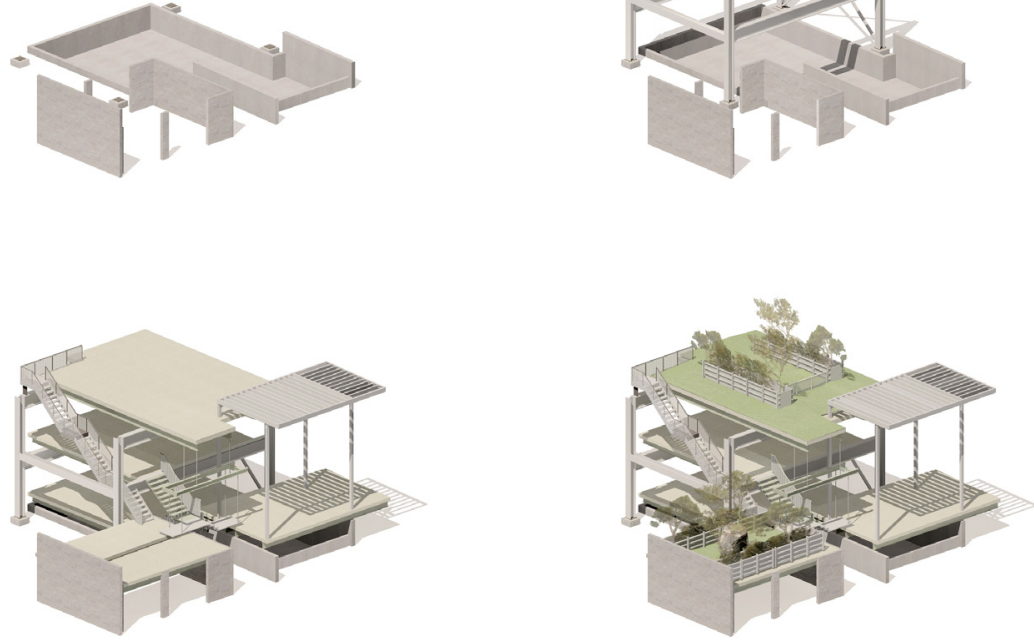

The steel components used in The Big Dig House were initially designated as struts, which installed in pairs held retaining walls during construction of the Big Dig tunnel. The retaining walls were constructed to avoid adjoining lot settlements. Single Speed Design used a means oriented design by treating given elements as prefab components, thereby streamlining the construction process at the structural stage. The available material was transported to a site merely 19.2 kilometers west of Boston, which shows investors and designers sensitivity towards embodied energy and environmental awareness.

The design firm and the owner who acted as a general contractor for the Big Dig House saw the project as not one of a kind, but as a prototype that showcases the reuse potential of temporary infrastructure construction. The Big Dig House is comprised of $60 \%$ reused material (by weight) which is a great accomplishment, considering that the material was not designed to be reused.

Learning from the process of design and working with reused materials on The Big Dig House, the design firm has developed a larger project, which also uses post infrastructure components. The Big Dig Building is a competition submission that won the Metropolis Next Generation Prize as well as the Holcim Sustainable Construction Award (SSD, 2005). The design was developed with Paul Pedini acting as the structural designer. In the building design the available structural elements affected the design.
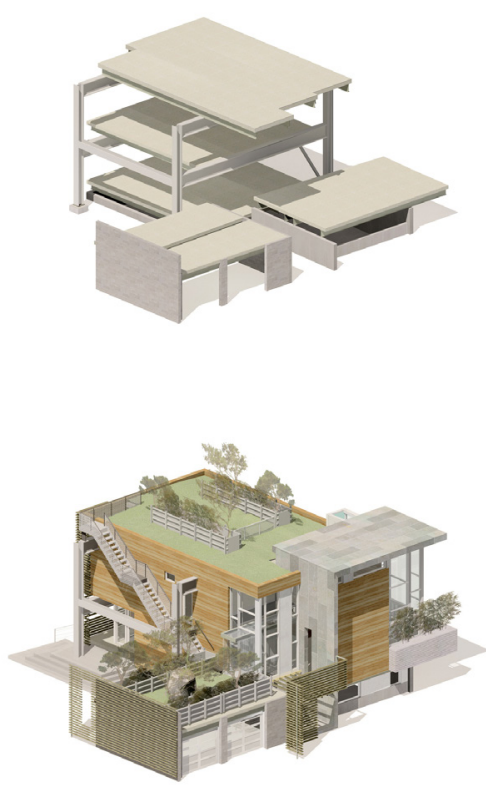

Fig 3.4 Construction sequence and assembly of structural steel frame and invertset floor/roof panels sourced from the Boston infrastructure project 

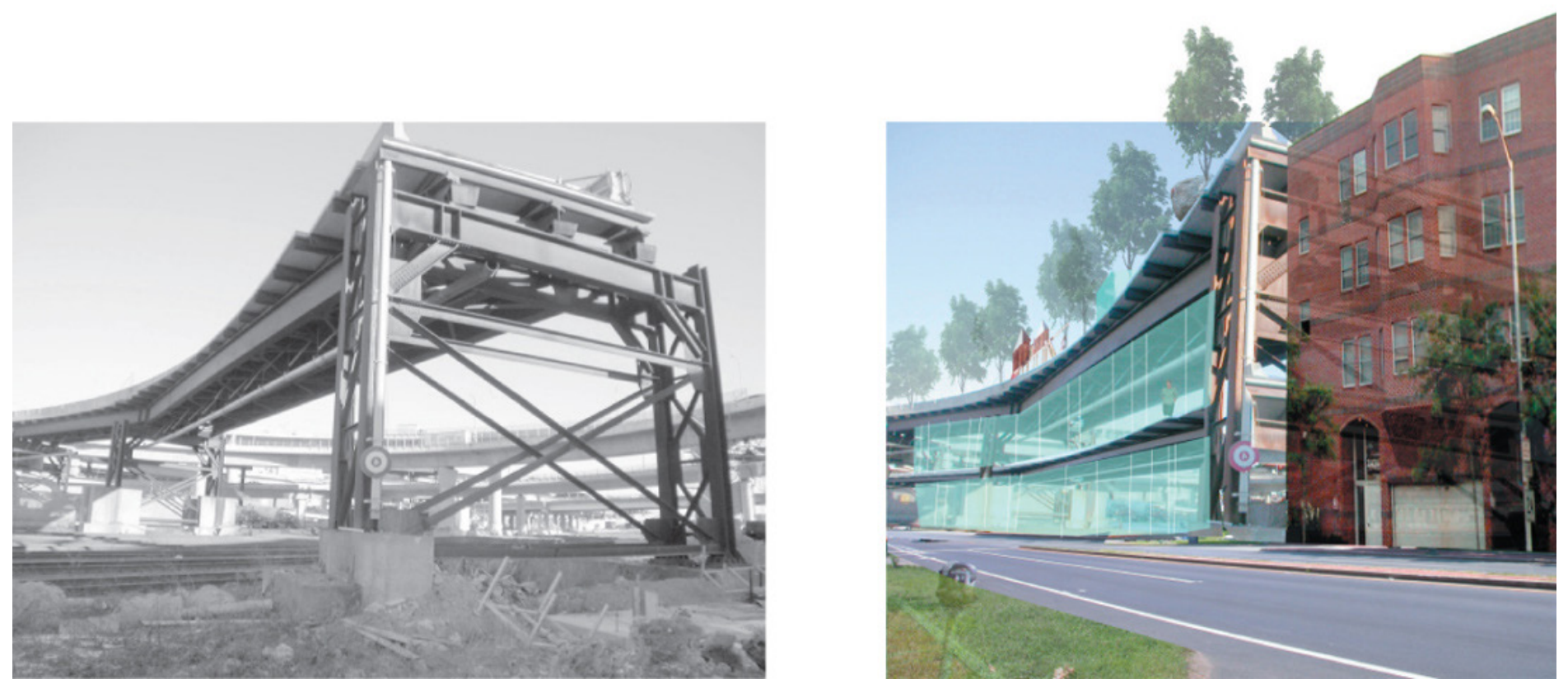

Fig 3.5 From infrastructure to architecture

Fig 3.6 Reuse of infrastructure elements - Big Dig Building
The concrete slabs that were built in accordance with HS20-44 military standards are capable of resisting up to 250 psf, which significantly surpasses the standard residential 40 psf. This, in turn, allows the architects to create interesting form variations by large cantilevers and their interactions (or vertical landscapes as the architects describe them). Architects explored different typologies as potential reuse of the structural material. Programmatic freedom associated with high load resistance structure permits flexibility to designate roof tops as family gardens, with program with high dead and live load (usually located at grade) in the midsection.In case of Big Dig House both the architect (Single Speed Design) and the builder (Paul Pedini) saw infrastructure projects such as "untapped potential for public realm"(SSD, 2006) where, if components are designed for disassembly, future reuse is easy and cost effective. For Pedini this was not a one of a kind project as he constructed a second Big Dig House and formed a construction company that strictly focuses on Design for Deconstruction or as he refers to it 'precycling' (Fitzgerald, M. 2006). Padini's attempts, however, to construct a 24-unit apartment building and boathouse made of reused materials have met with resistance, from North Cambridge residents, civic groups, and City of Newton respectively. (Maguire K. 2006). This suggests that some traditionally oriented neighbourhoods may not tolerate the aesthetics that are associated with reused material.
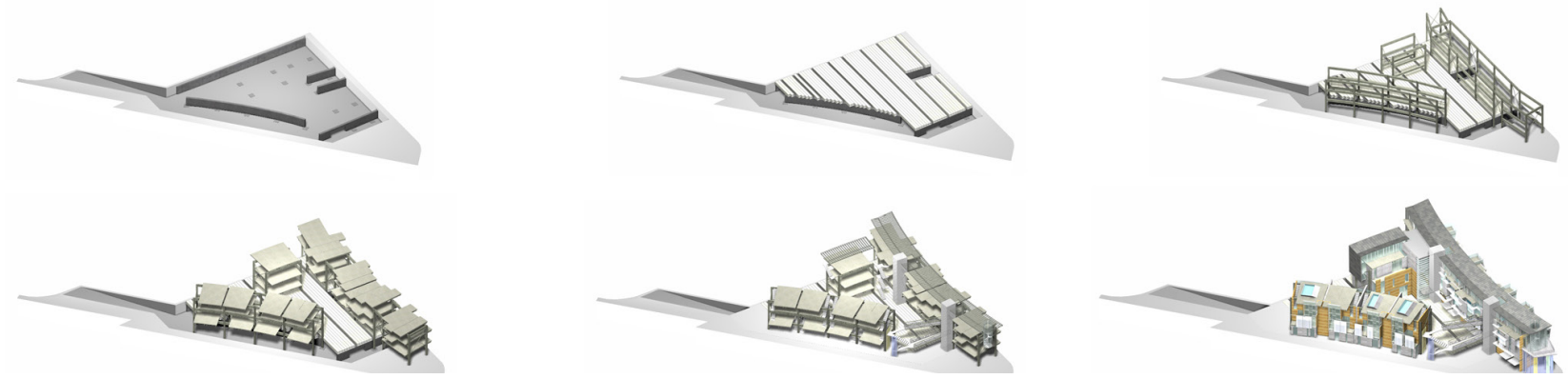


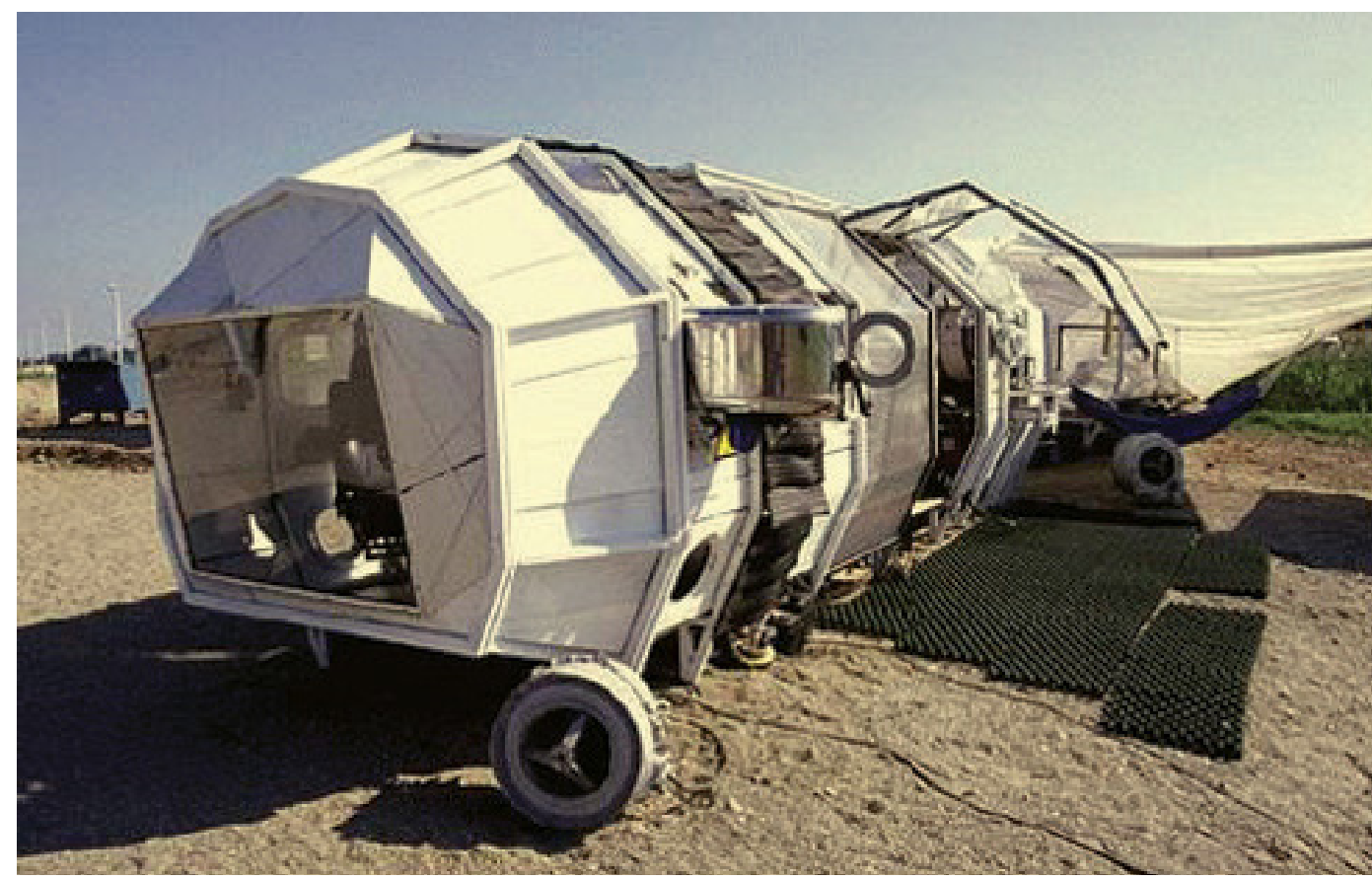

\subsection{Miele Space Station, Delft NL, - Superuse}

This project is the first superuse experiment of 2012 Architecten. It is constructed of waste materials, as a modular object, with fridge doors, car tires, sails and photovoltaic panels as infill. The project added a new task and narrative to otherwise boring object like fridge components that already passed their added value peak and were destined to landfill. It is an adaptive object that served as a show piece during various events, and was adapted as a pizza restaurant, music store, architecture office, storage for a fashion show and media centre. The installation can be easily moved as it can be subdivided into components that $600 \mathrm{~mm}$ wide (standard washing machine size) and can be transported through standard door openings $(700 \mathrm{~mm} \times 2100 \mathrm{~mm})$. For ease of transportation each of five elements can be handled by two people. The station's modules can be arranged in different combinations, providing a limited but various combinations of spatial definitions. The project was initially created for PARASITE PARADISE an experimental event where it served as a temporary architectural office. Due to legal restrictions it was designed to serve as a caravan once installed on a trailer and thus had to comply with Dutch traffic regulations. It retired as an espresso bar at Delft University's Faculty of Architecture. This project started a worldwide movement trough www. superuse.org, where designers post their creations from repurposed materials. (Brigitte, F. et al., 2010)

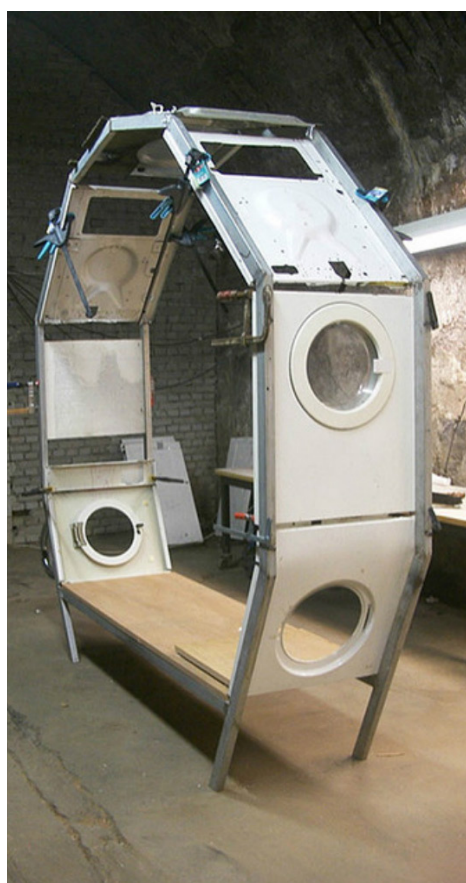

\section{From left:}

Fig 3.7 Miele Space Station Superuse of obsolete home appliances

Fig 3.8 One section (bay) of the installation, clearly showing exoskeleton and materials used as infill 
Fig 3.9 Mountain Equipment Co-op Winnipeg is an example of material reuse and adaptive reuse.

Fig 3.10 Construction Stages: two left buildings deconstructed for material reuse
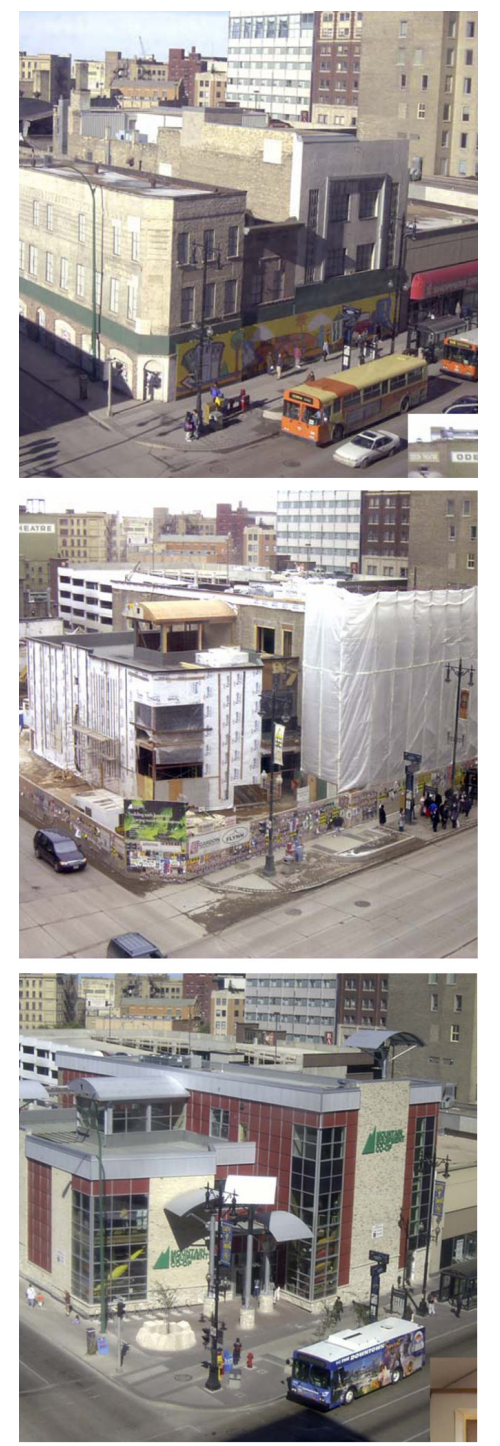

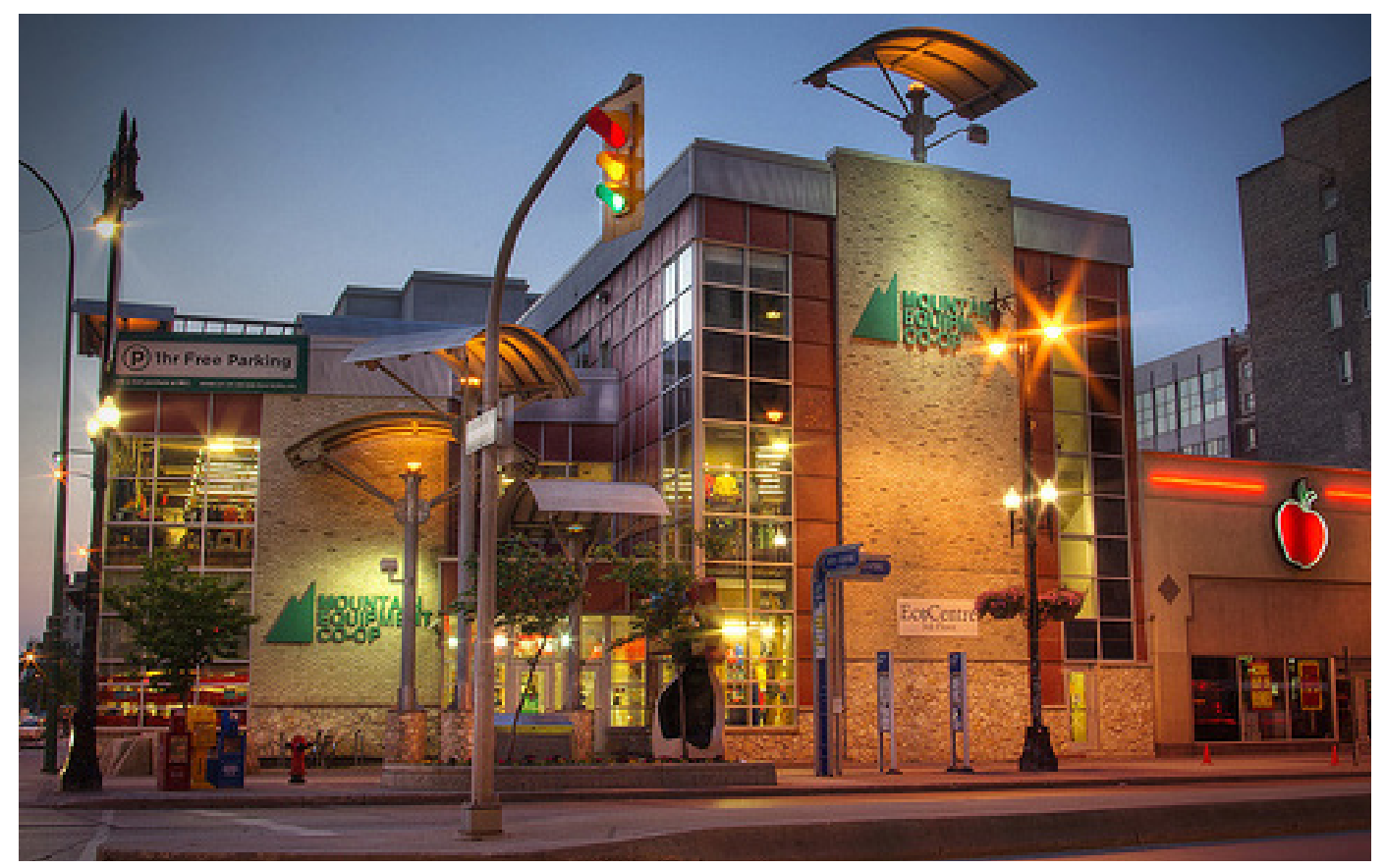

\subsection{Mountain Equipment Co-op Winnipeg}

Following the success of Ottawa MEC, which incorporated reused material, the company commissioned Prairie Architects to design their Winnipeg retail location. The new building was to be located on a site that at the time housed three neglected buildings that were planned to be demolished. The engineer's assessment proved that the largest of the three structures was sound and suitable for adaptive reuse; however, the other two were designated for demolition. Prairie Architects convinced the city to allocate funds for deconstruction rather than demolition, and prepared a list of materials to be purchased after deconstruction. The material in question was stored on site, eliminating transportation cost and energy. MEC donated 300,000 bricks to Habitat for Humanity, out of which 100,000 were bought back after being cleaned by volunteers at a discounted ten cents per brick (Ogbu, L., 2010). The remaining bricks were, in turn, sold by Habitat at market value which, when combined, generated enough income to complete two homes under Habitat's program. During deconstruction, six cast iron columns were discovered embedded in walls. This discovery resulted in modification of the structural in order to accommodate the find. Tyndall limestone, originally used for foundations, was reclaimed and replaced with poured concrete; the recovered material was repurposed for lower sections of the façade.

The project allowed the designers to consider the existing stock to be replaced, not as an obstacle, but as a high quality resource and supply point of high quality material, tested over time that in some cases required no modification. The adaptive reuse of the 20,000 square feet building, resulted in saving 723 tonnes 


\section{WINNIPEG STORE}

\begin{tabular}{|c|c|c|c|c|c|c|}
\hline MATERIAL & $\begin{array}{l}\text { ORIGINAL } \\
\text { USE }\end{array}$ & $\begin{array}{l}\text { REUSE } \\
\text { APPLICATION }\end{array}$ & SOURCE & $\begin{array}{l}\text { SOURCE } \\
\text { LOCATION }\end{array}$ & QTY & REFURBISHMENT \\
\hline Bricks & $\begin{array}{l}\text { Exterior } \\
\text { Masonry }\end{array}$ & $\begin{array}{l}\text { Flooring and } \\
\text { facade }\end{array}$ & On-site & On-site & $\begin{array}{l}5,965,820 \\
\text { Lbs }\end{array}$ & De-mortared \\
\hline Cast iron & Columns & Columns & On-site & On-site & $\begin{array}{l}117 \mathrm{Ln} \mathrm{ft} \\
7,605 \mathrm{Lbs}\end{array}$ & \\
\hline Steel L & $\begin{array}{l}\text { Structur- } \\
\text { al steel } \\
\text { framing }\end{array}$ & $\begin{array}{l}\text { Structural } \\
\text { steel framing }\end{array}$ & On-site & On-site & $\begin{array}{l}695 \mathrm{Ln} \mathrm{ft} \\
13,435 \mathrm{Lbs}\end{array}$ & \\
\hline Tyndall stone & $N / A$ & $\begin{array}{l}\text { Exterior stone } \\
\text { cladding }\end{array}$ & On-site & On-site & $\begin{array}{l}285,000 \\
\text { Lbs }\end{array}$ & \\
\hline Plywood & & Wood flooring & On-site & On-site & 4,224 Lbs & \\
\hline Wood flooring & $\begin{array}{l}\text { Wood } \\
\text { flooring }\end{array}$ & Wood flooring & On-site & On-site & $\begin{array}{l}20,000 \\
\operatorname{Lnft}\end{array}$ & Sandblasted \\
\hline $\begin{array}{l}\text { Shiplap } \\
\text { siding }\end{array}$ & Sheathing & Exterior siding & On-site & On-site & $\begin{array}{l}26,910 \\
\operatorname{Lnft}\end{array}$ & \\
\hline Wood beams & $\begin{array}{l}\text { Wood } \\
\text { beams }\end{array}$ & Wood beams & On-site & On-site & $\begin{array}{l}3,120 \\
\operatorname{Ln} \mathrm{ft}\end{array}$ & Sandblasted \\
\hline $\begin{array}{l}2 x \text { dimen- } \\
\text { sional lumber }\end{array}$ & $\begin{array}{l}\text { Wood } \\
\text { framing }\end{array}$ & Wood framing & On-site & On-site & $\begin{array}{l}44,025 \\
\operatorname{Lnft}\end{array}$ & Sandblasted \\
\hline $\begin{array}{l}\text { lxdimen- } \\
\text { sional lumber }\end{array}$ & $\begin{array}{l}\text { Wood } \\
\text { framing }\end{array}$ & Wood framing & On-site & On-site & $\begin{array}{l}33,440 \\
\operatorname{Lnft}\end{array}$ & Sandblasted \\
\hline
\end{tabular}

of GHG emission, and in combination with material reuse, reduced capital cost by

Fig 3.11 Material summary approximately $\$ 400,000$ (Prairie Architects Inc., 2002). MEC Winnipeg achieved Gold Certification from LEED New Construction Green Building Rating System and material reuse contributed towards reaching that goal. Disassembling, assessing and organizing reused materials on site, the project was granted LEED MR 3.1 one point credit for using 5\% and MR 3.2 two point credit for incorporating 10\% salvaged material (Ogbu, L., 2010) (U.S. Green Building Council, 2001). According to Prairie Architects, more than $95 \%$ of the existing building by weight, was reused in the new building design, which in turn classified the project for further LEED credits that relate to regional material.

The MEC Winnipeg project allowed Prairie Architects to build their reputation as a sustainable designer and further reinforced the company's image as environmentally sensitive and leading by example. Mountain Equipment Co-op store in Burlington takes the material reuse to the next level. SMV Architects designed that location with future reuse in mind and as it is designed for deconstruction. 


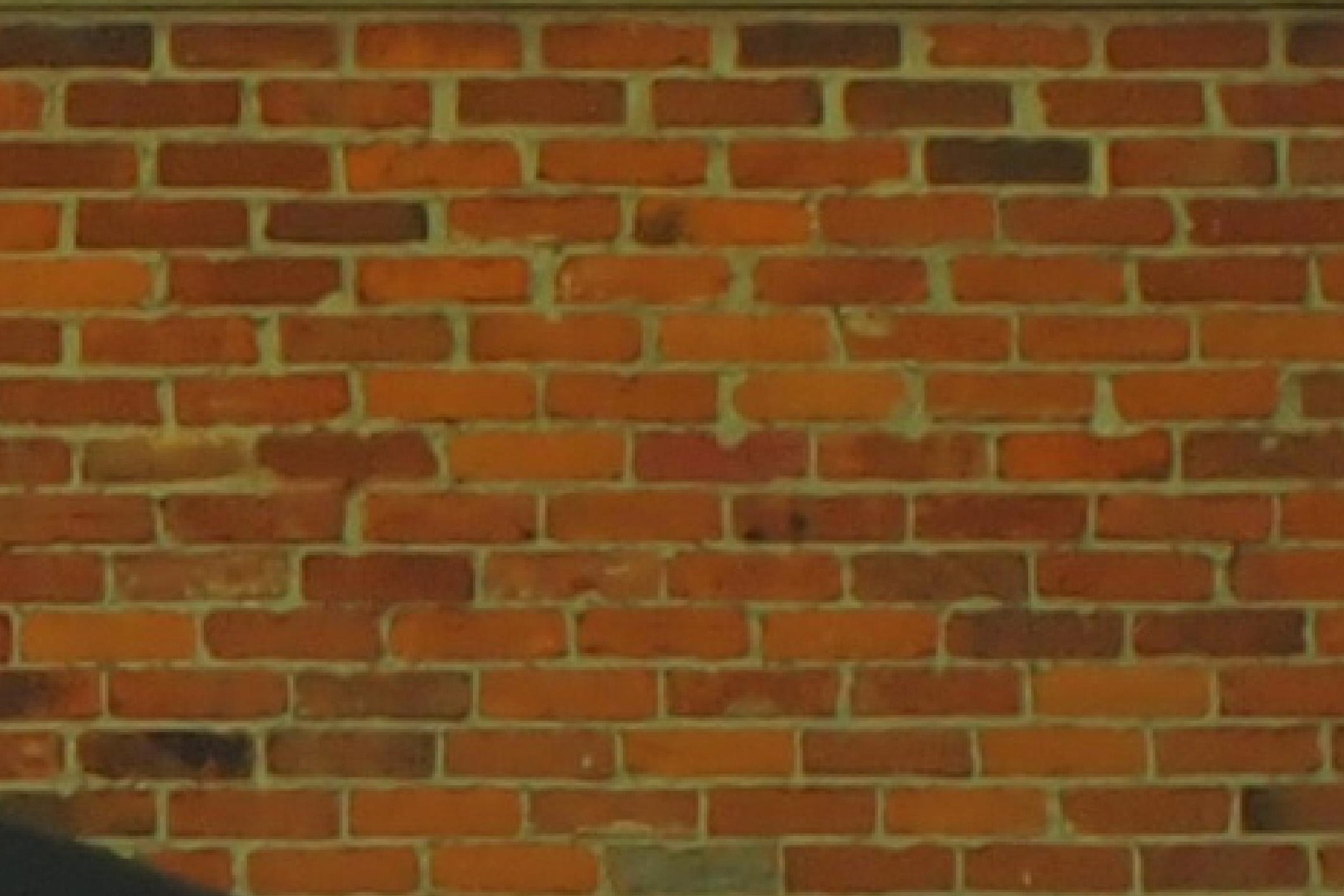


4. Construction materials and their embodied energy 


\section{Construction materials and their embodied energy}

Embodied energy is the total primary energy that a particular material unit used, from extraction of the raw material, through to fabrication and transportation, to installation, maintenance and disposal. This is often referred to as 'Cradle-to'Grave (Hammond G., 2008). In the case of buildings, it includes the construction process as well as the life cycle of the building materials that the structure contains (Yeo D., 2011). There is also a term closely related to embodied energy, which is embodied carbon. Current designs heavily rely on materials that are energy intensive, with steel, concrete and glass being the most common ones. In attempts to take the maximum advantage of the energy already consumed to produce the construction materials, their life cycle ought to be extended through reuse, or recycling.

\begin{tabular}{|c|c|c|c|}
\hline Material & $\begin{array}{c}\mathrm{EE}- \\
\mathrm{MJ} / \mathrm{kg}\end{array}$ & $\begin{array}{l}\mathrm{EC}-\mathrm{kg} \\
\mathrm{CO} 2 / \mathrm{kg}\end{array}$ & Notes \\
\hline Concrete (General) & 0.95 & 0.13 & $\begin{array}{l}\text { Use of a specific concrete } \\
\text { specification is preferred to } \\
\text { gain greater accuracy }\end{array}$ \\
\hline Concrete $(1: 1: 2)$ & 1.39 & 0.209 & High Strength \\
\hline $\begin{array}{l}\text { For reinforcement add } \\
\text { to selected coefficinet } \\
\text { for each } 25 \mathrm{~kg} \text { rebar }\end{array}$ & 0.26 & 0.018 & $\begin{array}{l}\text { Add for each } 25 \mathrm{~kg} \text { Steel per } \\
\text { m3 concrete }\end{array}$ \\
\hline Glass & 15 & 0.85 & $\begin{array}{l}\text { Poor data availability on } \\
\text { recycled glass }\end{array}$ \\
\hline Plaster & 1.8 & 0.12 & \\
\hline Steel (General) & 22.4 & 1.77 & $\begin{array}{l}\text { Estimated form UK mix of } \\
\text { materials. Worldwide } \\
\text { recycled content of } 42.7 \%\end{array}$ \\
\hline Stone (General) & 1 & 0.056 & \\
\hline Timber (General) & 8.5 & 0.46 & $\begin{array}{c}\text { Estimated from UK } \\
\text { consumption of timber }\end{array}$ \\
\hline Glue Laminated Timber & 12 & 0.65 & \\
\hline Plywood & 15 & 0.81 & \\
\hline
\end{tabular}

Fig 4.1 Embodied energy of selected materials 
Depending on the region, methods used to extract raw materials, fabrication methods, regional energy source, distance to raw materials, and distance from fabrication facility to construction site, the same materials can have different values of embodied energy. In the Netherlands, improvements made to brick manufacturing through higher efficiency ovens, resulted in cutting energy requirements for such production by $50 \%$ between 1990 and 2010 (Rovers R. 2008). The recent improvements to the manufacturing process, higher efficiency in transportation, energy generation etc., have impacted the levels of embodied energy (and embodied carbon); however, construction still remains the main consumer of energy.

The focus of my study is west part of Toronto - Etobicoke. The most commonly renovated building typology in this area is wartime bungalow. Built by developers both during and after World War II, this subdivision configuration is composed of single story buildings, with a carport or garage and one flight of stairs. This type of building can be characterized by a low slope gable or hip roof, with the front wall indenting in half of its width, creating a covered porch, or additional gable covering the front porch. The lots are large in size in relation to the houses, ranging from 35 to 75 feet. The size of the lots and the increase in real-estate value from 2000-2012, makes the redevelopment of these houses a profitable investment. Extensive renovations with minor parts of original buildings remaining, as well as new construction, create a large opportunity for material reuse.

The following is a breakdown of a typical post wartime bungalow, with emphasis on potential material recovery and its embodied energy values. The isometric drawing represents a house located at 13 Lothian Avenue in Etobicoke, which I had an access to for accurate takeoffs. The dwelling in question, however, is built with double wythe brick as a structure rather than typical $2 \times 4$ framing. For the calculation I have assumed the building to be constructed with stud framing, as typically it would be the case in this construction type. Cladding is assumed to be a 
brick veneer with one inch air space. Due to labour requirements concrete blocks from foundation wall below grade would be difficult to be extracted. Any poured concrete slabs and footings are only suitable for recycling, as in older houses the quality of concrete and its thickness is not consistent and varies from one area of the house to the other. Due to lack of access to attic the hand cut roof rafters were not measured and were not included in the calculation. It is noteworthy that in older homes roof rafters were hand cut and the rafter lumber is reusable, whereas newer construction uses engineered trusses built of smaller lumber both in length and size, finger joint to achieve desired spam. This renders newer engineered trusses not reusable for its material but reusable as a component only.

After survey of the existing house, plans and elevations were created, which permitted material takeoff for the chart below.

Fig 4.2 Materials reuse opportunities within a selected typology

\begin{tabular}{|c|c|c|c|}
\hline Material & Volume/Area & Notes & Embodied Energy \\
\hline Concrete block 10" & $853 \mathrm{ft}^{3}$ & Below grade & $21,006 \mathrm{MJ}$ \\
\hline Poured Concrete 3" & $32 \mathrm{ft}^{3}$ & not salvagable & $1,894 \mathrm{MJ}$ \\
\hline Stud framing & $80.39 \mathrm{ft}^{3}$ & Salvagable by unit and in sections & $8,707 \mathrm{MJ}$ \\
\hline Floor Joists 2x6 & $58 \mathrm{ft}^{3}$ & Old growth lumber & $6,282 \mathrm{MJ}$ \\
\hline Floor Decking $1 \times 4$ & $10.6 \mathrm{ft}^{3}$ & & $1,885 \mathrm{MJ}$ \\
\hline Brick & $380 \mathrm{ft}^{3}$ & Salvagable by unit and in sections & $250,000 \mathrm{MJ}$ \\
\hline Roof rafters & $\mathrm{n} / \mathrm{a}$ & & $\mathrm{n} / \mathrm{a}$ \\
\hline Roof Sheating & $91.6 \mathrm{ft}^{3}$ & & $9,921 \mathrm{MJ}$ \\
\hline
\end{tabular}




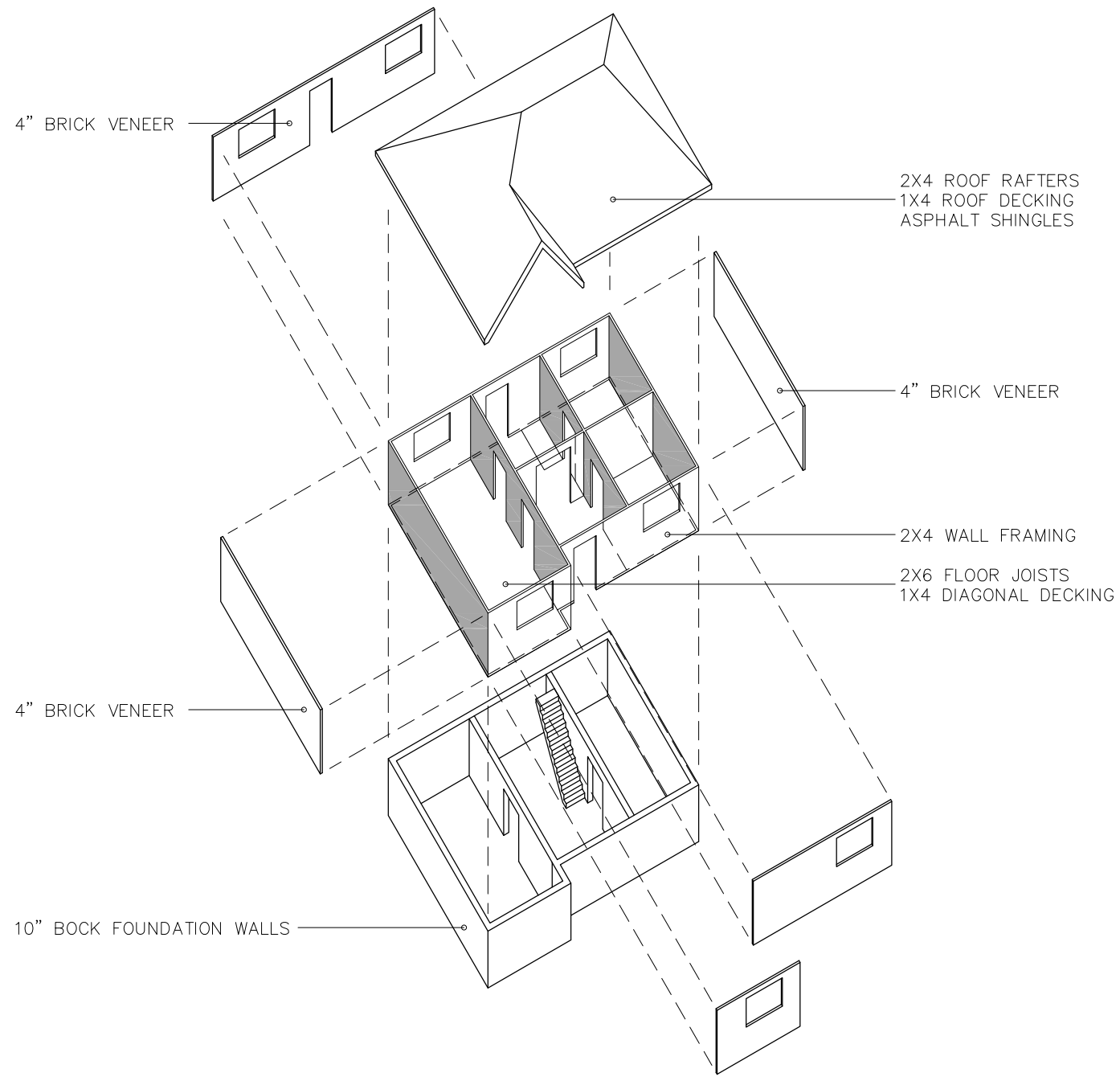

Fig 4.3 Wartime house components breakdown materials reuse opportunities 



\section{Experimentation}

As families grow and the standards for space change, homeowners require their real estate to be modified. The most common solution is an addition, followed by a second story addition, with a large addition and new construction often being the case. In the case of large additions keeping the existing structure can be challenging. Old construction does not match current standards for interior space height and existing footings often cannot accommodate the desired design, forcing the owners to make a decision for full demolition and new construction. Another challenge that contractors are facing is the lack of level, plumb or square in existing structures. This, in turn, forces the general contractor to bid higher on renovation/ addition in comprising new construction as it requires more labor and time on the site. At times, the higher labor cost offsets the financial savings of preserving the old structure in case of extensive renovation.

Zoning is another aspect that sometimes discourages from existing structure preservation, as the existing tends not to comply with current zoning (as it changes over time) and additions or alterations do not comply with regulations and require minor variance (which increases the designer's fee and delays construction start date), further discouraging from preservation of existing building material. 


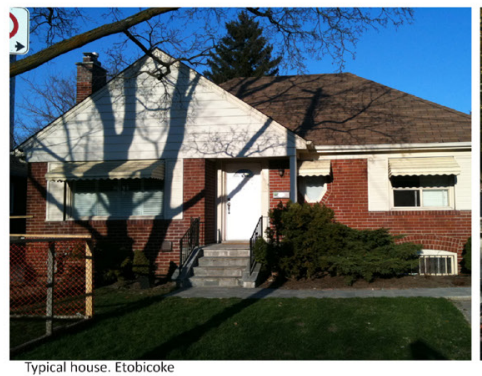

\subsection{House \#1}

At the beginning of 2012, I was involved in the design of a residence in Etobioke, where parts (50\% of exterior wall) of the existing house were saved to qualify the construction as a renovation. The exterior wall was a double wythe wall with a four inch block on the inside and brick on the outside. Since the design called for increased ceiling height on the ground level, it was required to add several courses of brick and block on top of the existing wall. The walls that were to be demolished were carefully disassembled layer by layer and bricks cleaned, which allowed for the bricks to be reused on site, thus reducing requirement for new material. In other areas where the design called for an existing opening to be filled, post demolition brick was used as well.

\subsection{House \#2}

The first experimentation with reclamation of the brick and reuse on the same project is what made me consider larger scale reclamation. Individual unit material discards the energy that was put into the setting of the brick and creates a requirement for setting the brick in the new application, thus increasing the embodied energy of the brick. In the next project I set a goal for the preservation of the energy spent on wall assembly and decided to remove the brick in sections. These sections were set to be small enough for one mason to easily handle and large enough to create a form that would permit some pattern experimentation.
Fig 5.2 Component extraction
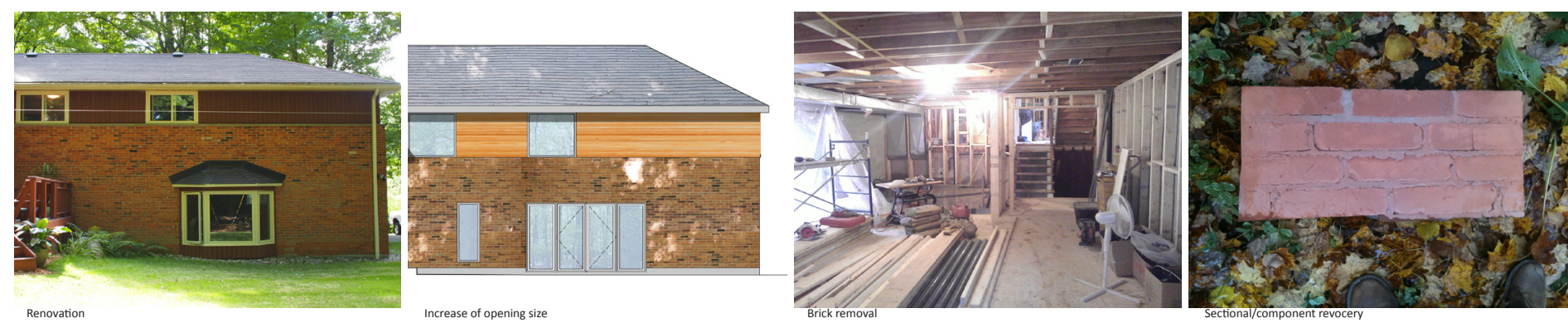


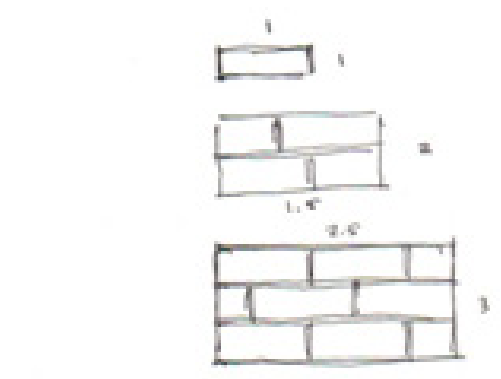

Considered components sines

Fig 5.3 Small unit arrangements

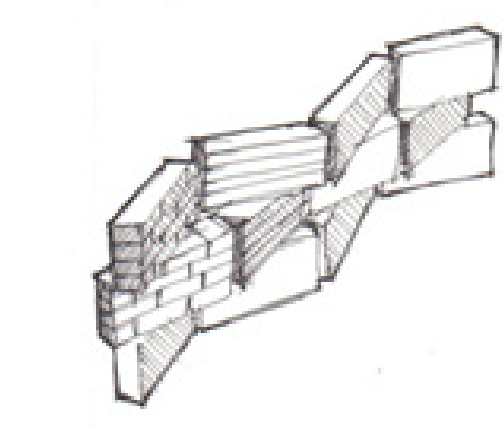

Norsible pattern

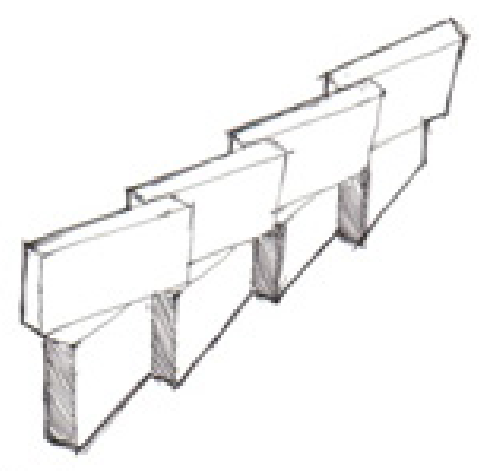

Posilible panters

The problems that were encountered turned out to be a typical challenge for this type of disassembly (veneer). The brick ties that secure the brick to the structural part of the wall needed to be cut in order for the section to be removed. This, in turn, limited the size of the sections as the ties needed to be accessible by the tool. Once the size of the section was determined, vertical cuts separated it from the wall. Any horizontal joints could be easily removed by hand without any additional tool. Cleaning of the horizontal edges of the brick from the mortar is required to permit proper joints in the new application. The component I worked with was 10 " x 23.5" which, at the bricks embodied energy of $5170 \mathrm{MJ} / \mathrm{m}^{3}$ contained about $79.61 \mathrm{MJ}$ (actual number varies depending on the method of brick production and efficiency of the oven used in the process).

In the case of brick veneer on wood frame, the brick ties are nailed to sheathing and are easily removable with simple tools. The nails securing the tie on the wall side usually have a half inch bearing. Further experimentation with brick veneer on wood stud will be required.

Ties are usually nailed to $1 / 2$ inch sheathing, which, regardless of the nail length provides with $1 / 2$ nail bearing. It is possible to remove the nail securing the brick tie without excessive force. During deconstruction, the nails can be pushed out from the inside of the structure, allowing the free standing brick veneer to be subdivided into larger sections, giving the designer the freedom to extract exact sections required for the new design. Standardising sections of bricks permits components from a different origin to be used together on one project. Components at 9 feet or more in height can be directly used in other designs with no requirement for infill pieces or additional processing. 


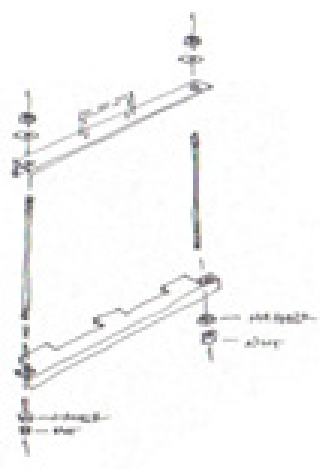

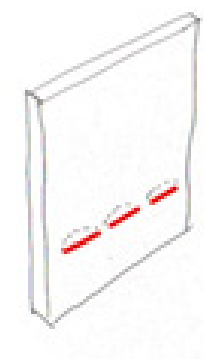

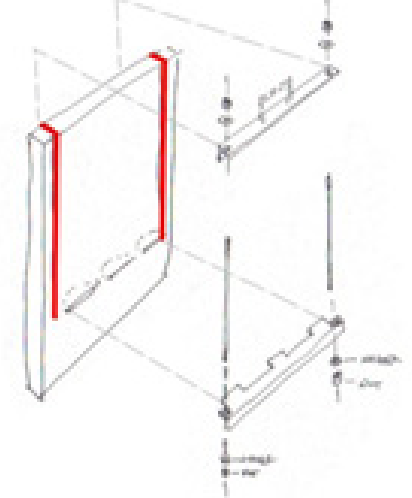

The image below illustrates sequential removal of a component from a building that was to be decommissioned. The system suggested in the sketch would permit the reclaimed material to enter the cycle as being designed for deconstruction, further prolonging its life cycle. Steel rails that are to be inserted at the bottom and top of the wall section are used to compress the brick and prevent mortar joints from separating. A component under compression allows for some freedom during the storage and transportation of the component.

The horizontal cuts are made to set the bottom rail. The distance between the cuts leaves small sections in-between that are large enough to support the wall's vertical force, but weak enough for easy removal (tilting the component will force the mortar in between the cuts to break as it will be the weakest point). The upper rail is then installed, and steel rods are threaded to connect the upper and lower rail. Compression rods are then tightened to secure the component and allow for easy hoisting and transportation. The sectional removal of components on one hand offers faster erection of veneer in the new application and preserves more embodied energy (saving in cleaning brick and laying it in the new application) but requires heavy machinery for handling and hoisting/craning. A component 9'x5' contains about $2195.97 \mathrm{MJ}$ of embodied energy in brick material alone, considering that it is preserved with the mortar joints, increasing that value of the embodied energy of mortar and energy required to install it. From an environmental standpoint, there is a great opportunity in developing, testing and implementing a system that would allow for a sectional component removal of elements that were not designed for deconstruction
Fig 5.4 Large unit extraction

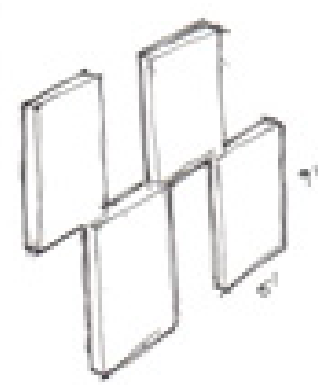

Fig 5.5 Large unit arrangements 


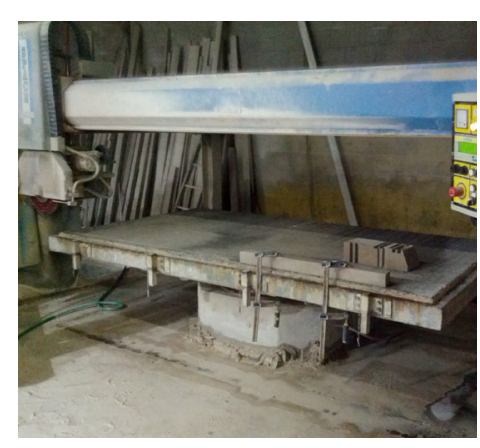

Fig 5.6 Stone fabrication saw

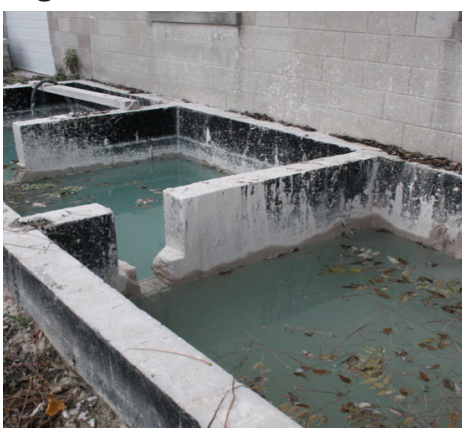

Fig 5.7 Settlement tank / Deposit collector

\subsection{Waste Elevation}

Stone fabrication has advanced and moved toward modern water cooled sawing machines. With saws and CNC machines, the milling bits and blades grind the material and mix it with the cooling water. The flow takes the mix into the settlement tanks where the stone particles settle at the bottom of the tank and the clean water gets recirculated for cooling. In most stone fabrication shops, the exterior elements are made of limestone; in the case of Toronto, it is Indiana Limestone. During milling, particles of Indiana grind down to fine sand and are moved to the settling tanks. Once the tanks reach their capacity, they are emptied and the mix of limestone and a small amount of water is disposed of and sent to a landfill at a fee every month.

Precast concrete elements require cement, sand and water for casting. In the case of a stone fabricator, aggregate (fine grinded stone) and water are free as they are a bi-product of the fabrication process, with the only part missing from equation is a bounding agent. One of the options is replacement of cement with fine limestone powder wastes to produce lightweight masonry units (Turgut $P$., 2006), however, I consider the limestone as aggregate, premixed with water that requires cement for bonding. This will measure the energy input required to produce precast cladding panels and will calculate the embodied energy of the panels with the exclusion of limestone, as it is added into the equation as a biproduct.

\subsection{Local Superuse Opportunities}

This investigation was conducted in accordance with the principles of Urban Harvest Map for superuse developed by 2012 Architecten. The mapping of available resources of little to no value and future deconstruction opportunities took place in November 2012. Interviews of local businesses helped me to create a list of potential material sources. One of the requirements that needed to be met was volume. 
In the case of car body shops, on average, a medium size facility generates 20 pieces of large area metal components as waste (hoods, roofs, etc.). These usually left for scrap collectors are free of charge. If cut to size, these elements can be used in an overlapping cladding system. Some of the readily available materials that require a disposal fee in order to be discarded of are pallets and spools. Usually stored in one location, they can be repurposed for cladding or furnishing.

A small size (2 person operation) replacement glass company replaces about a dozen 29x78 front windshields. These tractor trailer truck windows are replaced often due to safety regulations. The discarded material is often intact with minor chips or cracks that do not affect the weatherproof nature of the glazing units and these can be used for cladding or roofing elements in non weather tight applications.

Other opportunities include buried train tracks and rail ties, which are no longer used for service. 
Fig 5.8 Harvest map for reuse and superuse

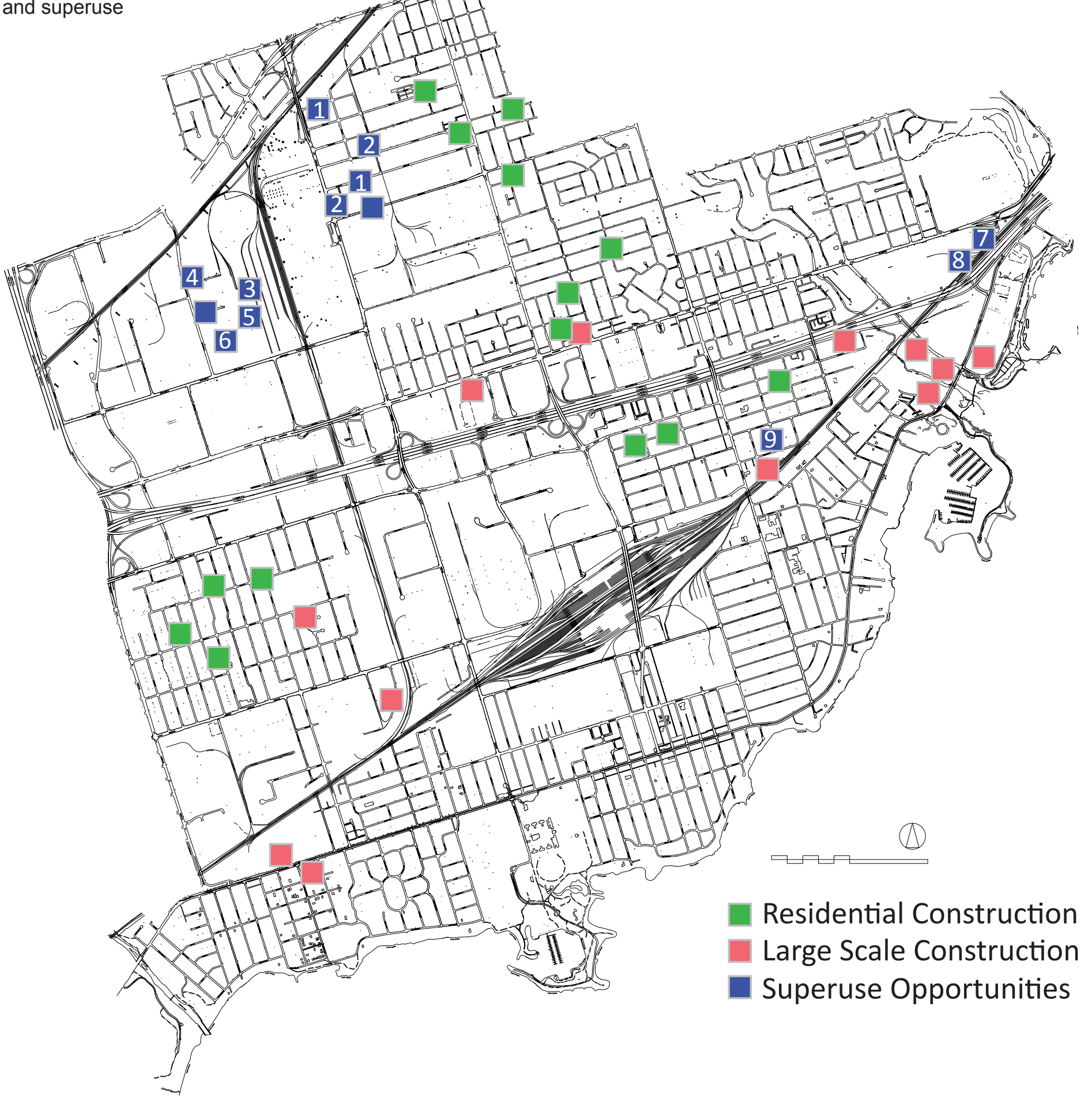



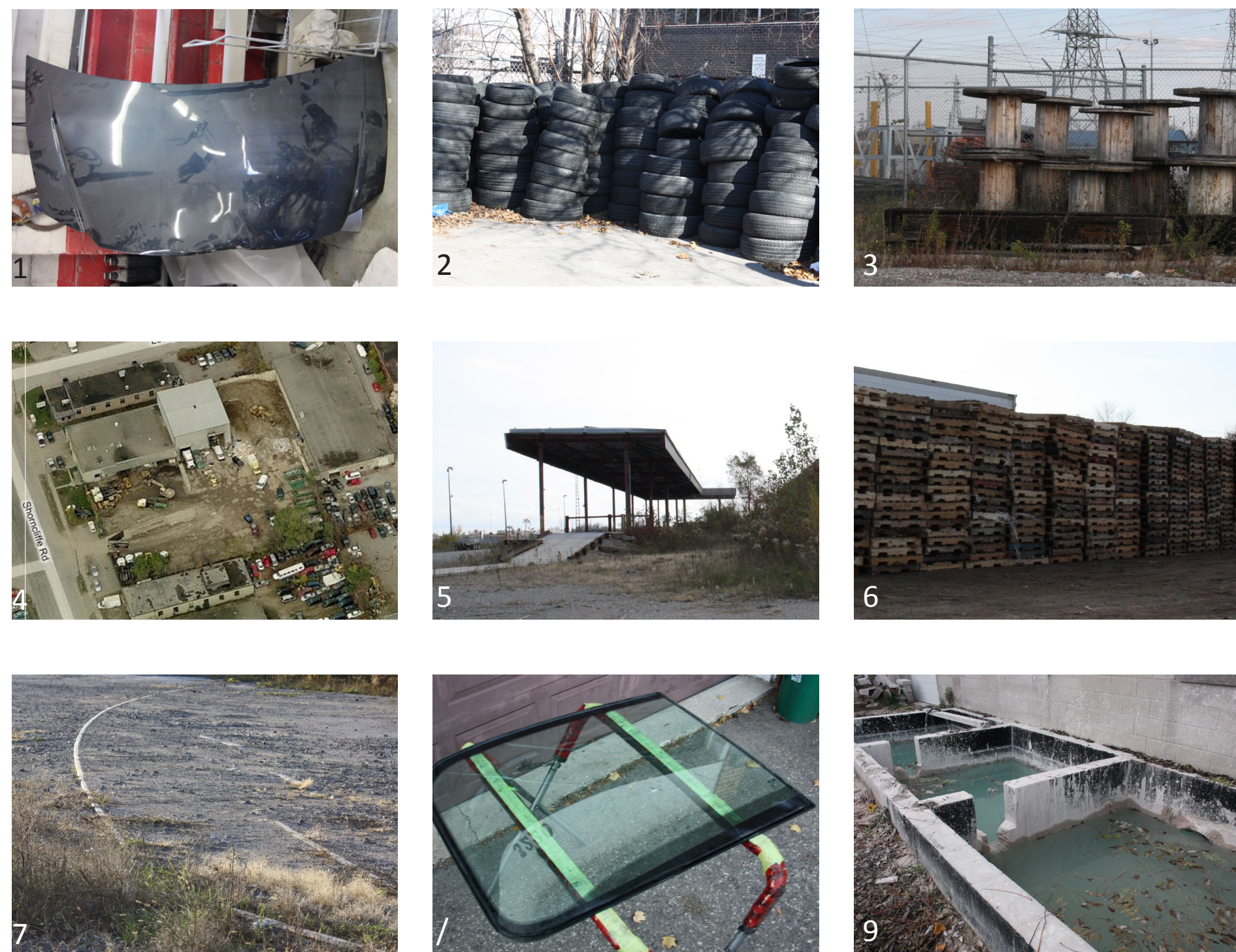


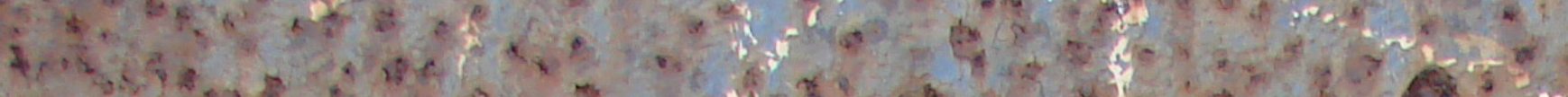

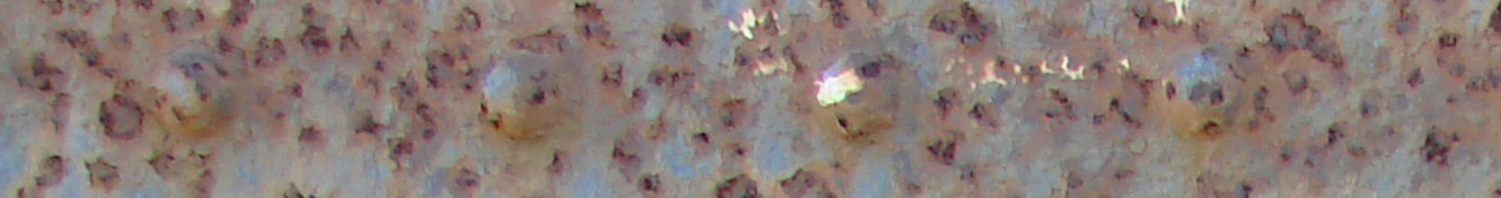

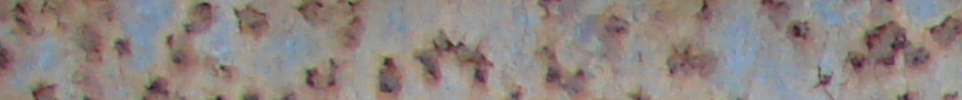

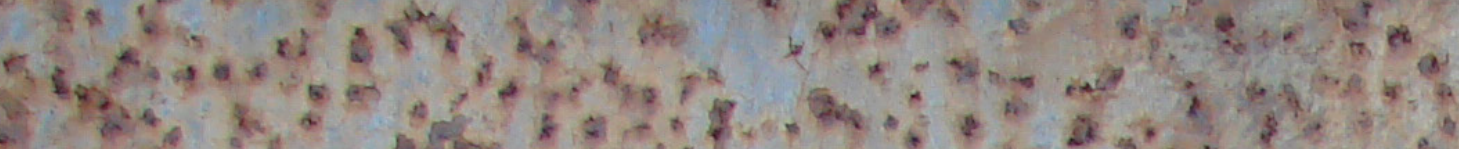

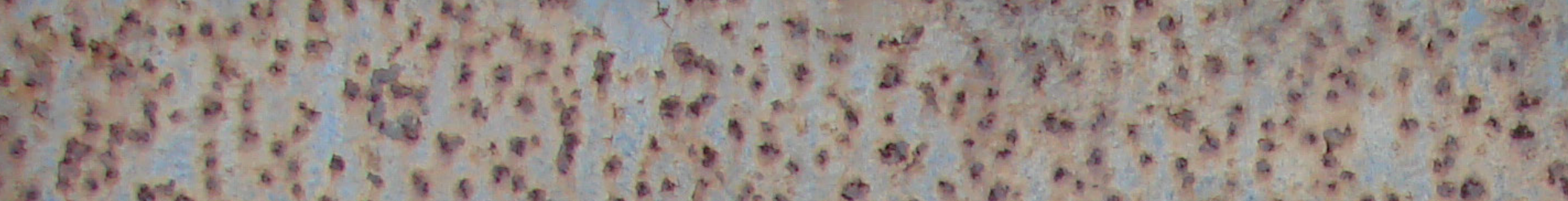

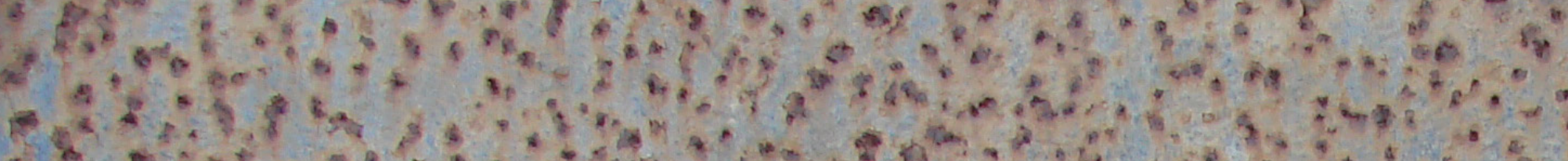
A 20 a on:

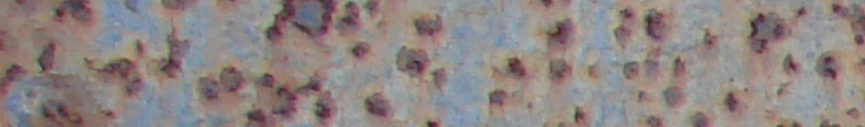

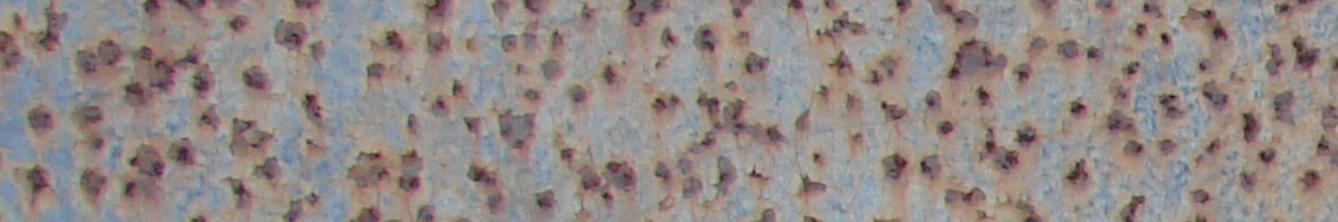

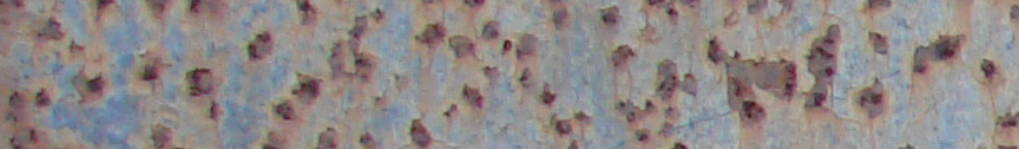

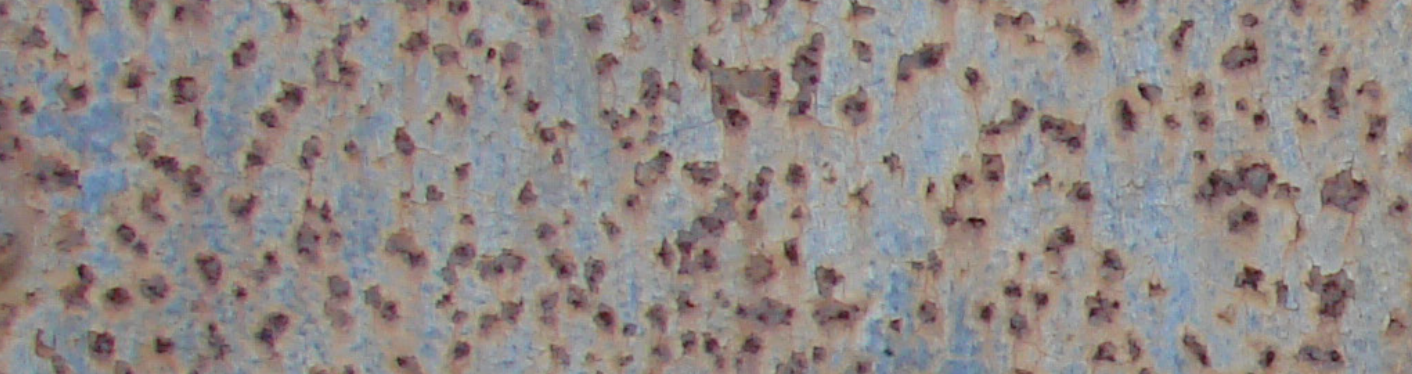

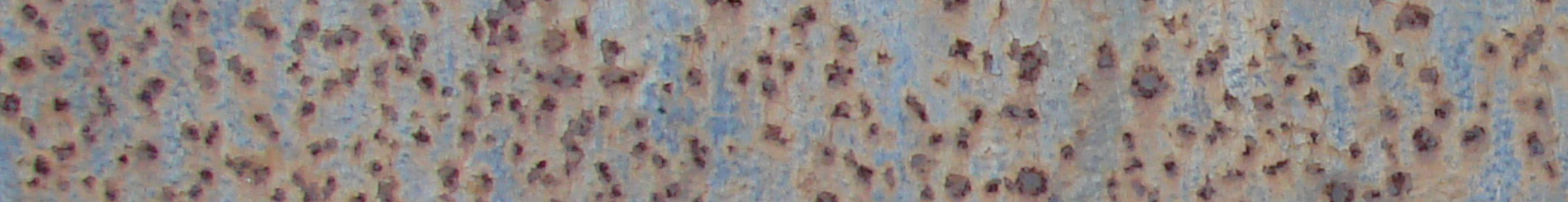

3.

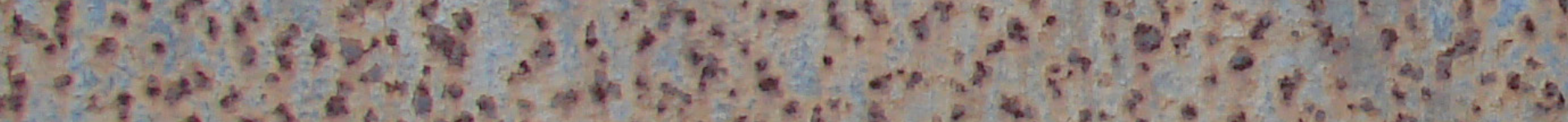

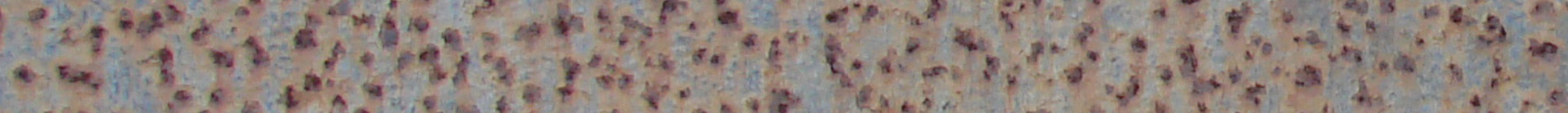

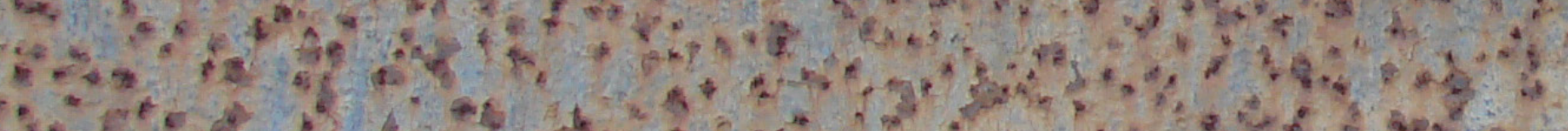

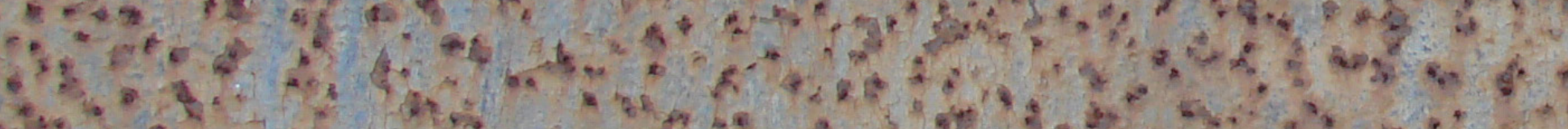

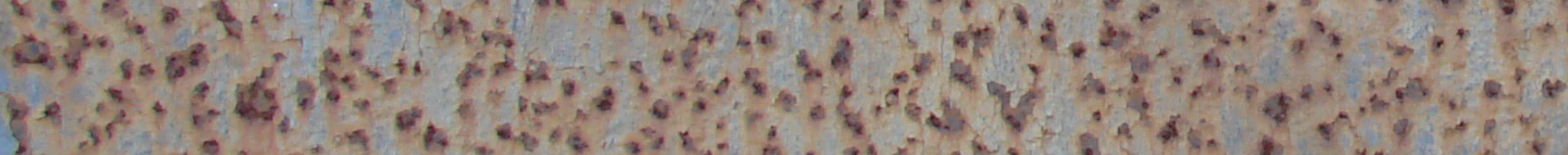
D. 0404 ang -

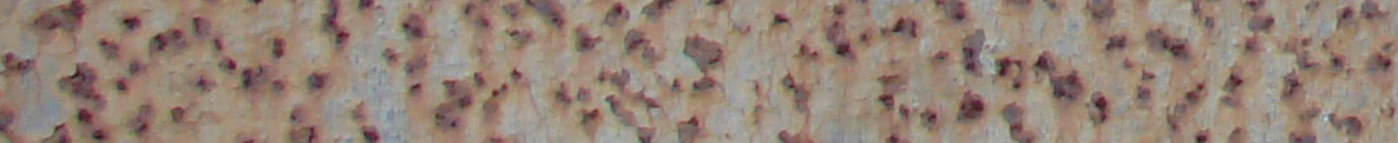

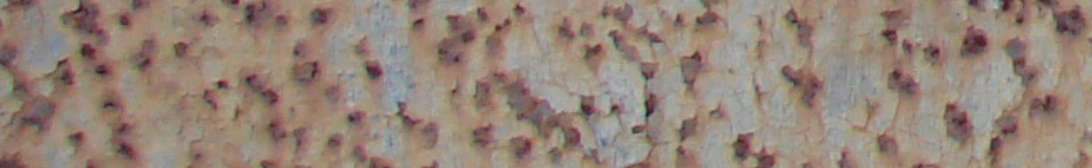
and -4. 


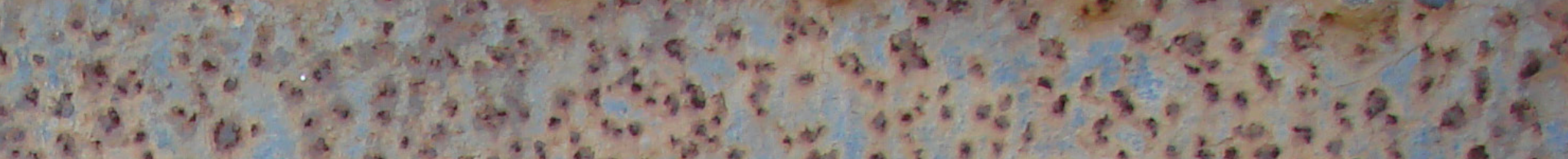

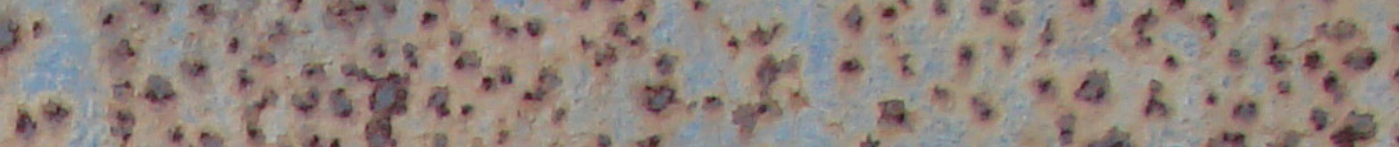
3

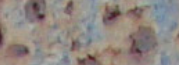
roposal:

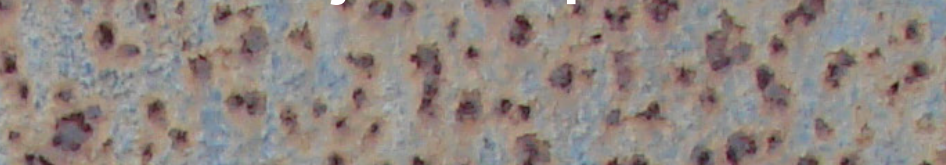

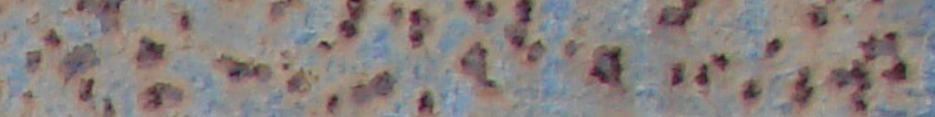

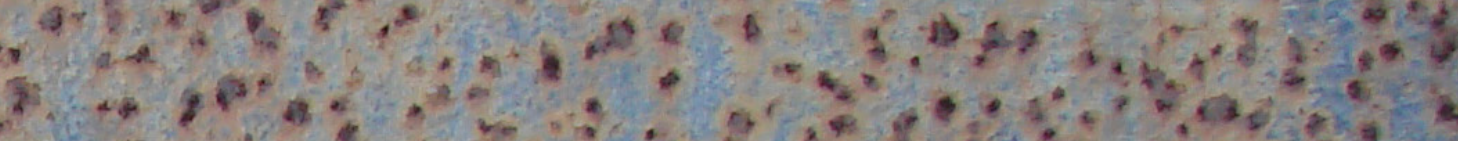
i. $\sin ^{6} \rightarrow 4^{*}$

$r^{8}, 8$

$x^{2}+e^{+3} x^{3}$

an $x^{2}+t^{2}$

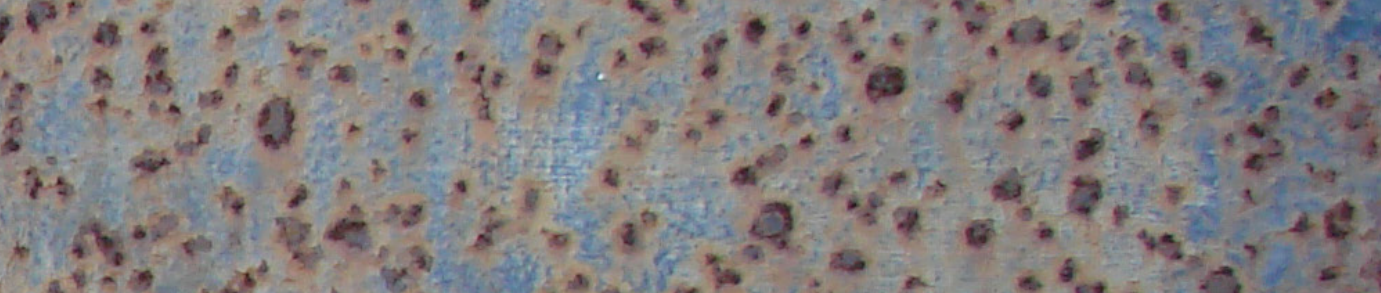

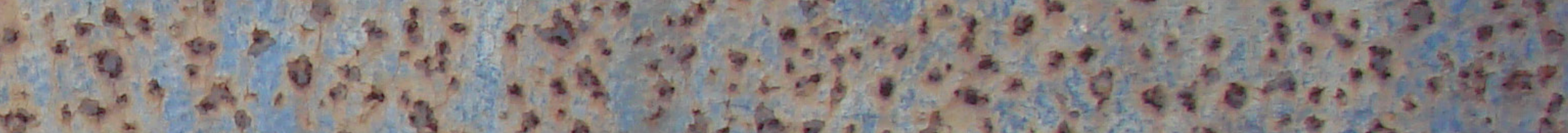

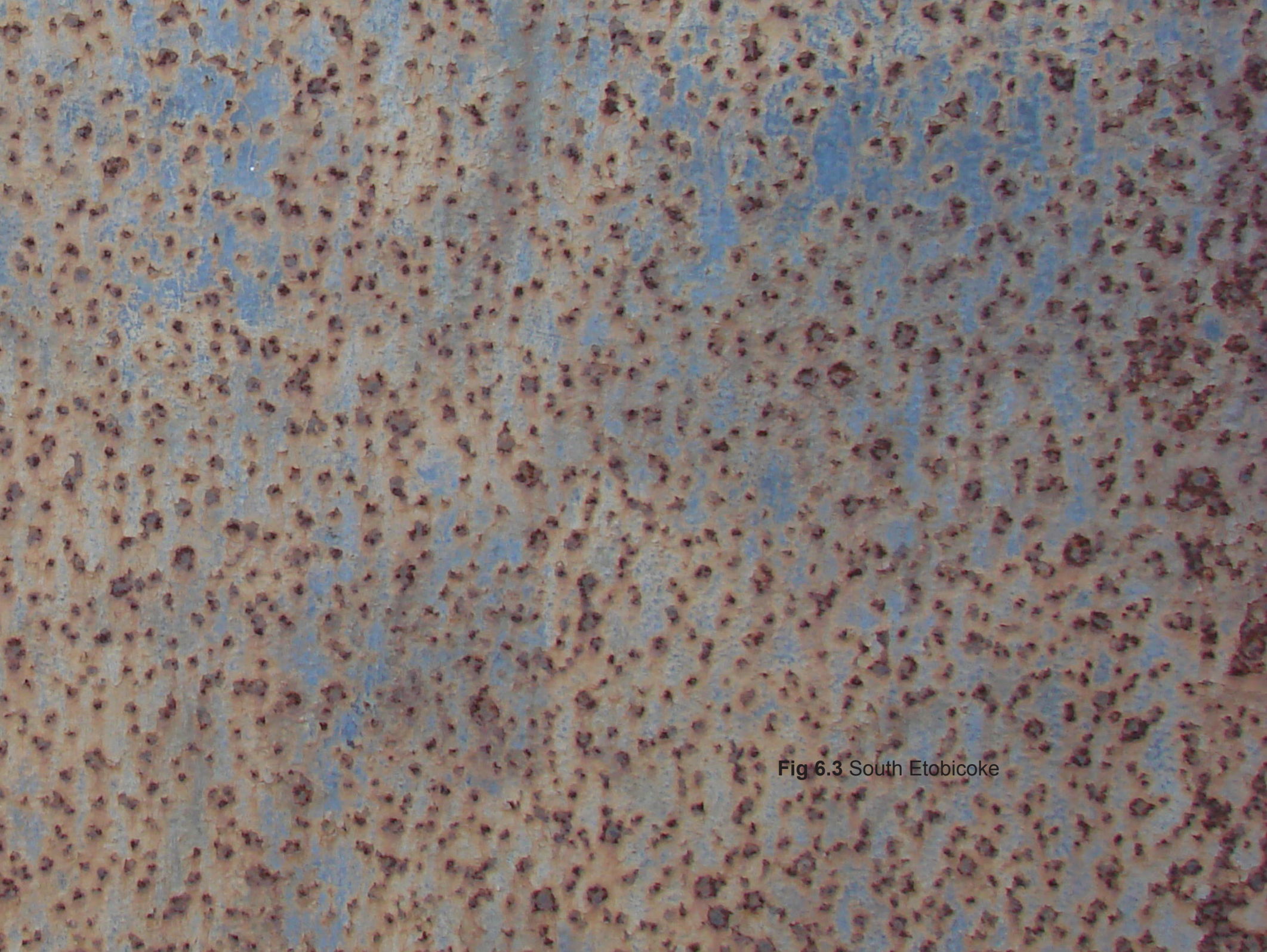




\subsection{Project Proposal}

Every year industrial buildings are cleared out to make space for new residential development. Tracing development trends within South Western Toronto, specifically Etobicoke, allows for locating buildings that have the potential of becoming a donor for material reuse and applying research findings in the process of design to a mixed use multifamily building.

Fig 6.1 Below: Outline of the demolished industrial buildings still visible as the lot is being prepared for residential row housing development. During each real estate boom commercial lots are redeveloped to accommodate residential housing
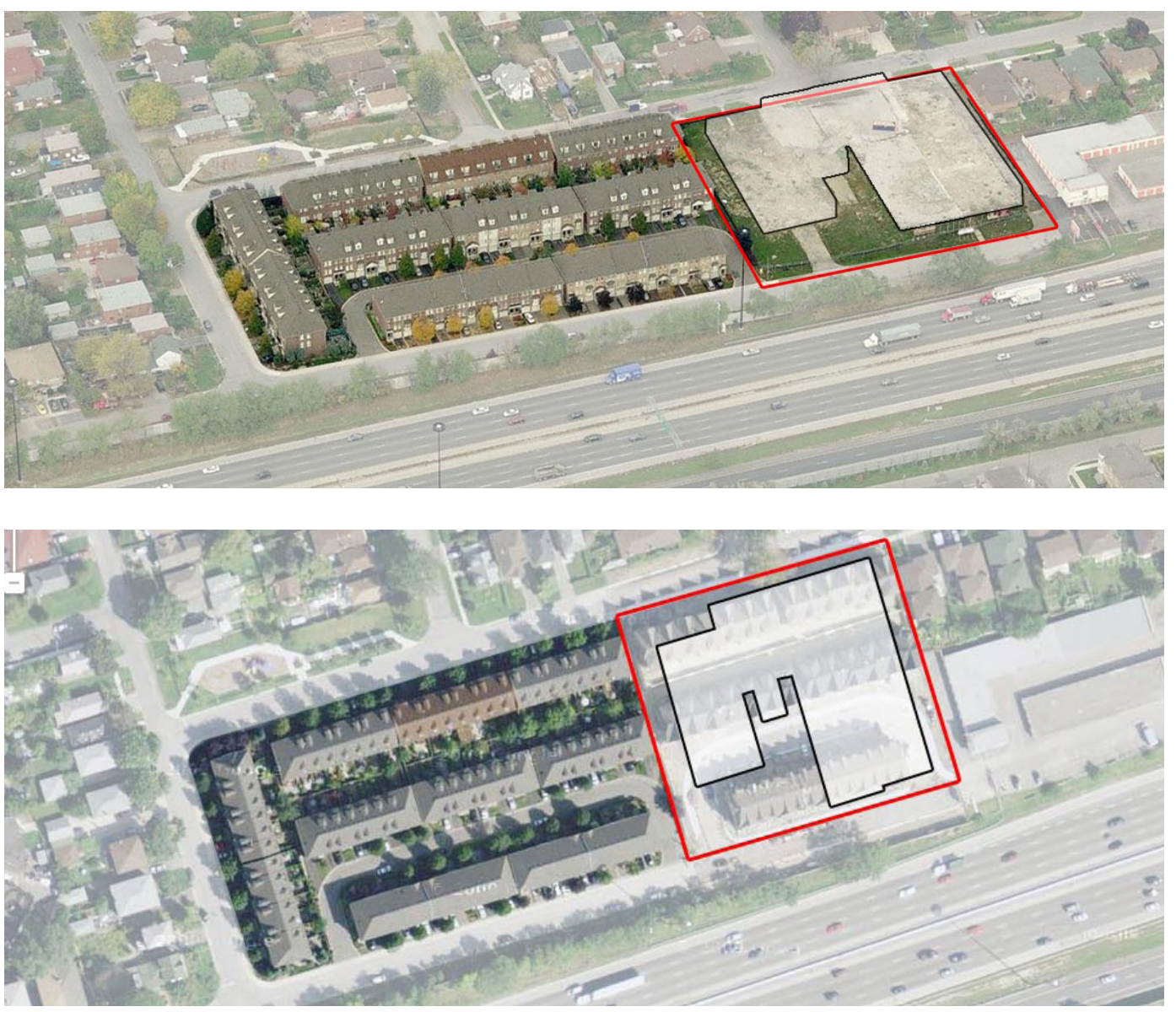

Fig 6.2 Above: Completed row housing development. Town homes west of the lot are located on land that was previously designated for industrial development. 
Mimico, a part of Etobicoke, is undergoing a constant redevelopment. A lot of the industrial land that has been redeveloped within this region into residential occupancy has the potential of being a great source for building materials. The common procedure once the buildings are vacated is a quick demolition with the new construction following within a very short period of time. However, if the buildings were to be deconstructed and reused in situ it would significantly reduce environmental impact of the new forthcoming development.
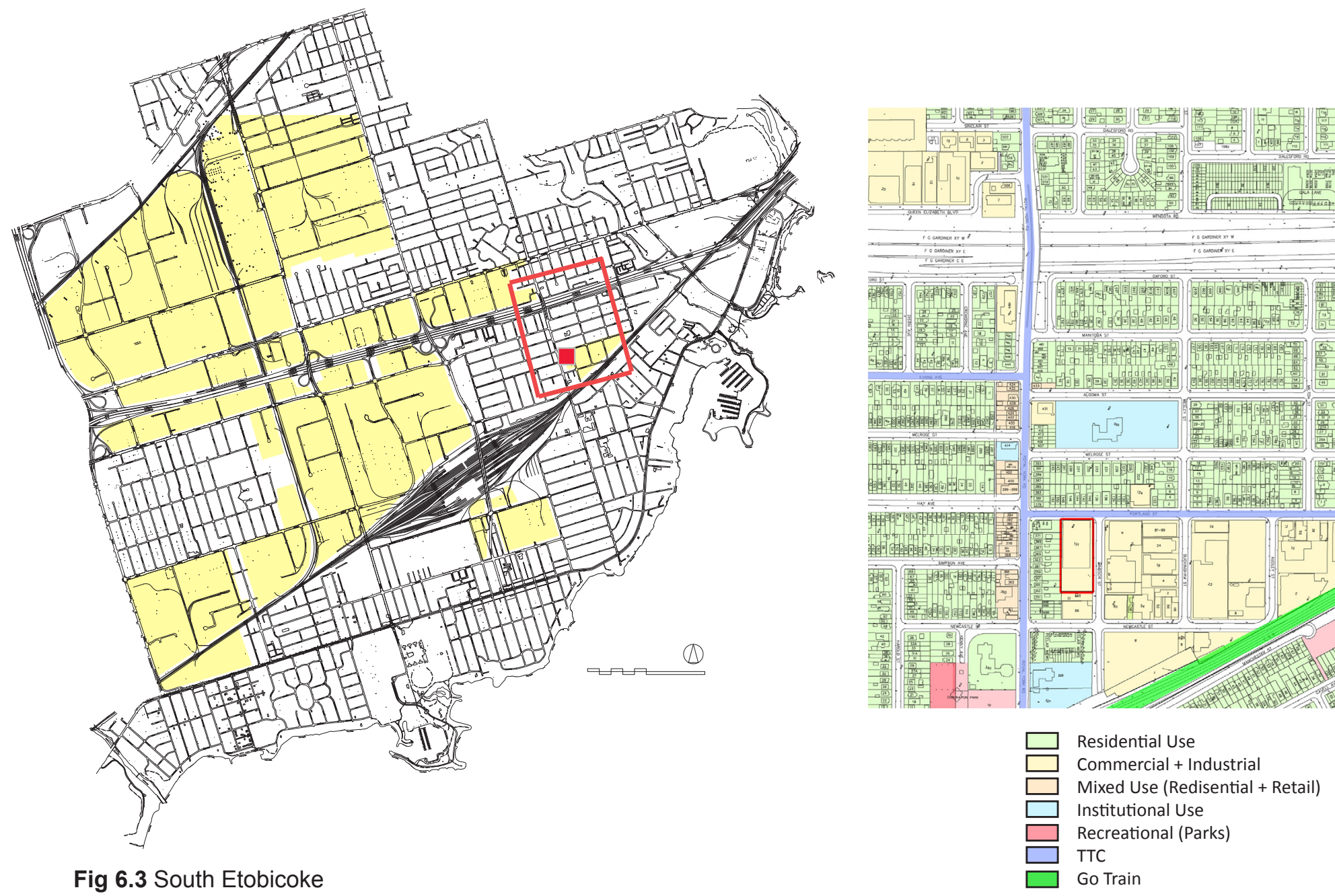

Fig 6.3 South Etobicoke 
Fig 6.4 101 Portland St Adjacent typologies:

Red - single family housing Green - Low rise condominium Blue - multiplexe apartments
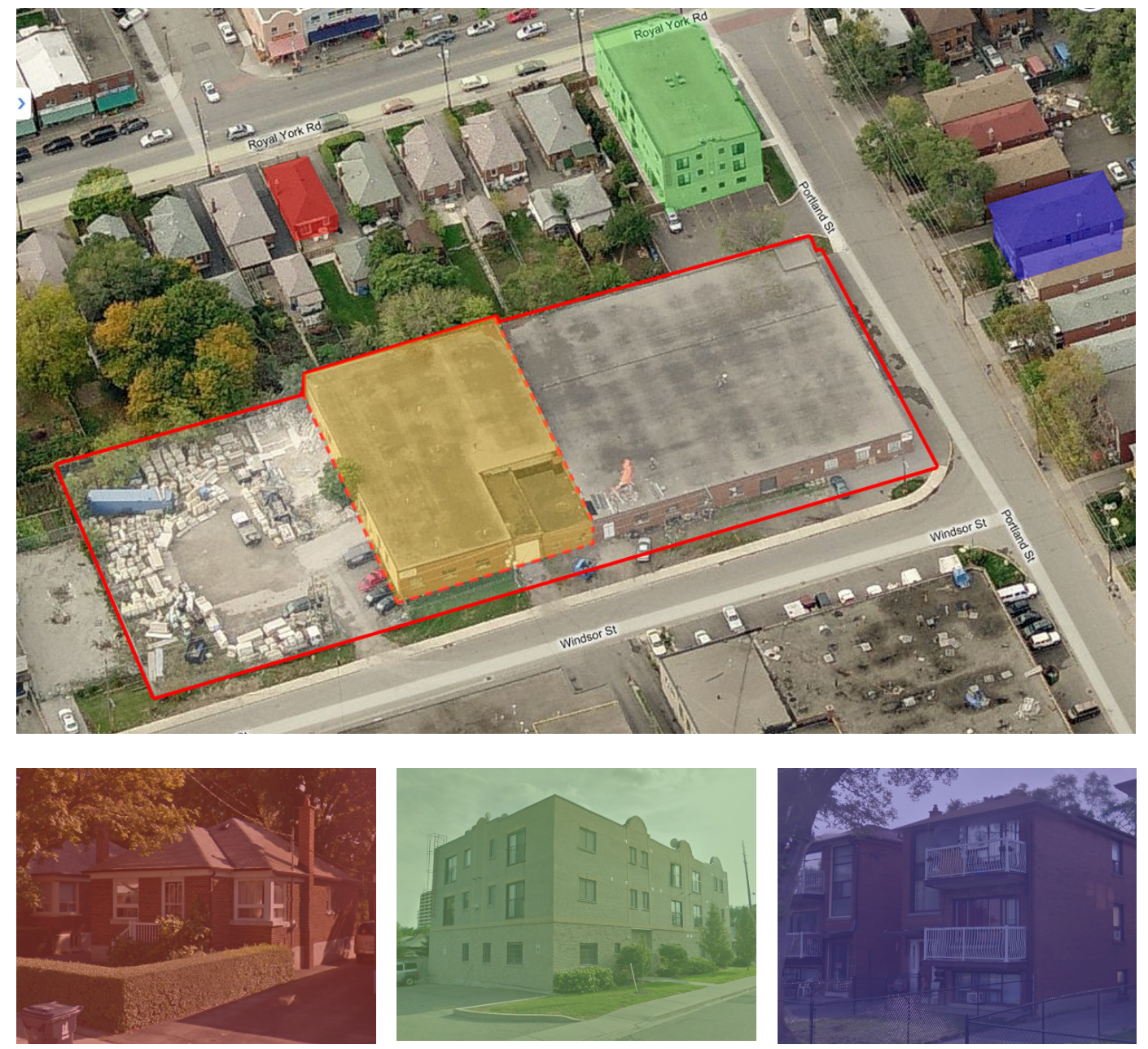

The southern part of the existing building is suitable for deconstruction material processing. The deconstruction process is to start at the north end of the building, clearing the lot for the new development. Deconstruction would occur within stages, allowing for the southern part of the building to be used for sorting, processing and storing of acquired material. 
The bolted connections at the slab as well at the top of the 4.5" diameter columns are an advantage in terms of deconstruction. Bolted connections between the beams eliminate any damaging disassembly and allow for maximum reuse of the existing steel components. The columns vary in height, from 11'- 6 " in the lower section of the building, to $15^{\prime}-10$ " in the southern part of the structure.
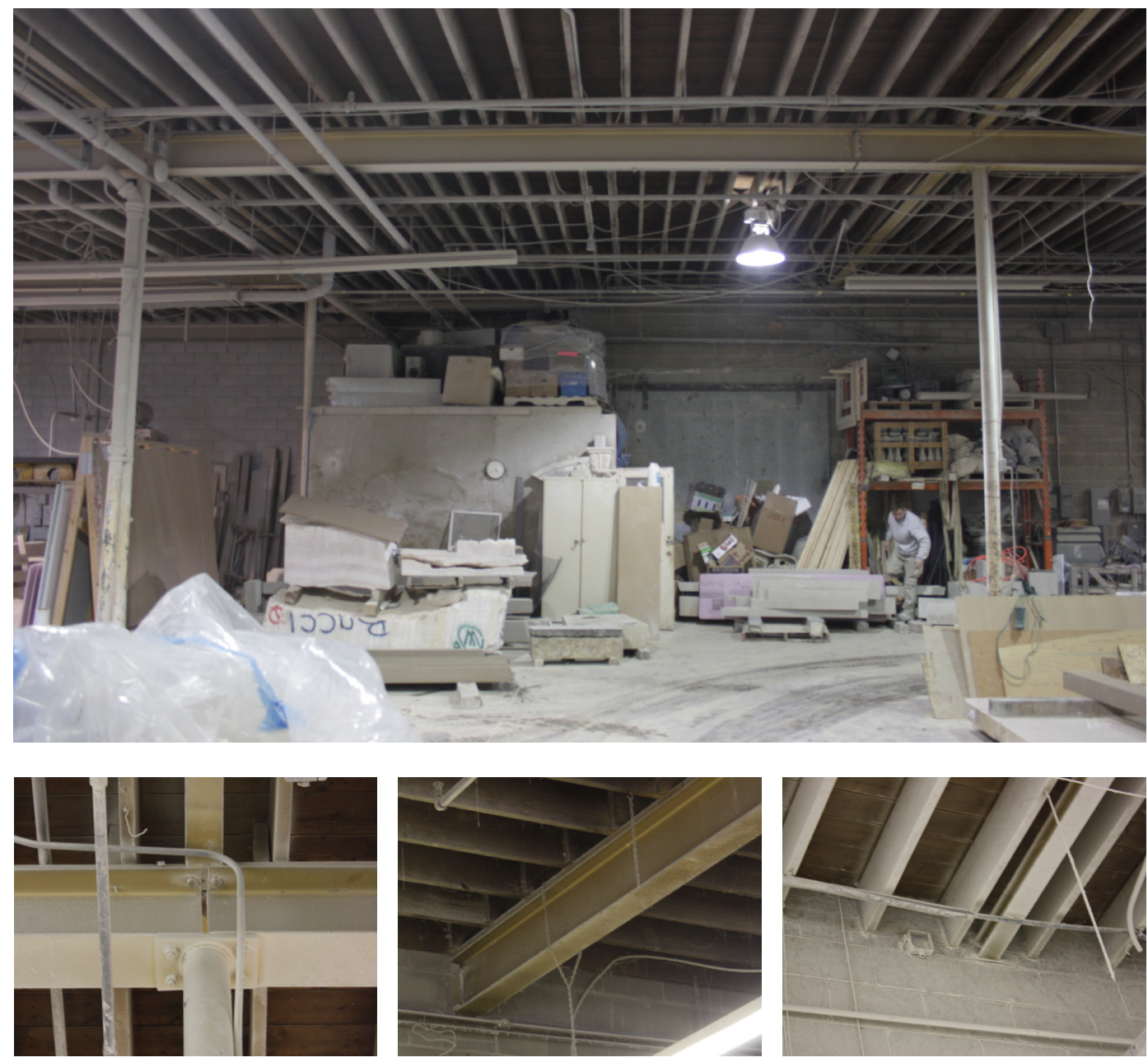

There were two sizes of beams noted at $\mathrm{W} 12 \times 6.5 \times 35$ (which is equivalent to

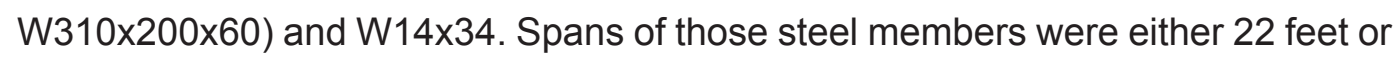
28 feet. $2 \times 10$ roof rafters are spaced at 16 " on centre and are fastened only at the top deck side with nails leaving bottom sitting on the steel beams without mechanical fastening.
Fig 6.5 Investigated building; well preserved structural components with bolted connection suitable for deconstruction 
W310x60 span varies depending on supported length and number of supporting floors in dwelling units. It ranges from $9.5 \mathrm{~m}$ to 10.2 in case on one storey, and $7.4 \mathrm{~m}$ to $8.5 \mathrm{~m}$ when the supported length is maximum allowable span of the lumber.

Fig 6.6 Investigated building; well preserved structural components with bolted connection suitable for deconstruction
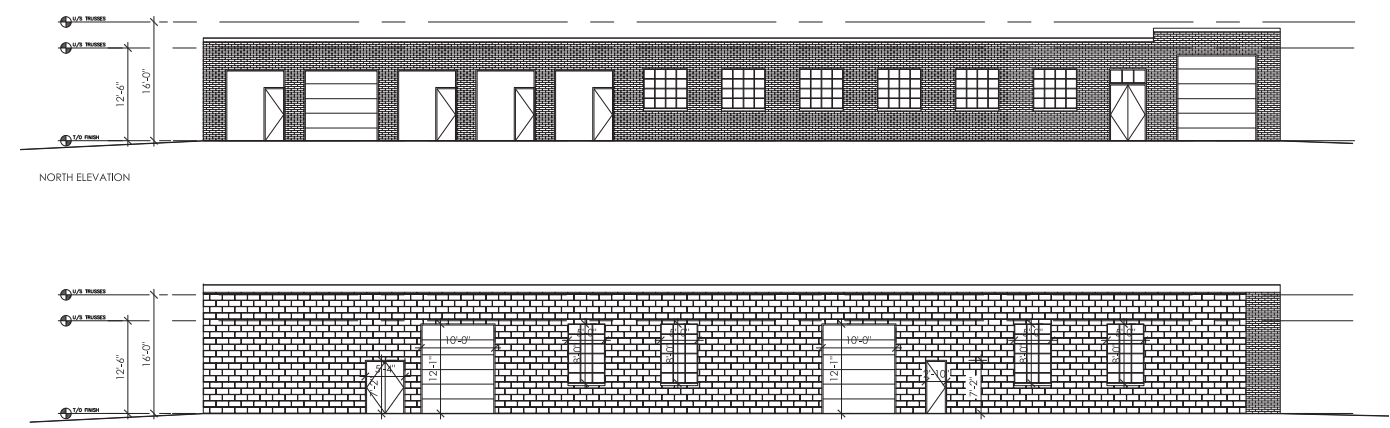

Fig 6.7 Full take off of potential material to be reused including the material sizes and quantities

\begin{tabular}{|c|c|c|c|c|c|}
\hline \multicolumn{3}{|c|}{101 PORTLAND ST MATERIAL TAKEOFF } & \multirow[b]{2}{*}{ \# OF GRIDS } & \multirow[b]{2}{*}{ TOTAL (FT) } & \multirow[b]{2}{*}{ TOTAL LBS } \\
\hline STEEL & LENGTH (FT) & ON ONE GRID & & & \\
\hline \multicolumn{6}{|l|}{ GIRDERS } \\
\hline W12x35 & 22 & 4 & 15 & 1320 & 46200.00 \\
\hline W12x35 & 28 & 2 & 13 & 728 & 25480.00 \\
\hline W14x34 & 28 & 1 & 4 & 112 & 3808.00 \\
\hline \multicolumn{6}{|l|}{ TIES } \\
\hline W4x13 & 15.85 & 5 & 16 & 1268 & 16484.00 \\
\hline \multicolumn{6}{|l|}{ COLUMNS } \\
\hline$\emptyset 4.5 "(11.35 \mathrm{lbs} / \mathrm{ft})$ & 15.85 & 5 & 15 & 1188.75 & 13492.31 \\
\hline \multicolumn{6}{|l|}{ WOOD } \\
\hline $2 \times 10 @ 16 "$ O.C. & 16.33 & 107 & 16 & 27956.96 & 94214.96 \\
\hline \multicolumn{6}{|l|}{$(3.37 \mathrm{lbs} / \mathrm{ft})$} \\
\hline CONC. BLK & SOUTH $\mathrm{ft}^{2}$ & EAST $\mathrm{ft}^{2}$ & WEST $\mathrm{ft}^{2}$ & NORTH $\mathrm{ft}^{2}$ & TOTAL ft ${ }^{2}$ \\
\hline $8 "$ & & 3014 & & 1112 & 4126.00 \\
\hline $10^{\prime \prime}$ & 2050 & & 3397 & & 5447.00 \\
\hline 8" (PARTITION) & 2000 & 2000 & 490 & & 4490.00 \\
\hline BRICK 4" VENEER & SOUTH ft ${ }^{2}$ & EAST $\mathrm{ft}^{2}$ & WEST $\mathrm{ft}^{2}$ & NORTH $\mathrm{ft}^{2}$ & TOTAL $\mathrm{ft}^{2}$ \\
\hline 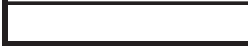 & & 3014 & & 1112 & 4126.00 \\
\hline
\end{tabular}


The diagram to the right illustrates different scenarios of single story supported structure with floor joist spacing (from left) 24", 16" and 12". Review of the available building material is essential in determining the possible bay sizes for the new construction. This is the main constrain in the design process.

Singular bay is approximately 420 square feet. The bays can be then arranged in single units (studio apartments), double with the area of 820 square feet, triple with 1260 square feet and so on. The most traditional arrangement is vertical stacking, which is typical for row housing, or horizontal, flat or apartment arrangement.
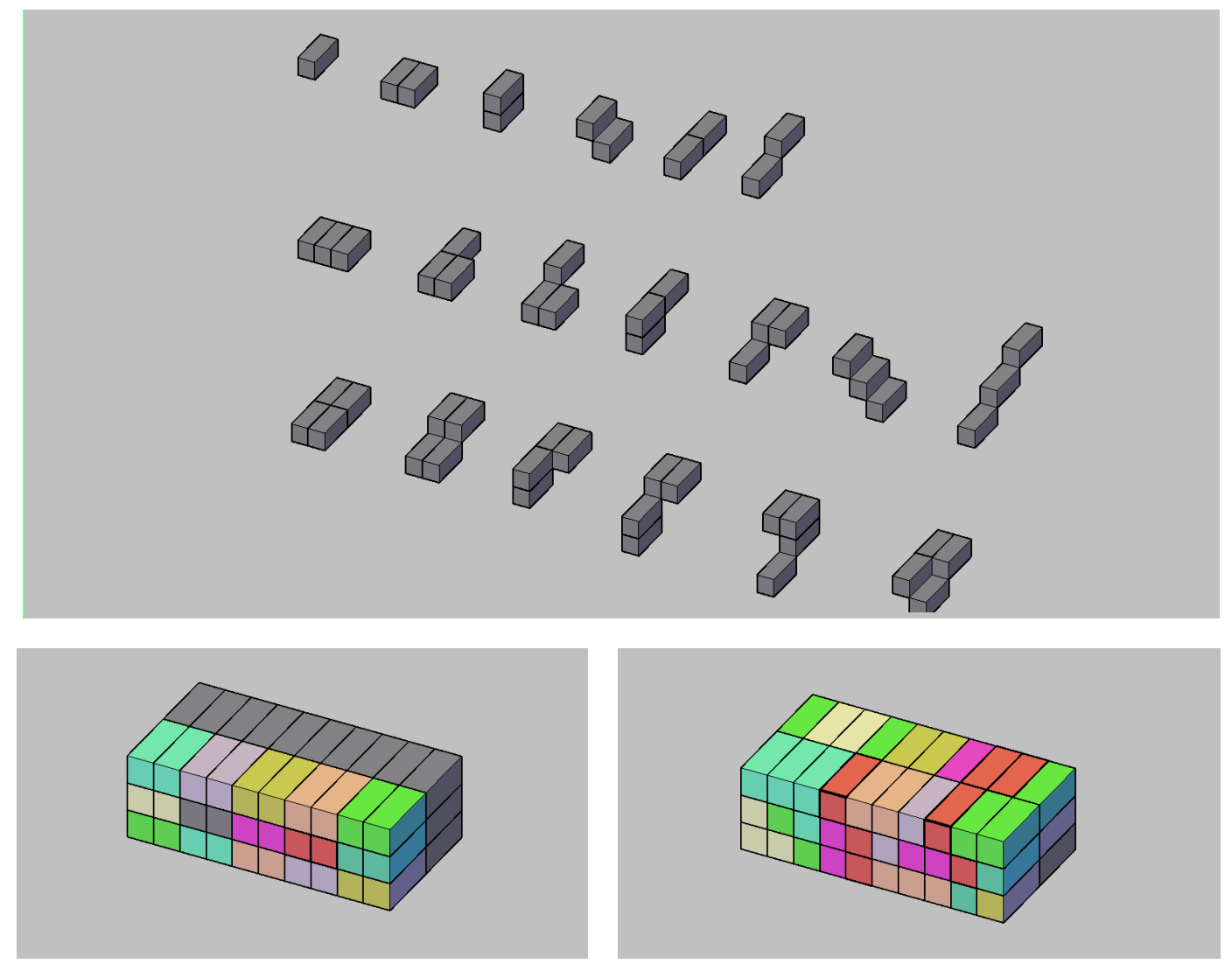

The image on the left represents typical apartment style arrangement. Each unit is assigned to one floor. The image on the right explores units occupying one, two and three stories. This resolution permits more units to have a direct access to the ground floor and eliminated to some degree common internal circulation.

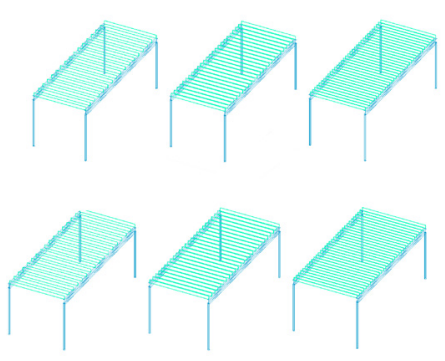

Fig 6.8 Steel structure with wood joists (open plan)

Fig 6.9 Unit variations

Fig 6.10 Arrangements Left: typical apartment, single directional; Right: diversified vistas, cross ventilation 
The structural bays were designed perpendicular to the axis of the building with units having both north and south facing windows. This promotes cross ventilation to alleviate load on hvac system and diversifies the vistas from each unit. This simplified standard framing pattern reduces construction time which was already impacted by the deconstruction of the existing industrial building.

Fig 6.11 Left: Comparison of steel frame to load bearing concrete block option Right: Shift of volumes creates cantilevers that can be used for sunlight control
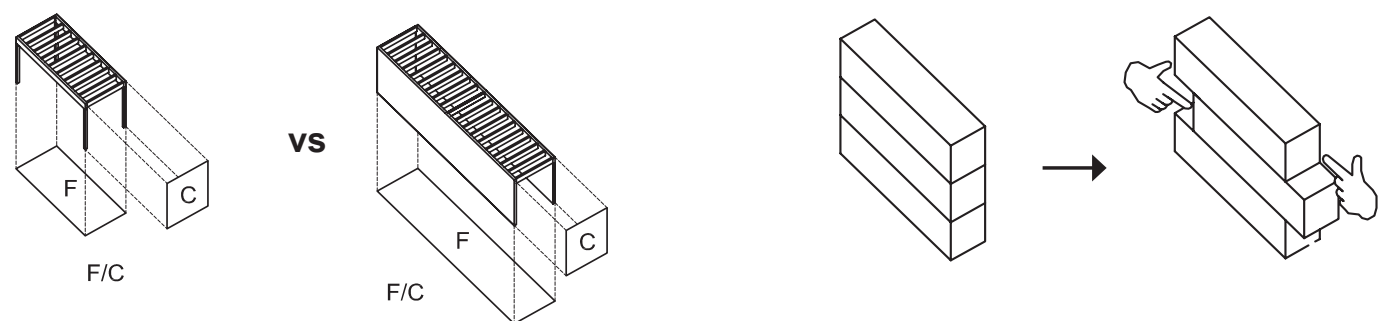

Fig 6.12 Section

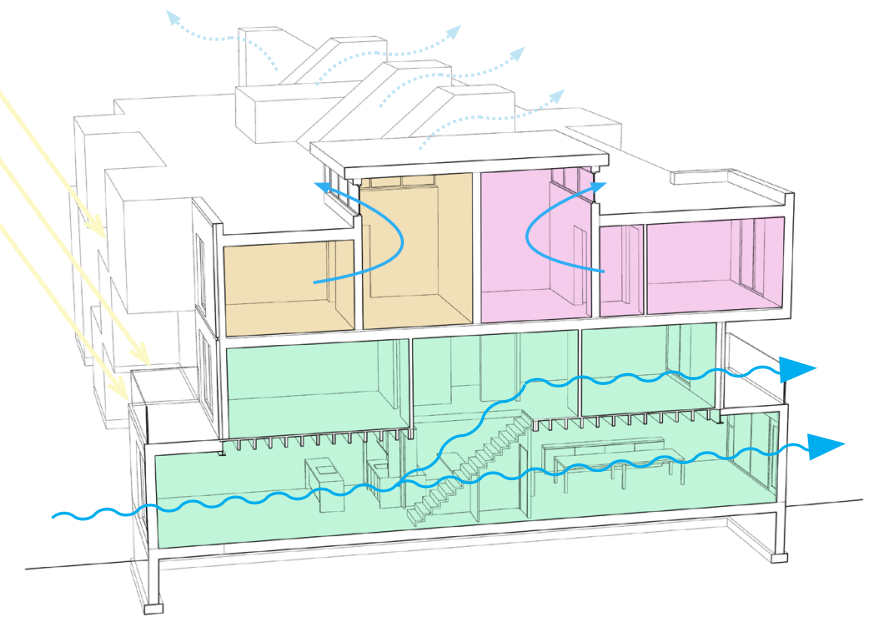

The choice of such arrangement provides the opportunity to increase the overall length of the building of any desired number of bays depending on material availability. This arrangement also brings forward the freedom to provide large floor to ceiling glazing areas at the exterior walls to take advantage of the natural light. 
Upon the design review and material takeoff required for the new built it was established that the demand for steel components if greater than the supply. The design opted for concrete block to serve both as a partition, fire separation and load bearing wall, this provided lesser flexibility of the space but greater utilization of material at hand.

Fig 6.13 Unit arrangement

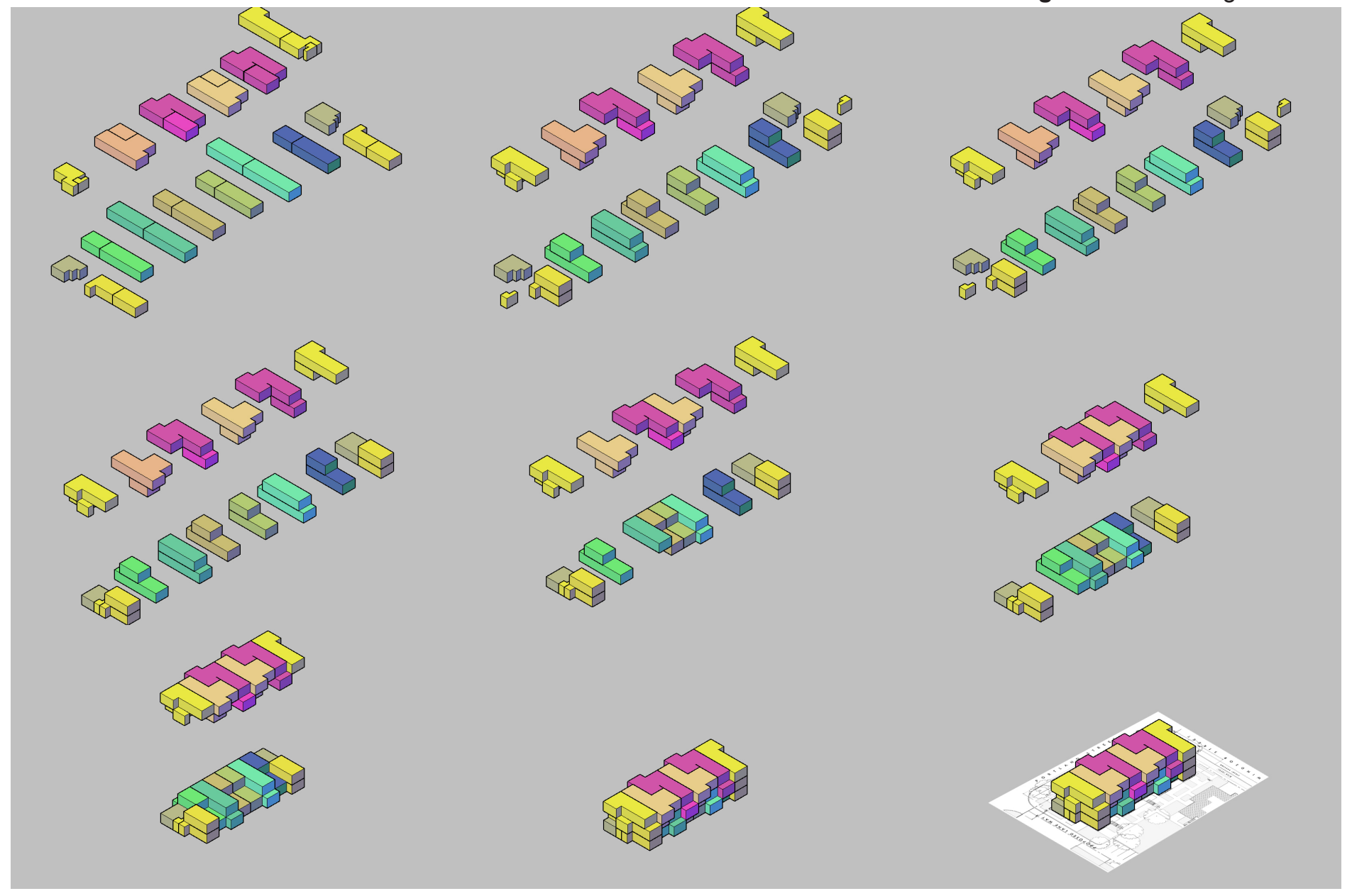




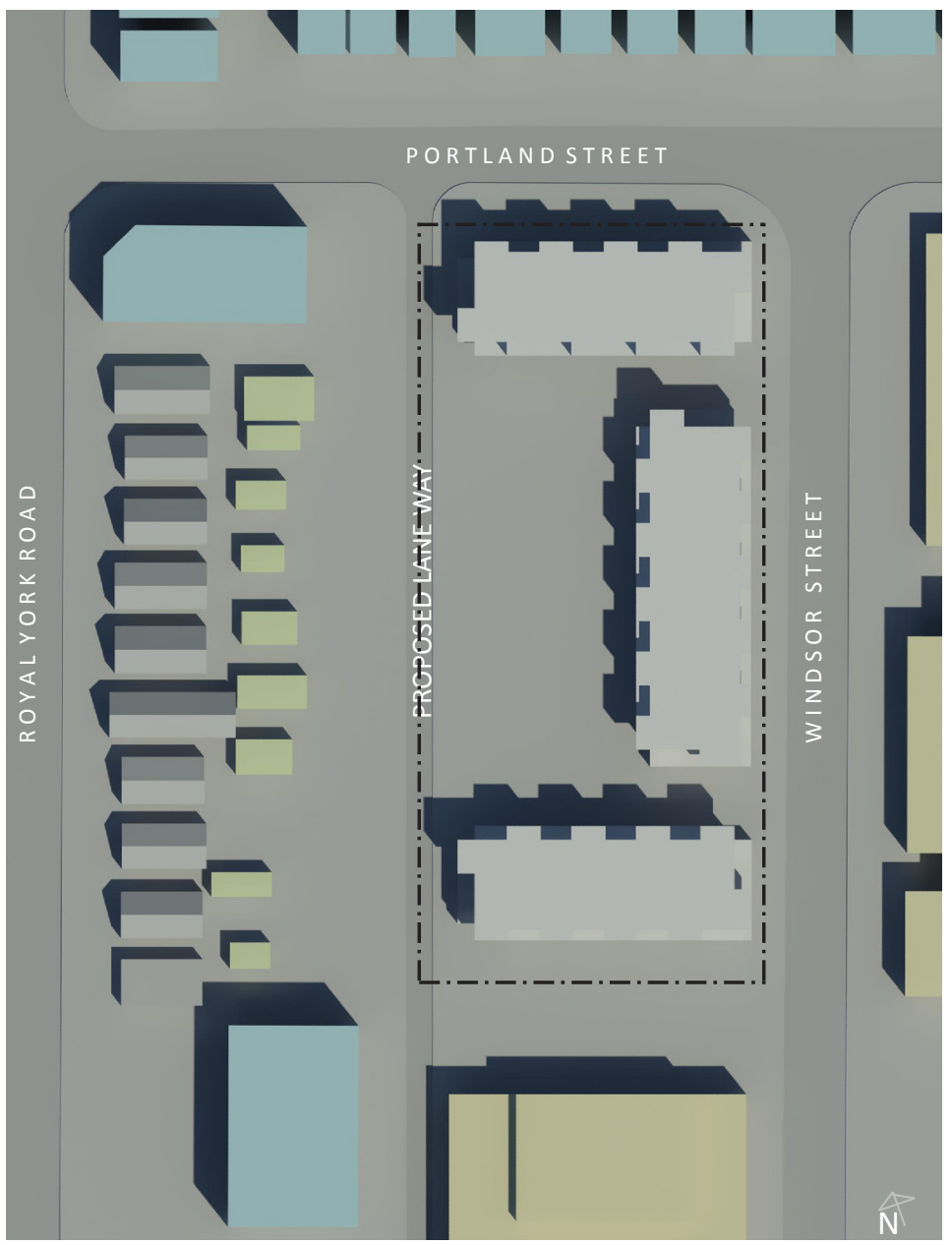

Both Portland Street and Windsor Street are heavily used by commuters during rush hours as those lead toward the Mimico Go Station. The traffic generated by GO commuters was taken into consideration in the decision to have the storefronts along the streets, be playful and inventive to encourage interaction of the passersby. Another item that was important to provide was a mix of commercial and live work units on ground floor. The images below depict the initial massing of the proposed building in its surrounding with yellow indicating commercial buildings, blue representing multifamily housing and grey being the single family housing along the Royal York Road.

Fig 6.14 Site plan 
Currently the single family houses located west of site have street access to from Royal York Road. Due to narrow lots they are located on, impacts possible future densification of the stretch. The proposed development at 101 Portland Street takes into consideration laneway access between the lots thus permitting street level parking accessible from the laneway, as well as garage access for the single family houses. This provides an opportunity for future laneway housing development which would complement the nature of the proposal. The below image shows possible densification that may occur over time facilitated by the laneway.

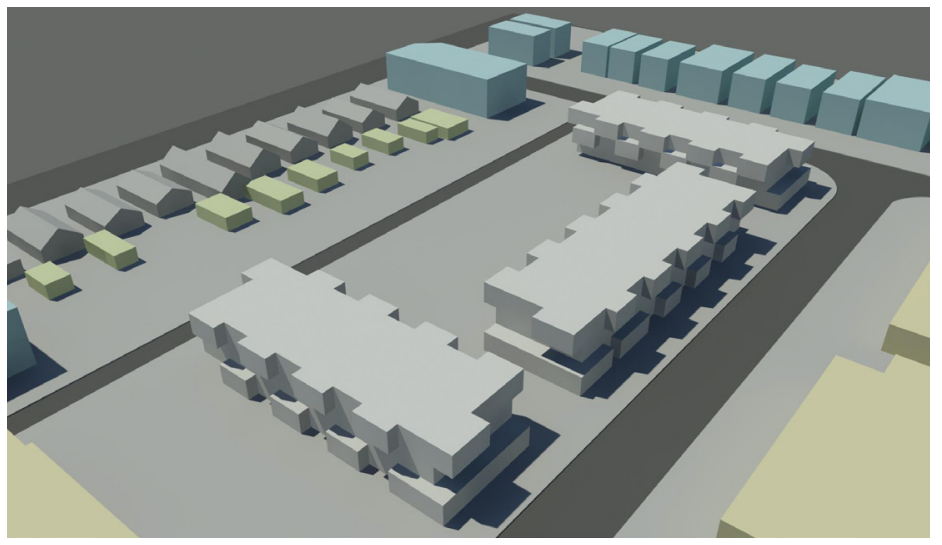

Looking North on Windsor Street

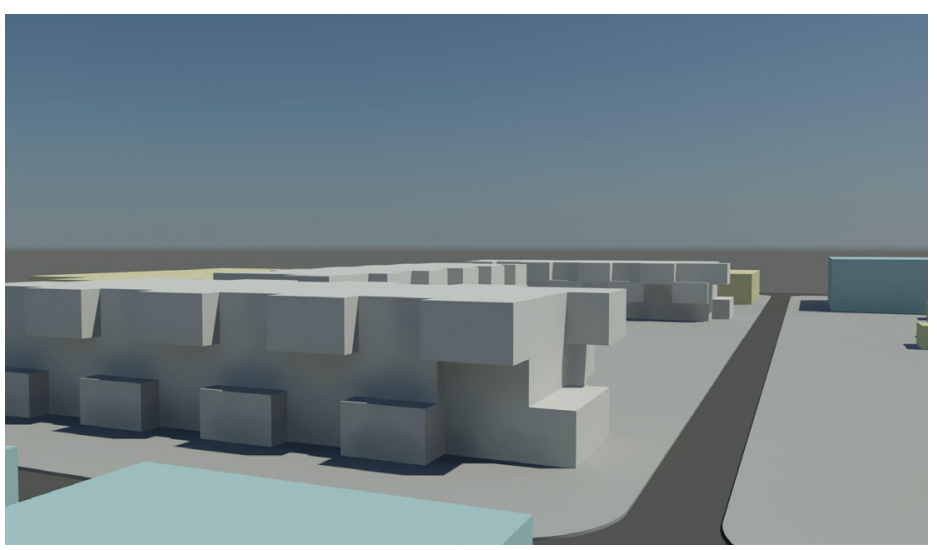

Looking South on Proposed Lane Way

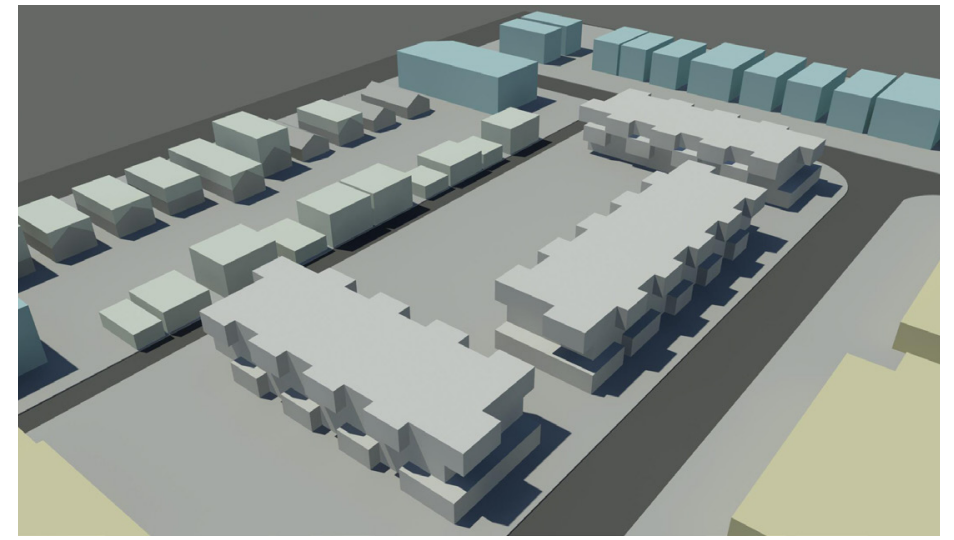

Increased density

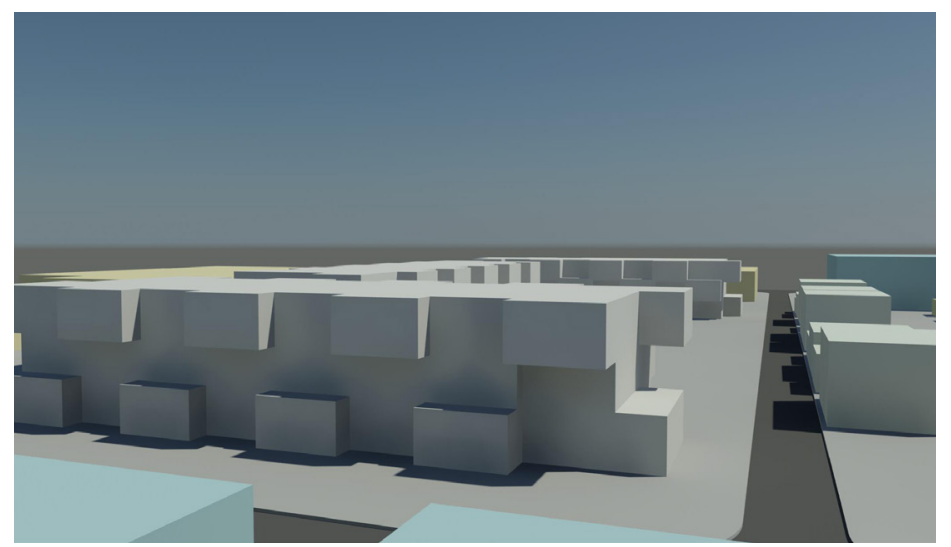

Fig 6.15 Projected densification and laneway development 
The cities imposed setbacks on the lot give an opportunity for street level parking which in combination with access to public transit (both Go Train and bus lines) makes it possible to discard heavy parking structures which the construction of is both energy in consumption and material heavyblue representing multi-family housing and grey being the single family housing along the Royal York Road.

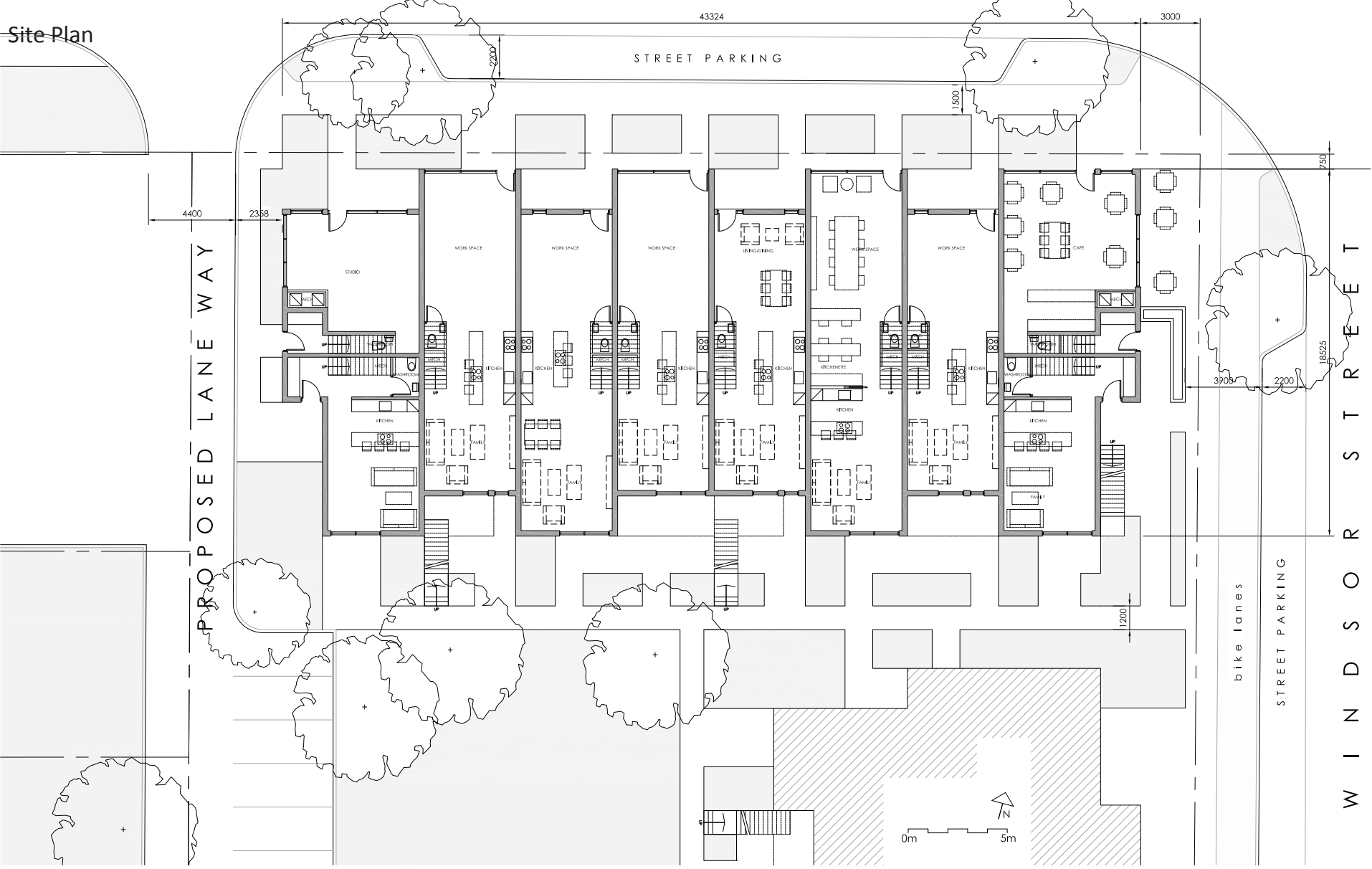

Fig 6.16 Detail site plan

Consideration was also made for cyclist, and as much as the area does not have designated bicycle lanes, it is advised to promote transportation that is not carbon emission heavy. Windsor Street is a 280 meter street that ends at Mimico Go Station therefore as setbacks encouraged such resolution, bike lanes have been provided on that stretch. 
Fig 6.17 Left: Looking west from Windsor St.
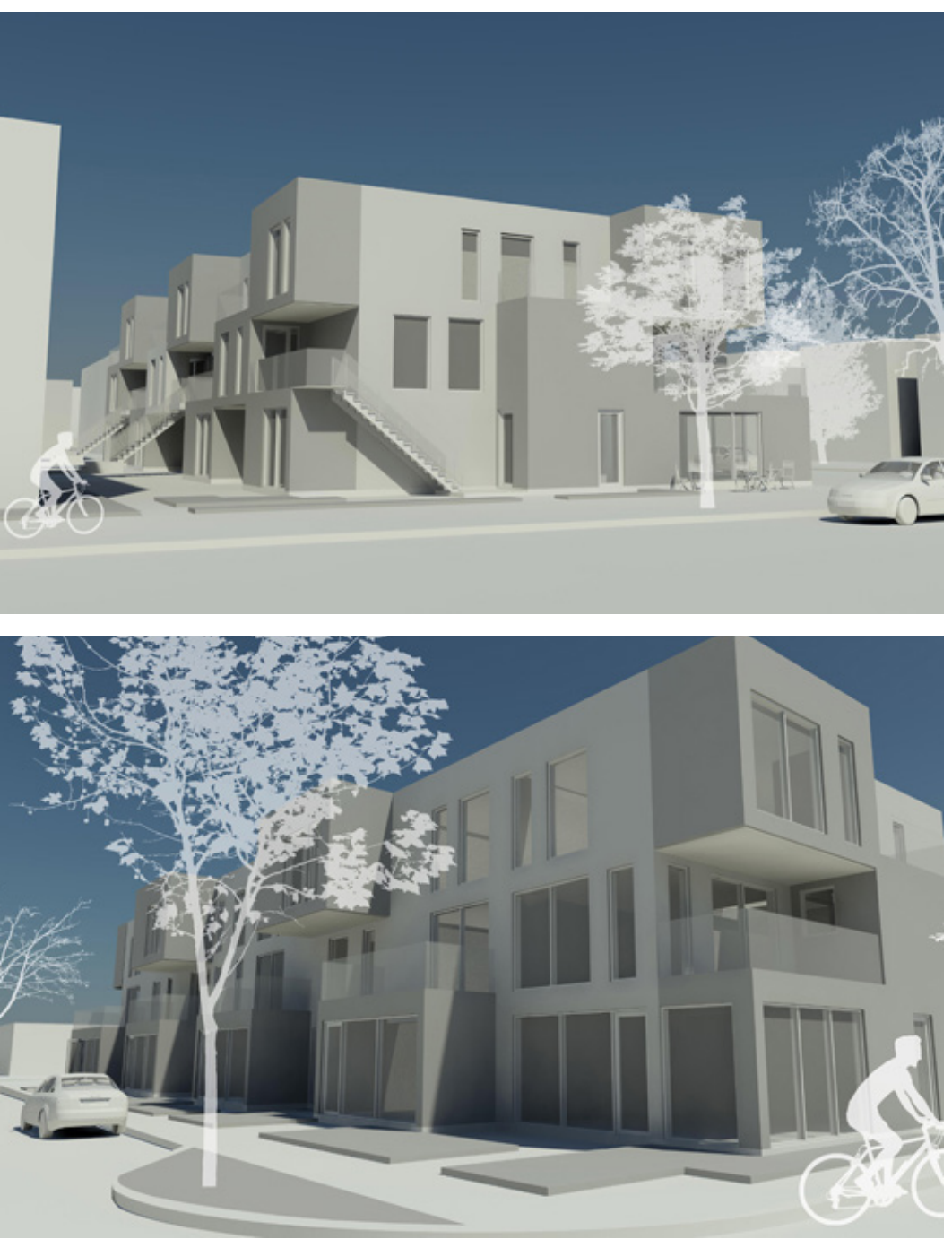

Fig 6.19 Left: Looking east along Portland St.
Fig 6.18 Right: Looking west along Portland St.
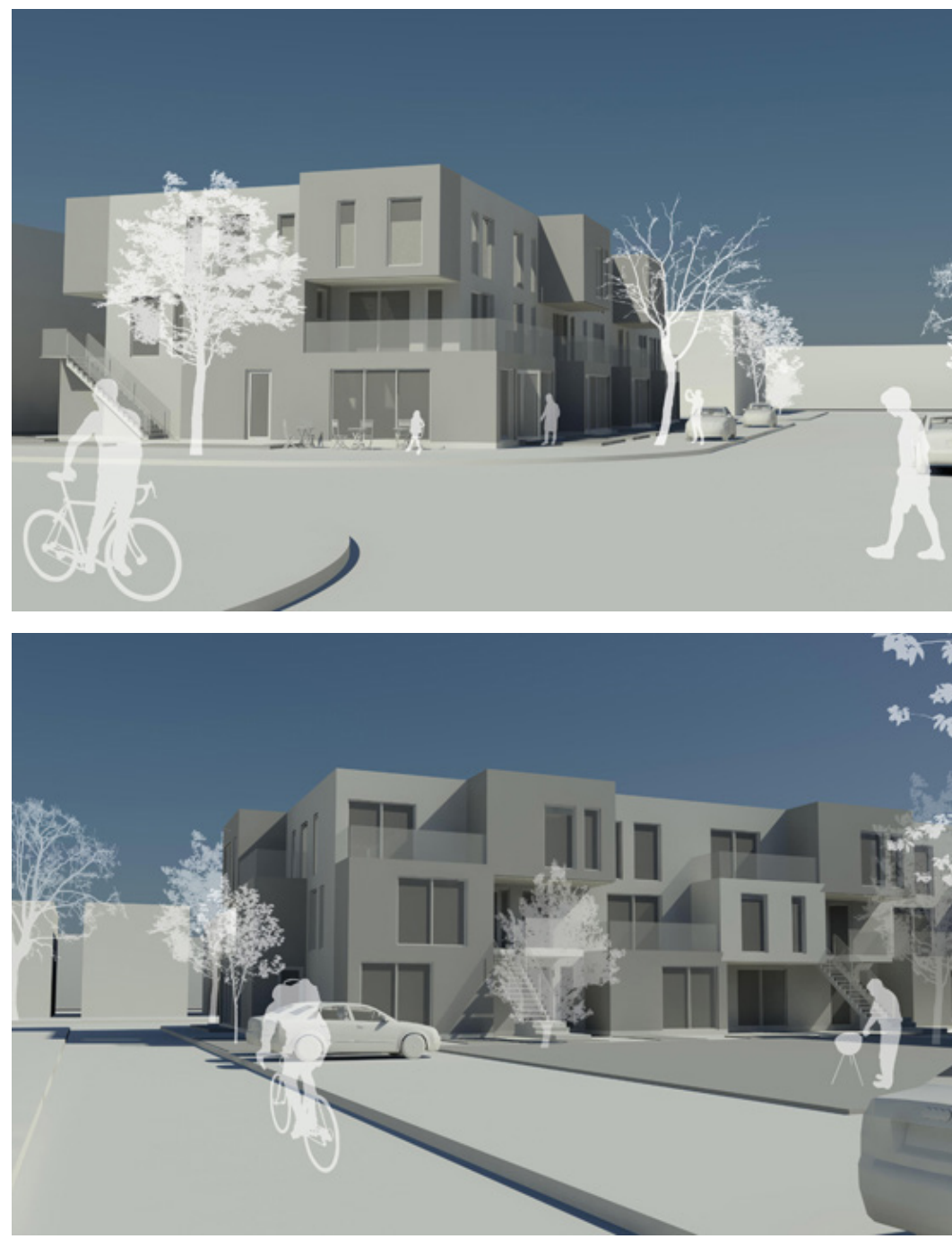

Fig 6.20 Right: Looking north along proposed laneway 
When resolving the cladding material the preference was given to materials already located on the site - sourced from deconstruction.

The protrusions are to be cladded with corrugated steel deck (Fig. 6.21) sourced from the adjacent industrial building. This allows for larger overhangs cantilevering from the main structure, which will be supported with the available W shapes. The sides of the protrusions hide structural components, therefore any perforations through those walls were not considered.

Fig 6.21 Cantilever cladding

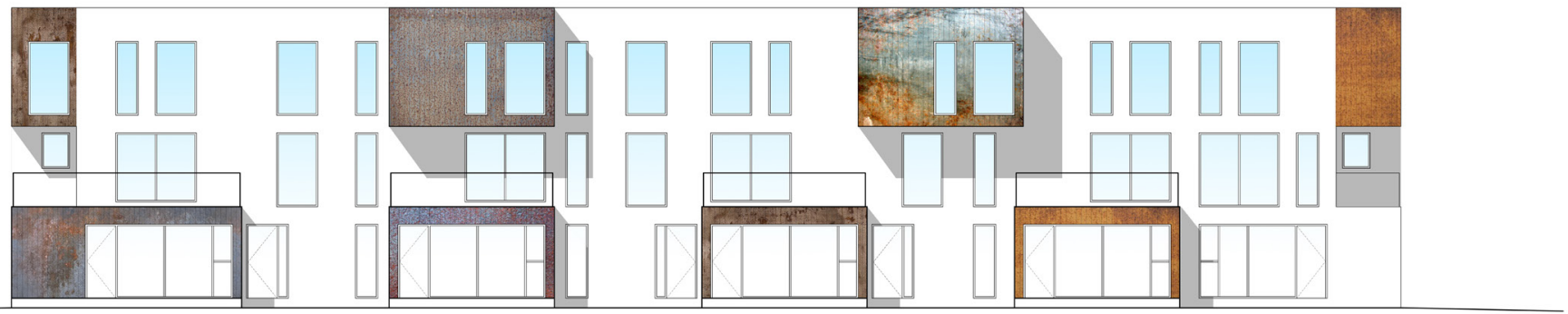

NORTH ELEVATION (PORTLAND ST)

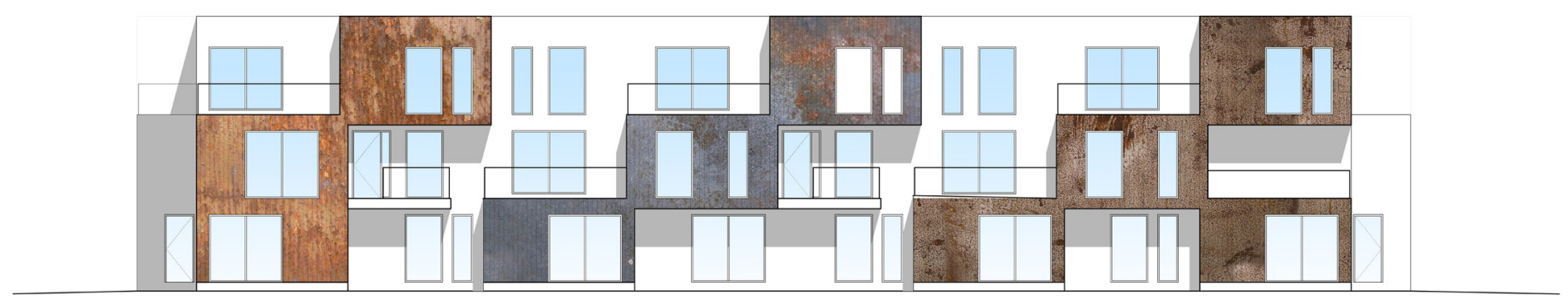

SOUTH ELEVATION 
The initial assumption was to use large brick components (Fig.6.22) - sections of brick wall compressed by a permanent frame that serves as a curtain wall structure. However upon closer examination of the available material it was found that within the existing stock there will be insufficient amount sections large enough to meet the requirements of the proposed design.
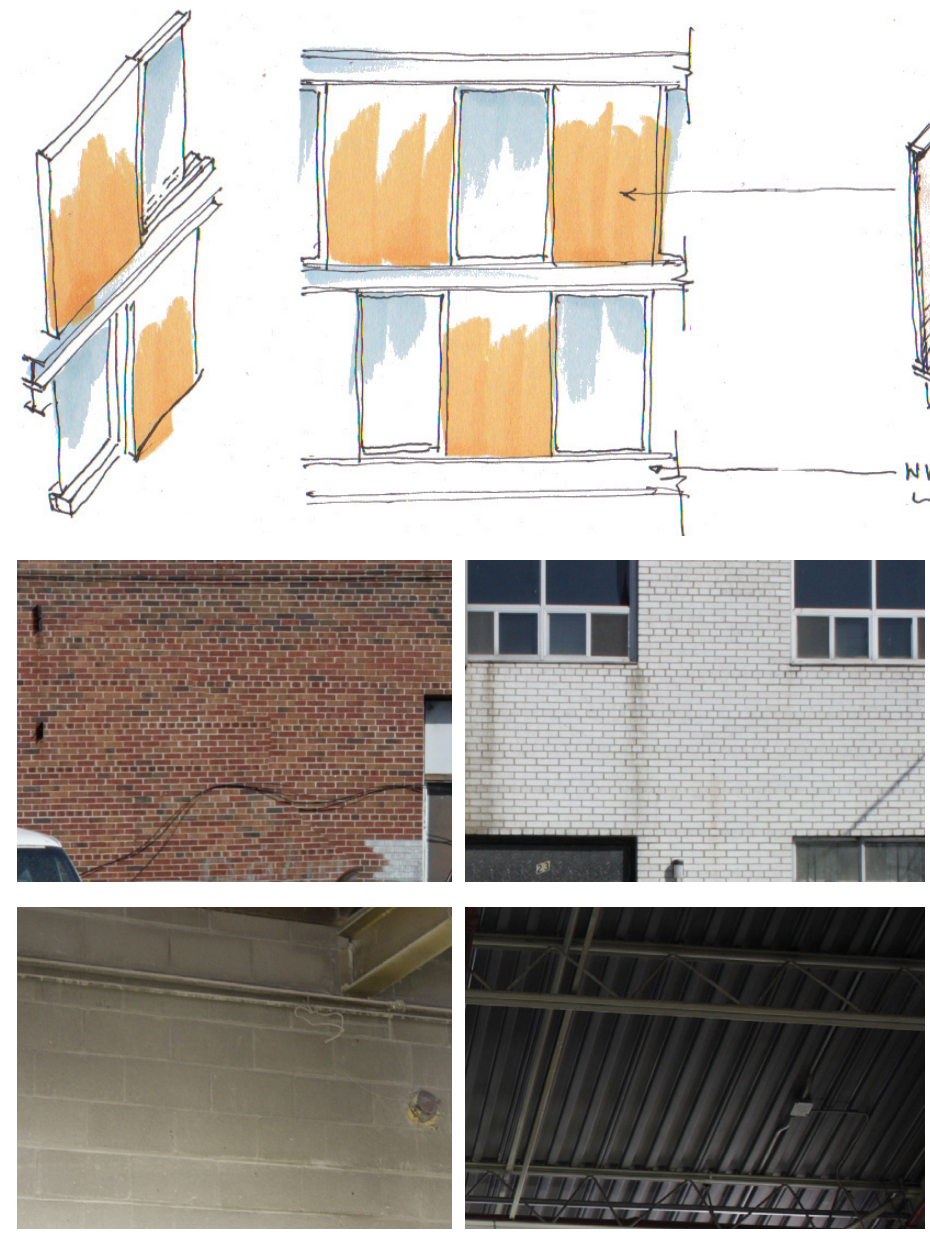

Fig 6.23 Available materials
Fig 6.22 Large reclaimed component cladding system

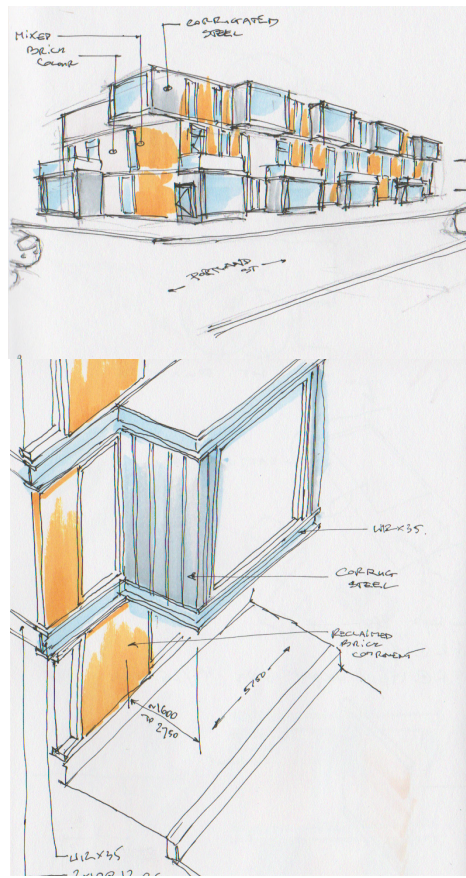

Fig 6.24 Initial material palette 
Fig 6.25 Right: Small component extraction

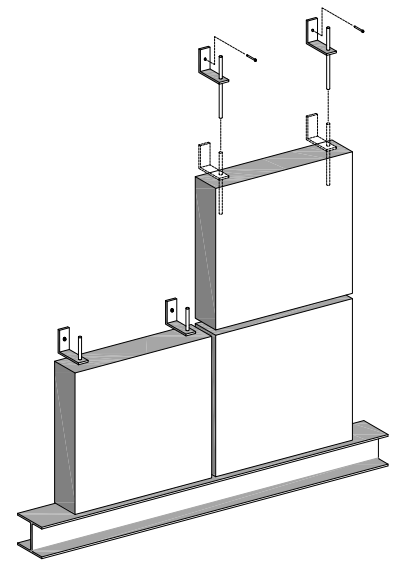

Fig 6.26 Small component cladding system using typical stone cladding brackets/ties
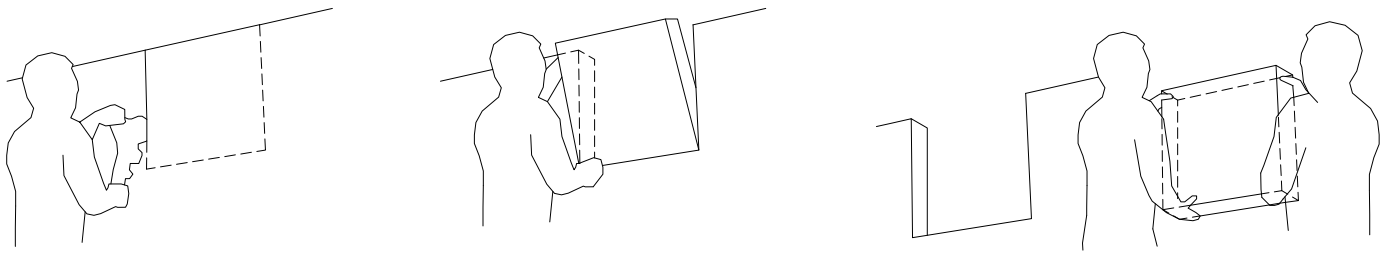

The size of the new component needed to be large enough to streamline the construction, but small enough to not require specialized cranes. At the same time it was important to take advantage of the existing buildings and minimize material leftover.The size of the small component was set to $450 \mathrm{~mm} \times 450 \mathrm{~mm}$. This is a 2 brick long and 7 brick high section that allow the removal during reclamation process to take place along the grout lines, thus preserving entire bricks and reducing labour requirements during material removal from the donor structure. The size of the component permits hand handling by 2 people during removal and installation. The small component preserves the embodied energy of brick and to large degree the installation as the amount of bricklaying labour in the new application is largely reduced.

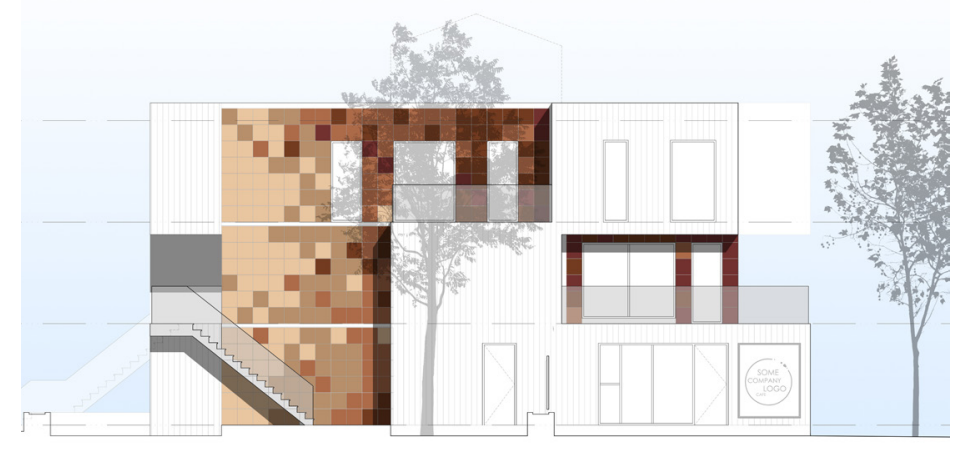

East elevation

Fig 6.27 Small component cladding system - elevations

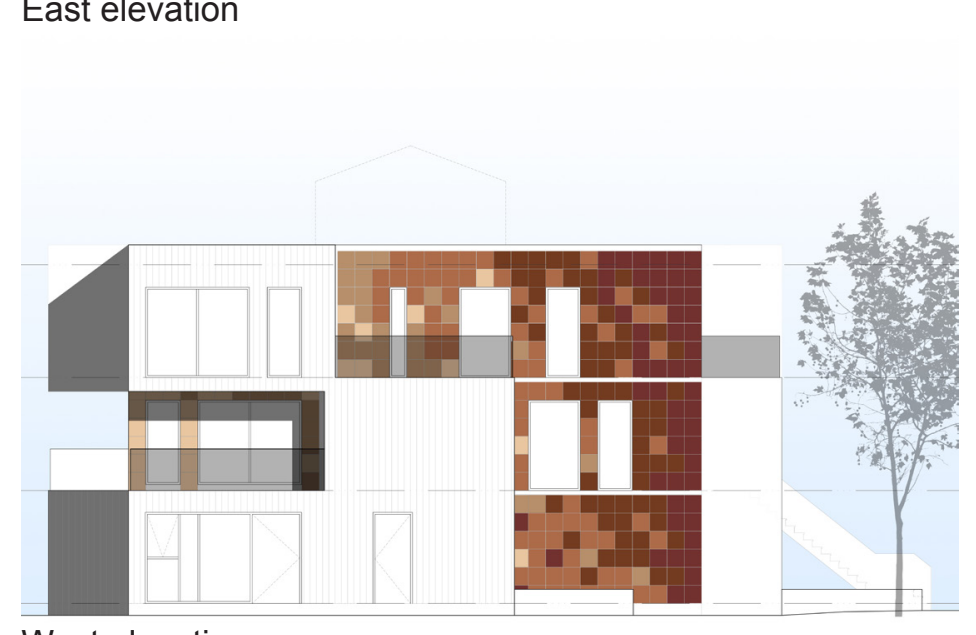

West elevation 
This size component can be sourced from industrial as well as residential construction, and does not require complex equipment at any stage and when drilled and fitted with pins, it can be fastened with metal brackets to the new structure.

The new fixed size of the small component required a redesign of the elevations in terms of opening sizes and lintel structure. Since it is nearly impossible to source only one colour of brick various colours had to be considered. By creating a governing principle, the overall elevation order is possible to accommodate small scale imperfection. A pattern of gradient colour transition permits random shades to be in close proximity and still seem governed and intentional. Such principle allows featuring non-perfect and off-colour components thus reducing waste and use of material from different sources.

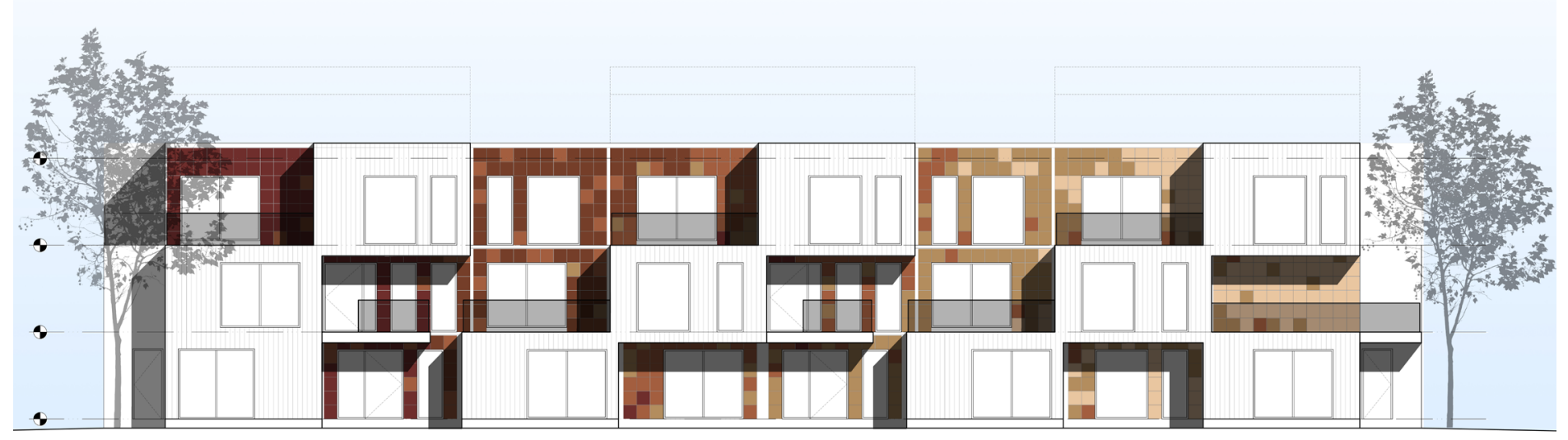

South elevation

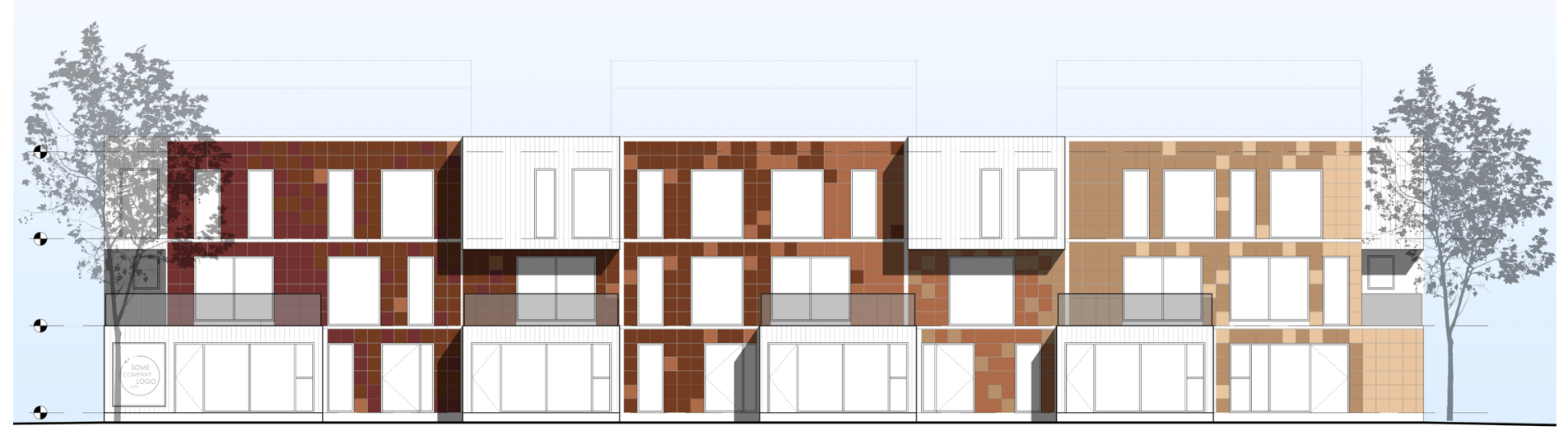

North elevation 
Fig 6.28 Floor Plans

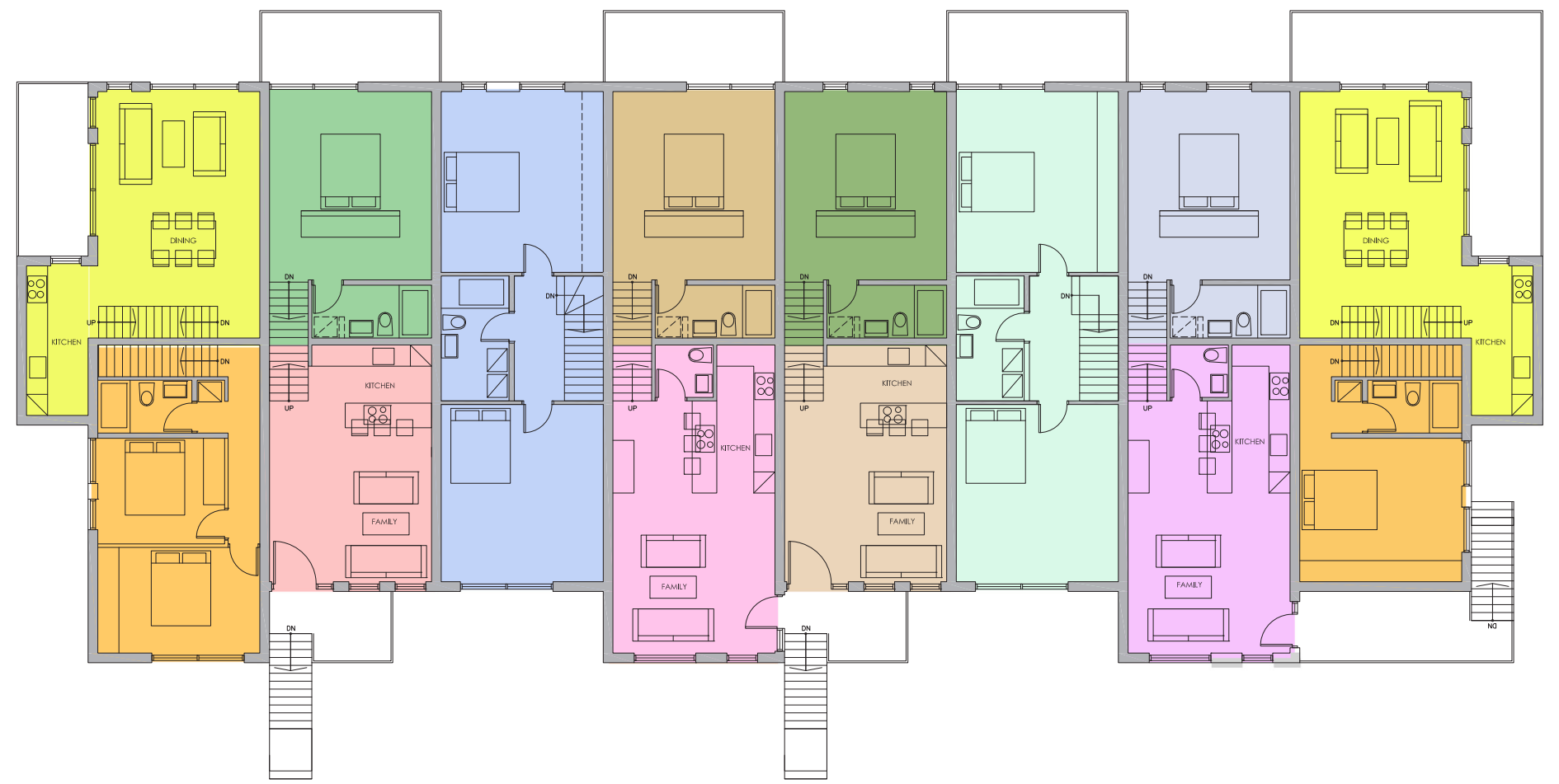

SECOND FLOOR PLAN

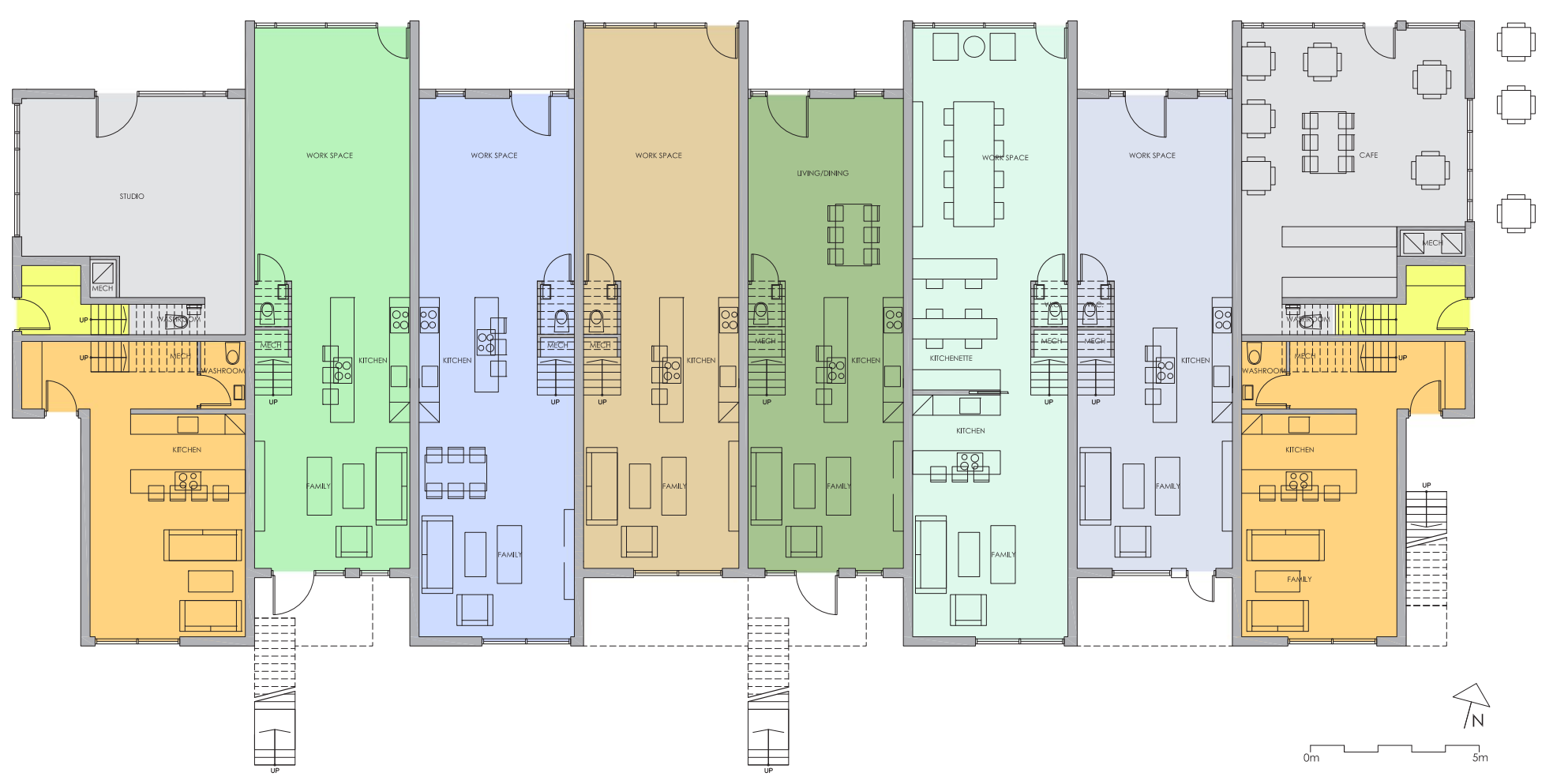




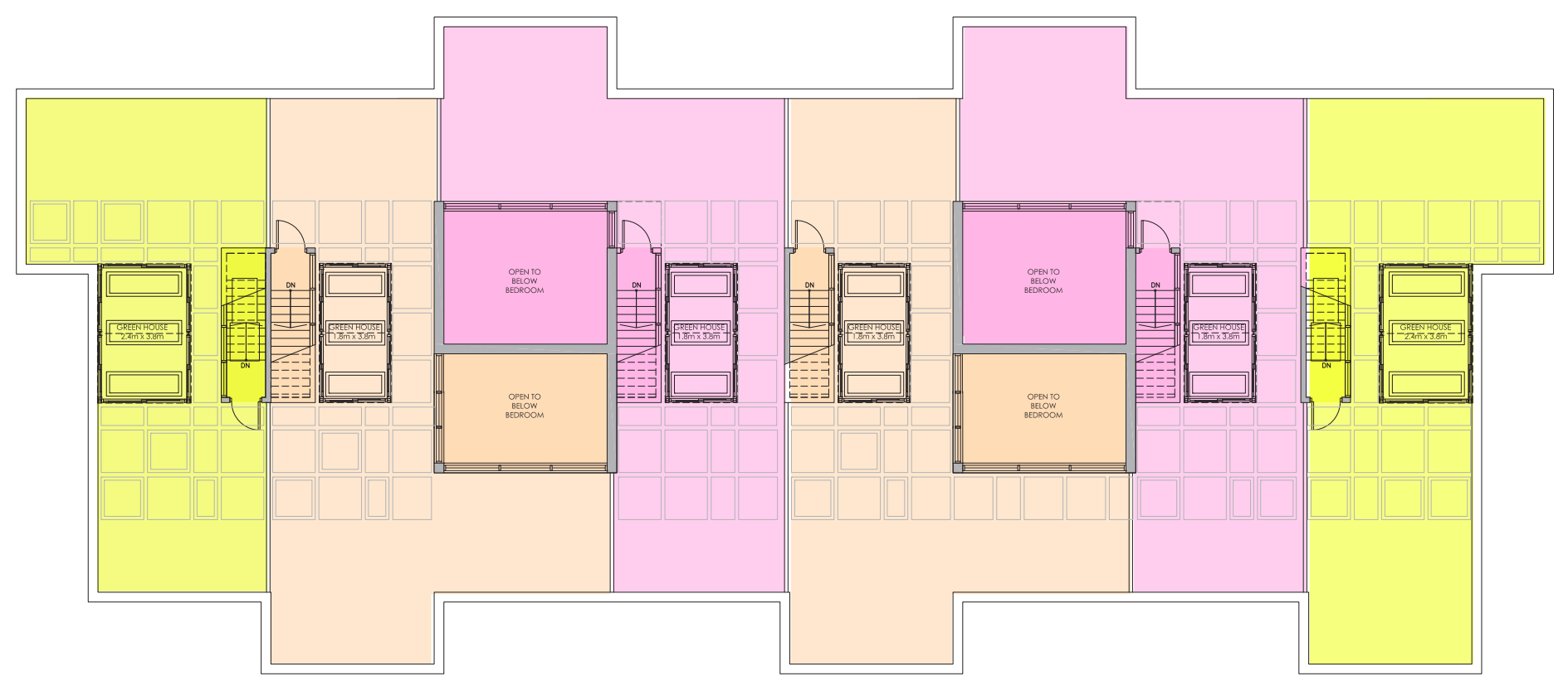

ROOF PLAN

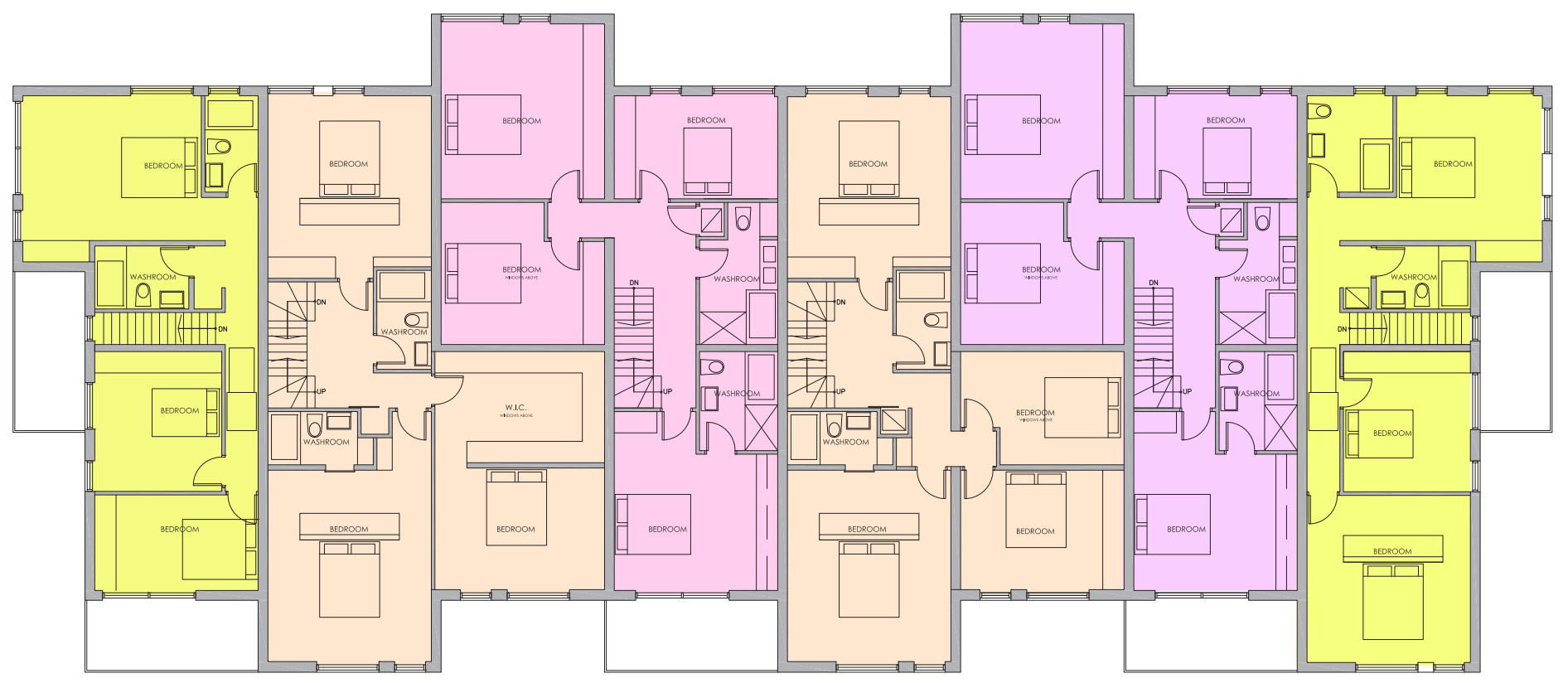

THIRD FLOOR PLAN

THIRD FLOOR PLAN

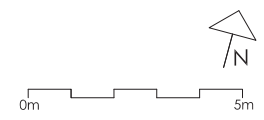


The units are can be delivered without partition walls (where possible), with a wall system available for installation by owner. All electrical systems are to be provided at the external walls. This arrangement leaves freedom to modify the interior spaces as needed by the occupant with minimal energy requirement and fast modifications can be made as conditions change (roommates, growing family etc.)

Fig 6.29 Variations within one unit, non-permanent partitions, all electrical on external walls for flexibility in space subdivision.
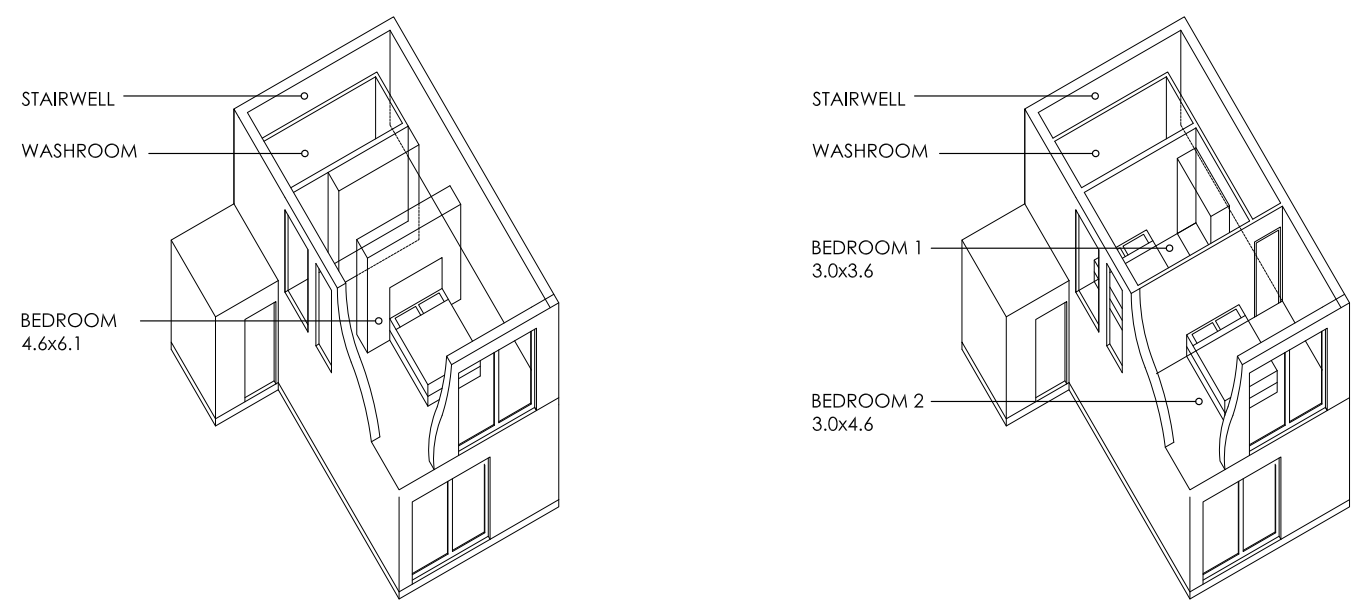

Fig 6.30 Partition detail, mechanical fastening, no adhesive or plastering, all elements designed for fast erection and disassembly
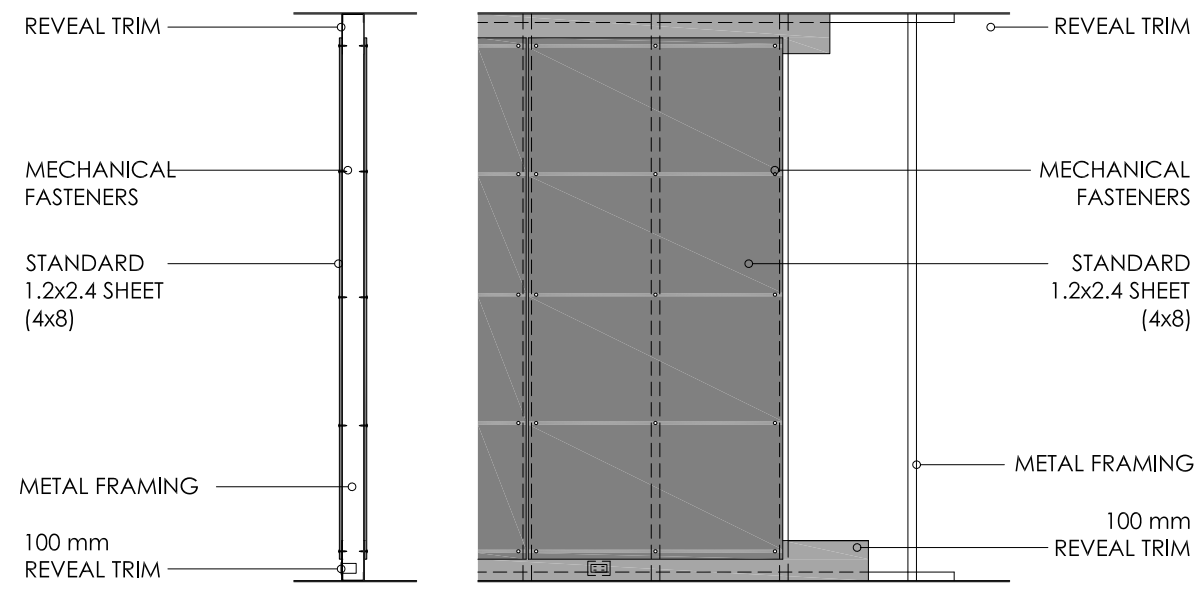
The roof top is to house a number of structures prepared to be used as gazebos or green houses. The bolted structure uses $100 \mathrm{~mm} \mathrm{~W}$ shapes sourced from the original building. The spacing of the steel structure is governed by typical residential patio doors with widths of 6 and 8 feet. It's a cost effective solution that gives a second life to components that otherwise would be discarded due to lack of performance. The doors are to be sourced from installation companies.
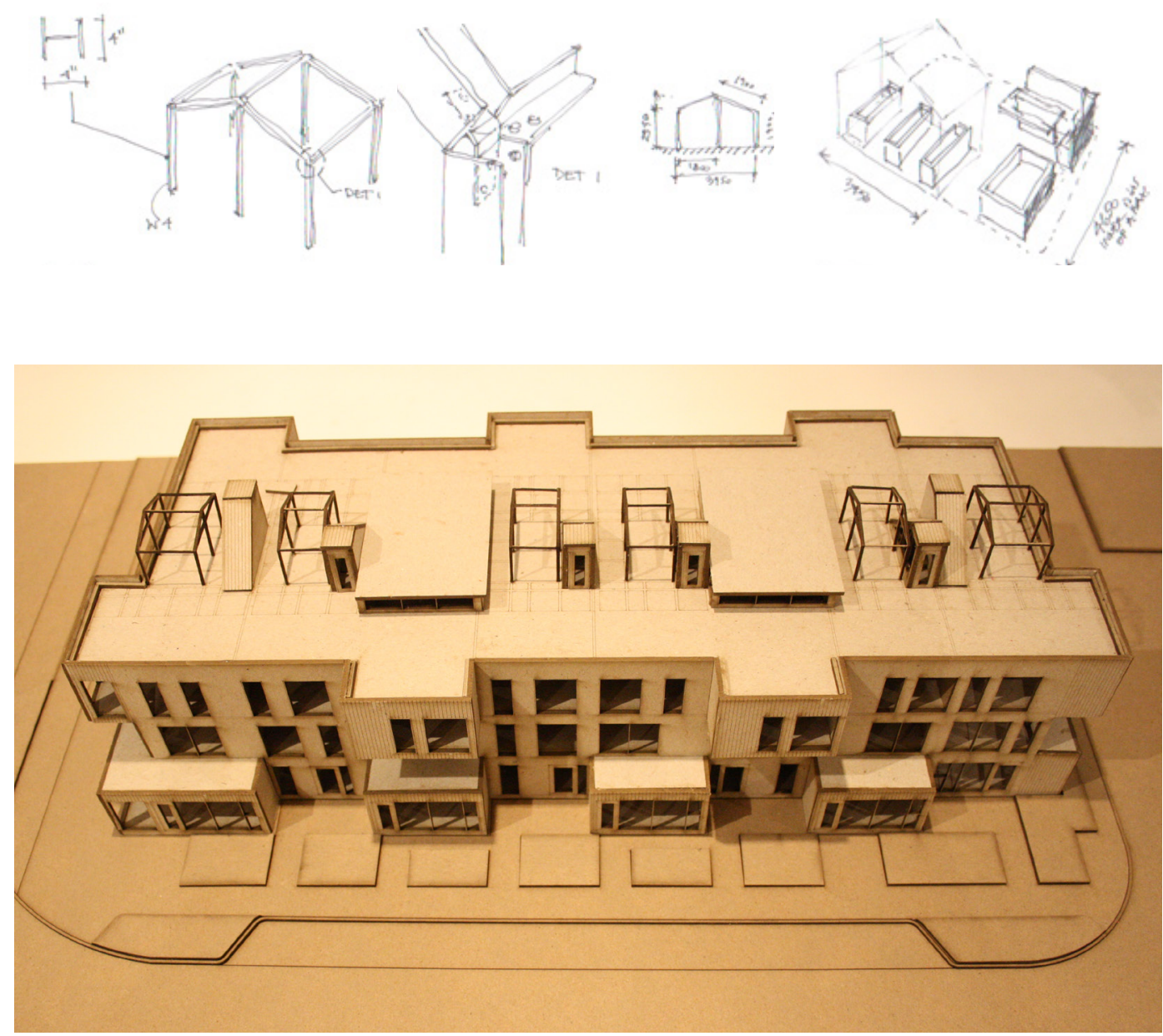
sign with full size stiar access.
Fig 6.33 Left: Final roof de-

Fig 6.31 Streel structure that can serve as greenhouses or pergola system

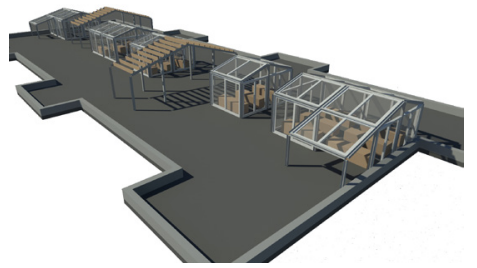

Fig 6.32 Above: Roof arrangement is access to the roof provided with hatches 


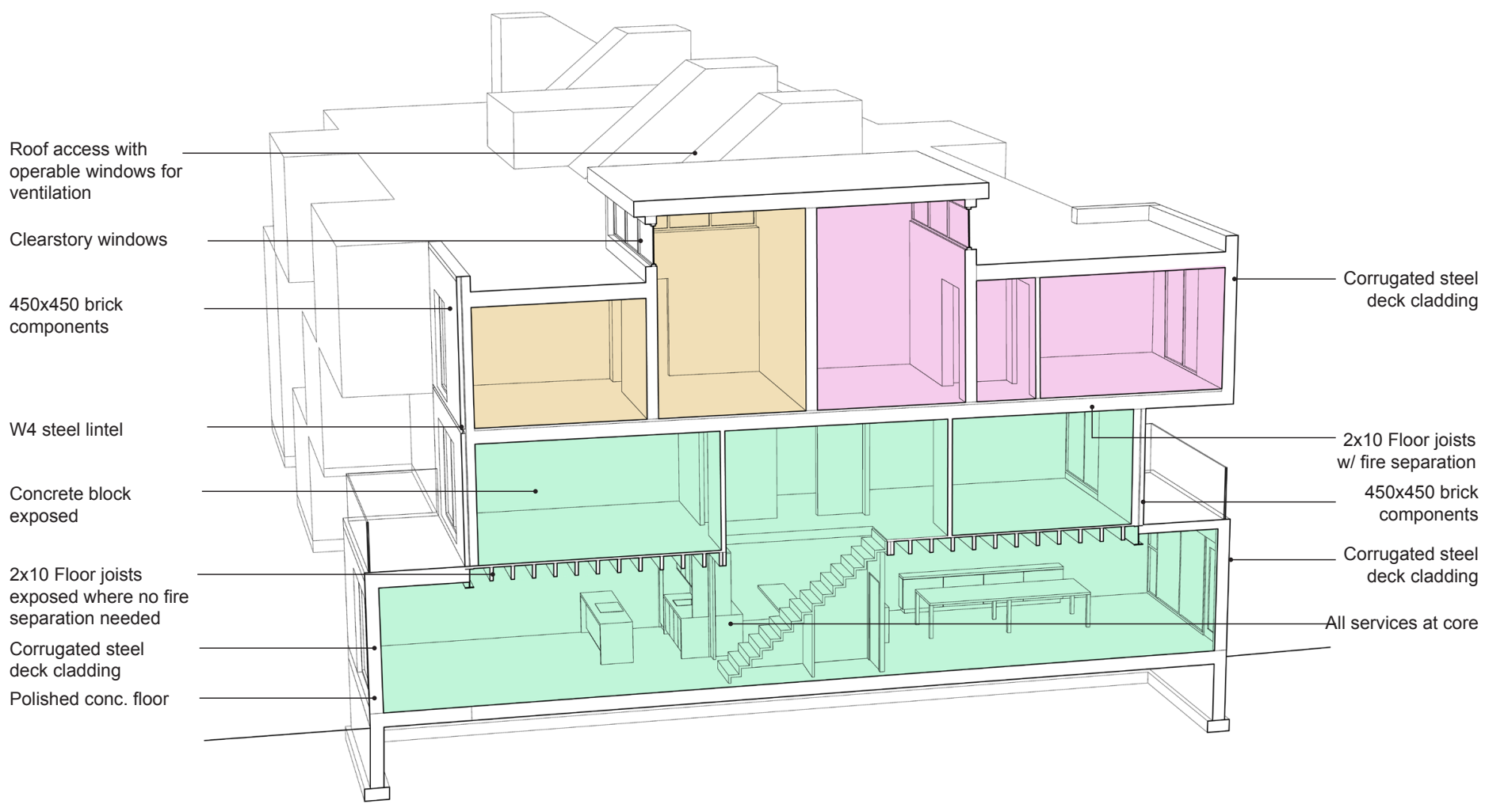

Fig 6.34 Section 

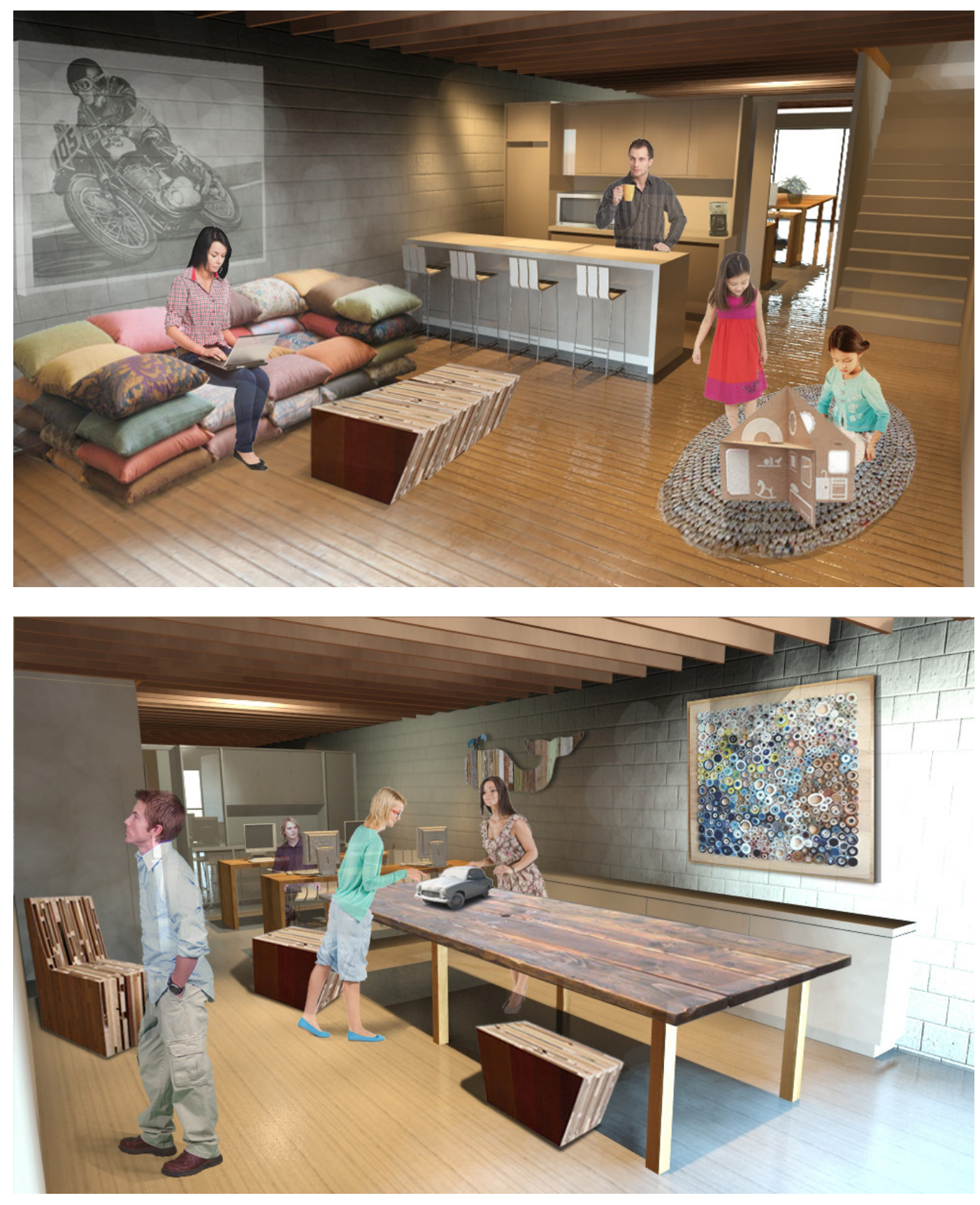

Fig 6.35 Interior, ground level, south (private) part of the unit; exposed concrete block partitions and exposed floor joists permit for structural honesty showing true character of reused material

Fig 6.36 Interior, ground level, north (work) part of the unit, furniture from reused material, display aging stain often sought after artificially in new construction 


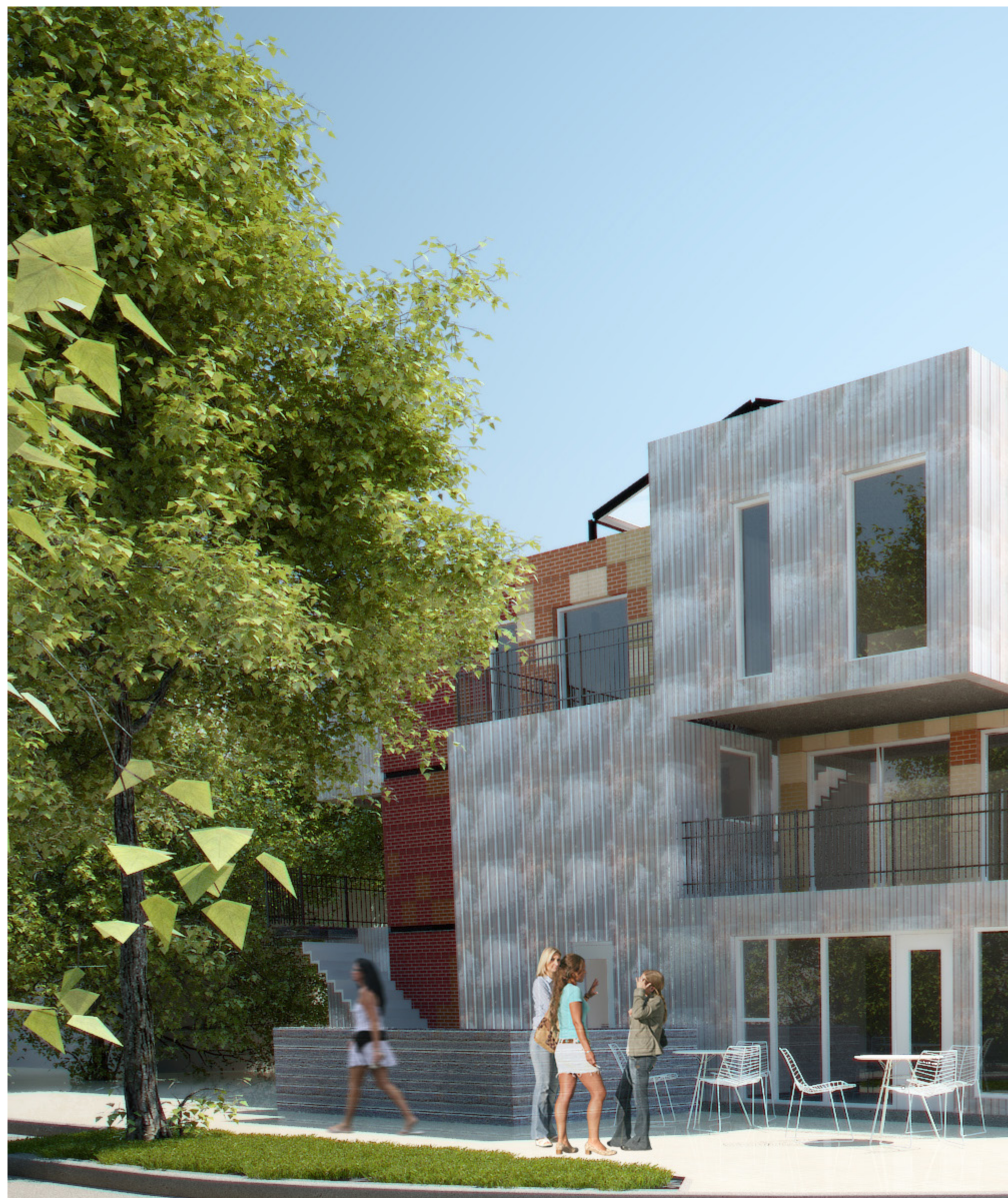


Fig 6.37 North east corner, intersection of Portland St and Windsor St.

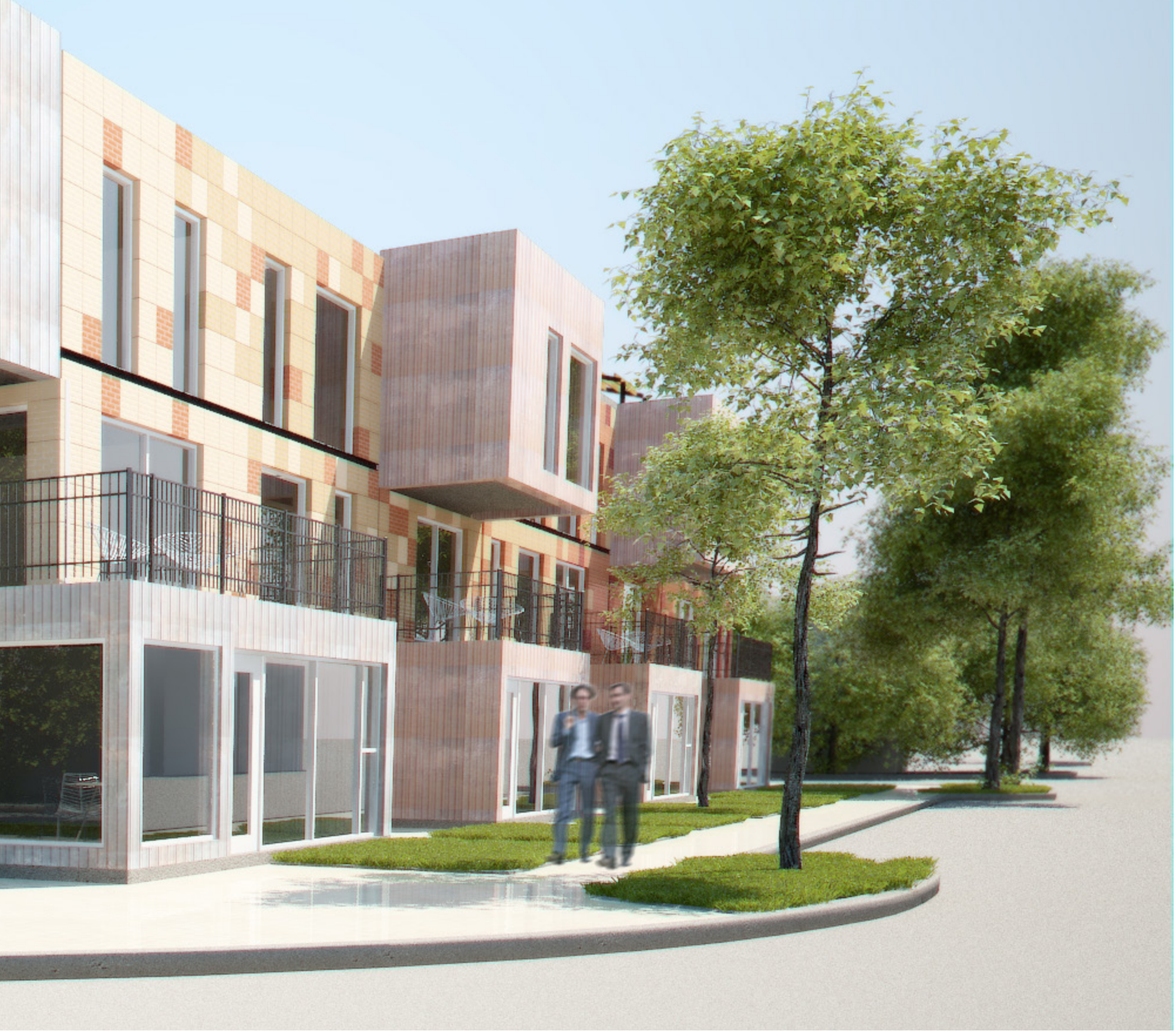




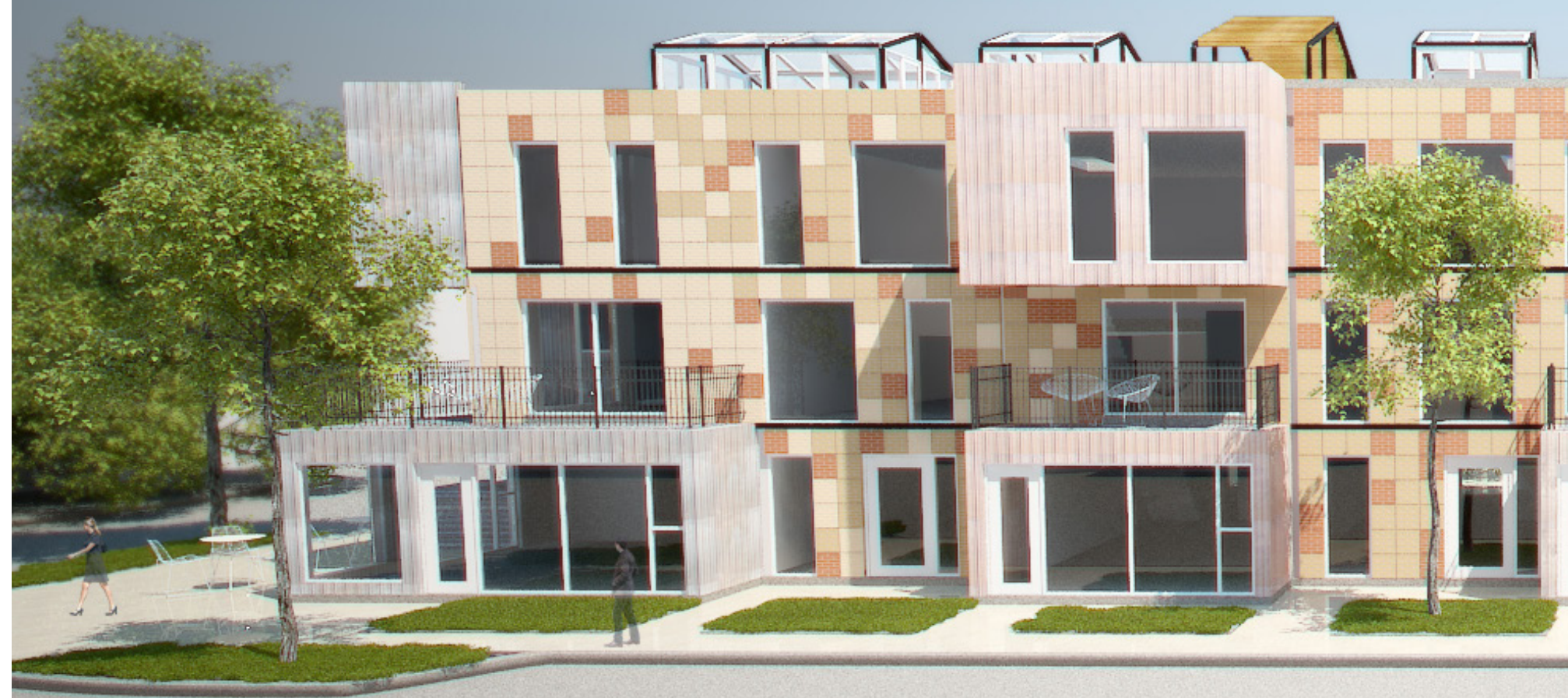




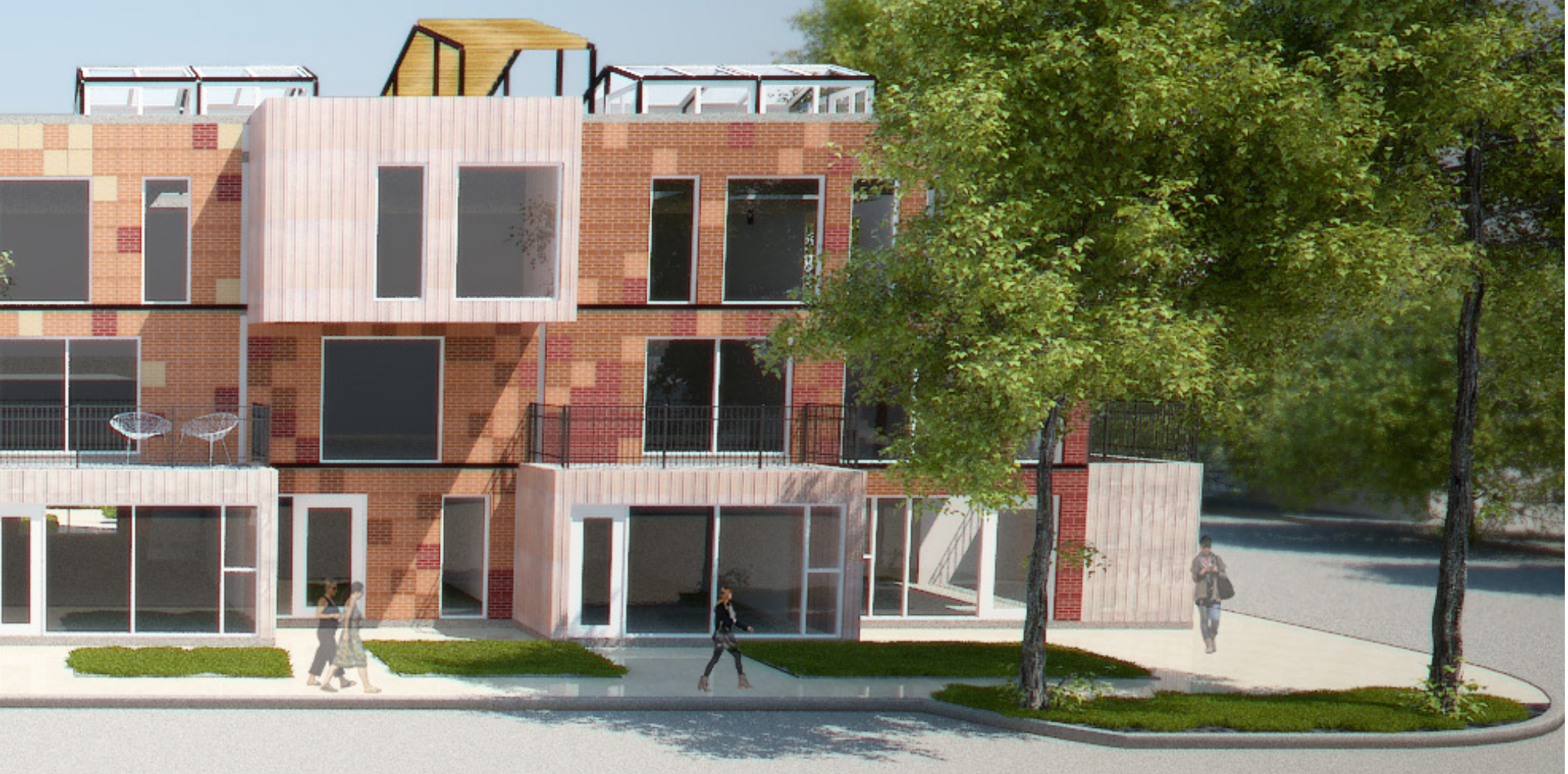




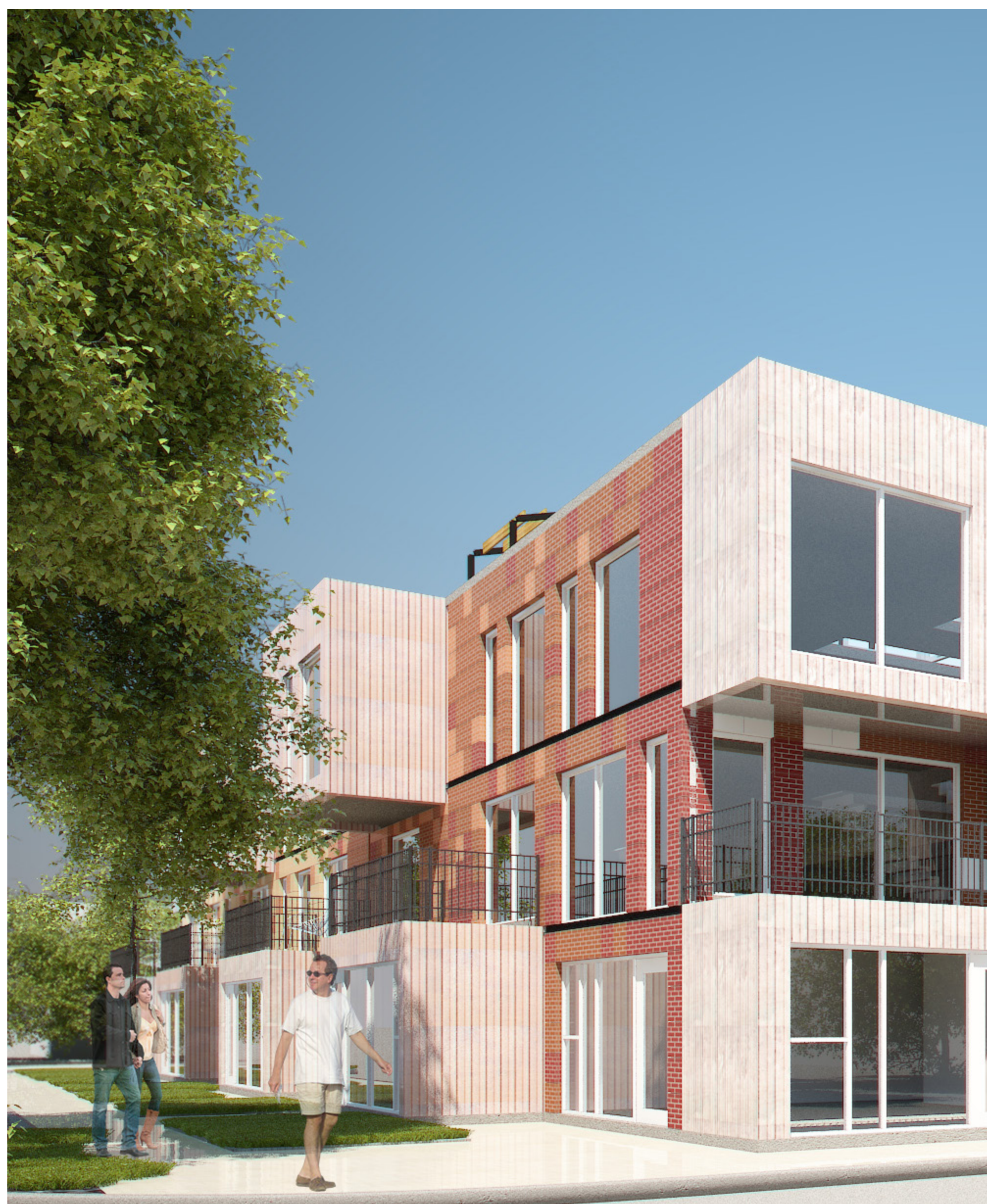




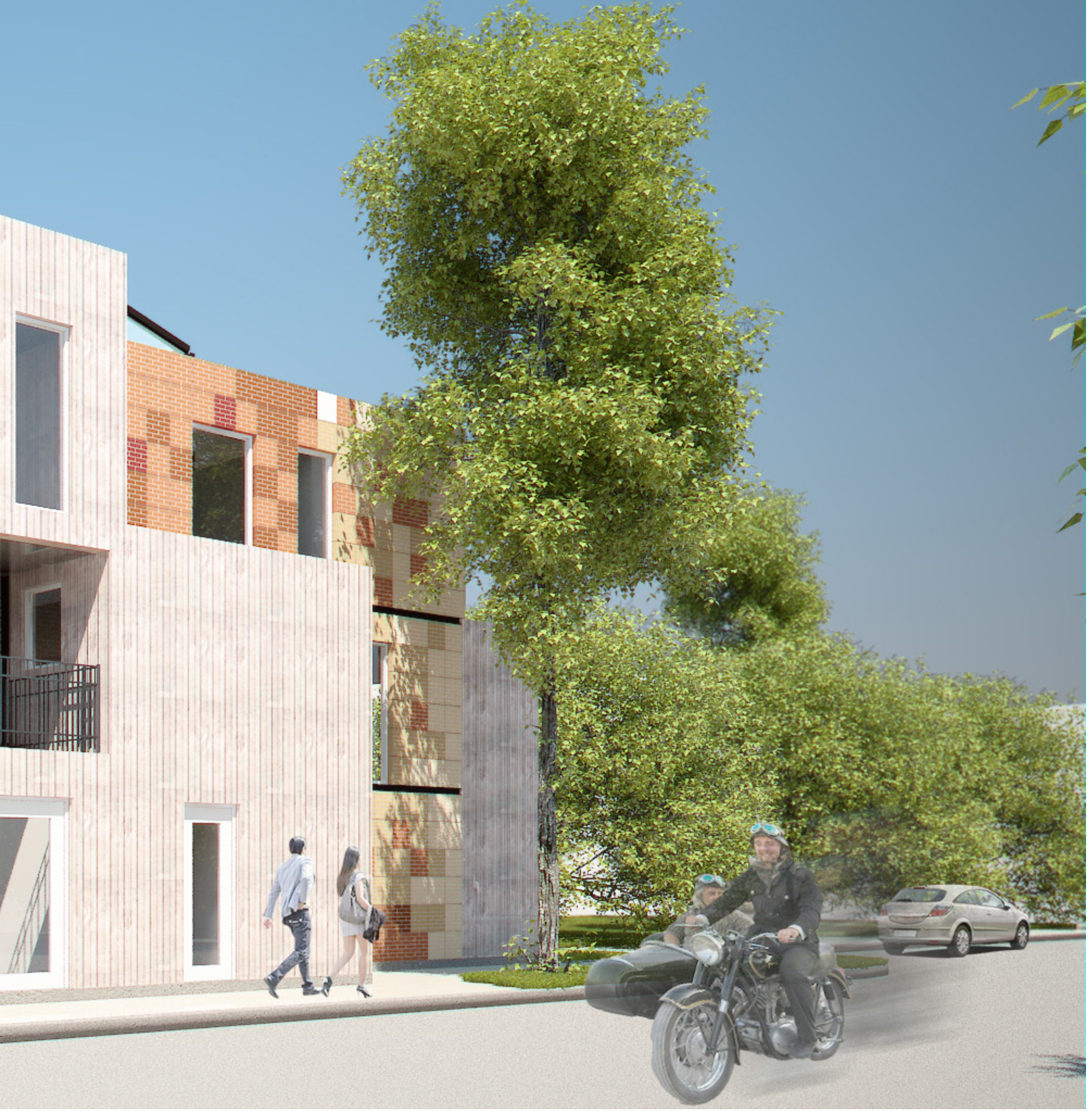




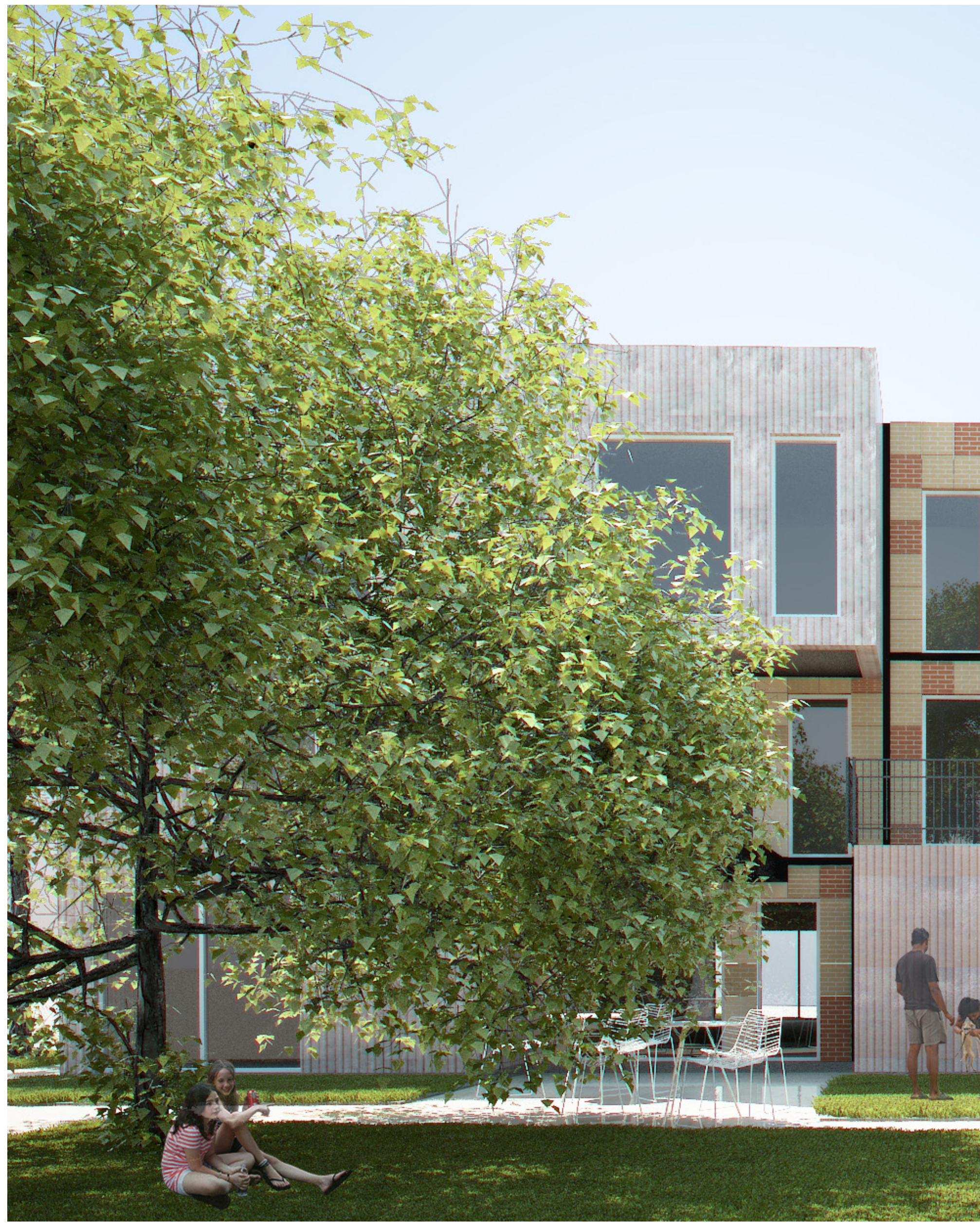




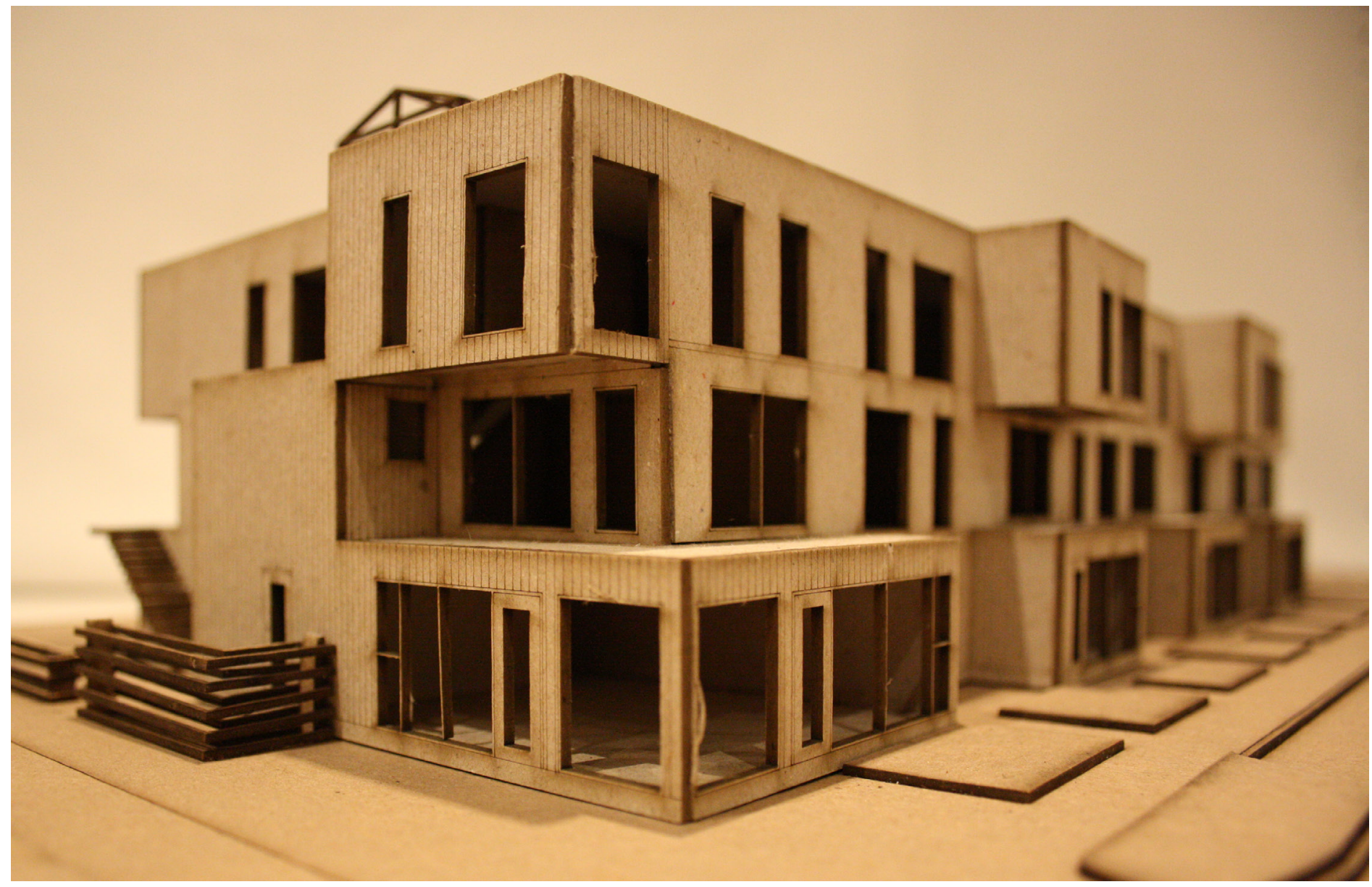

Fig 6.41 North East Corner

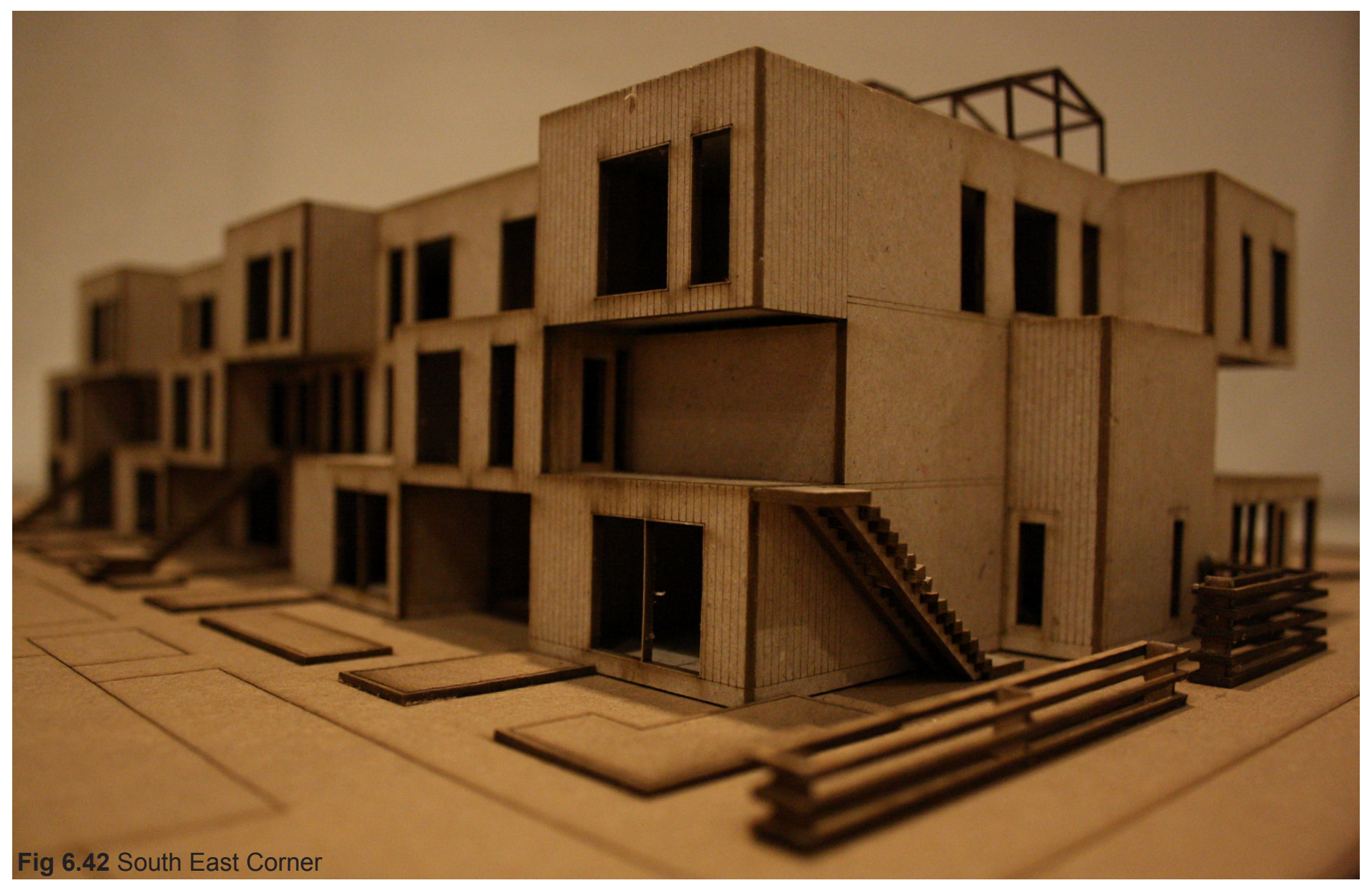




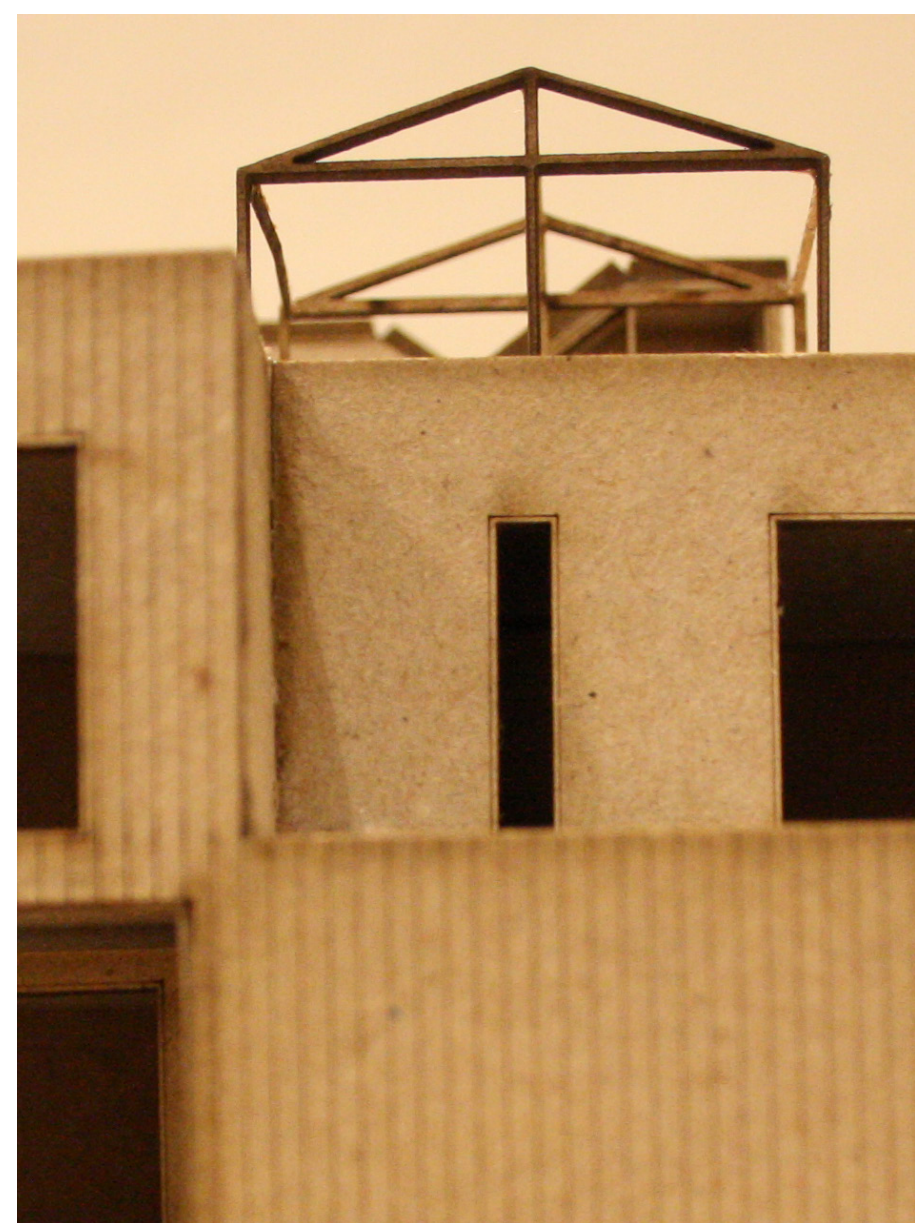

Fig 6.43 Greenhouse, West Elevation

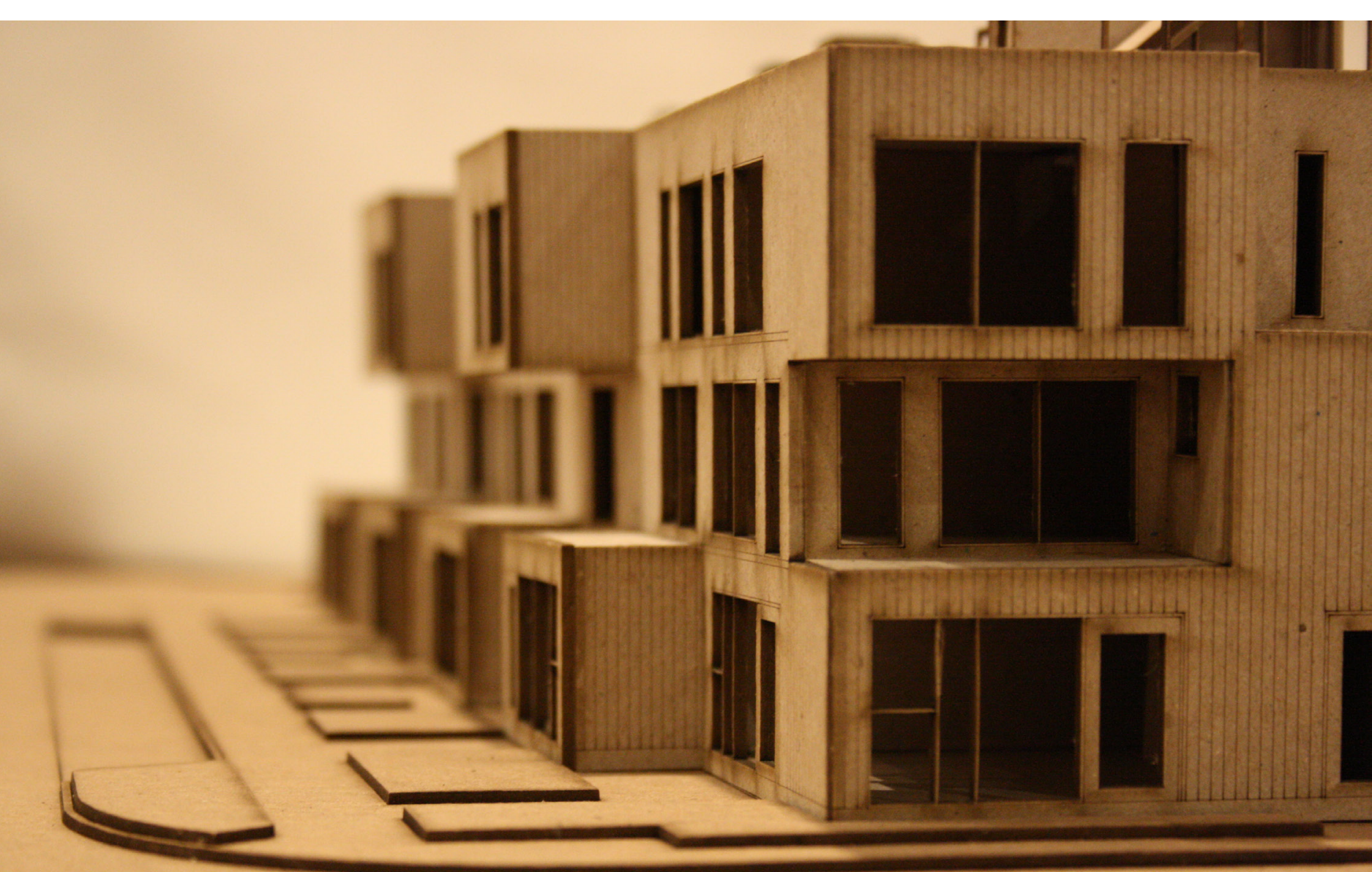

Fig 6.45 North West Corner 
Fig 6.46 Transverse Section, Section: NTS

All details scale 1:10

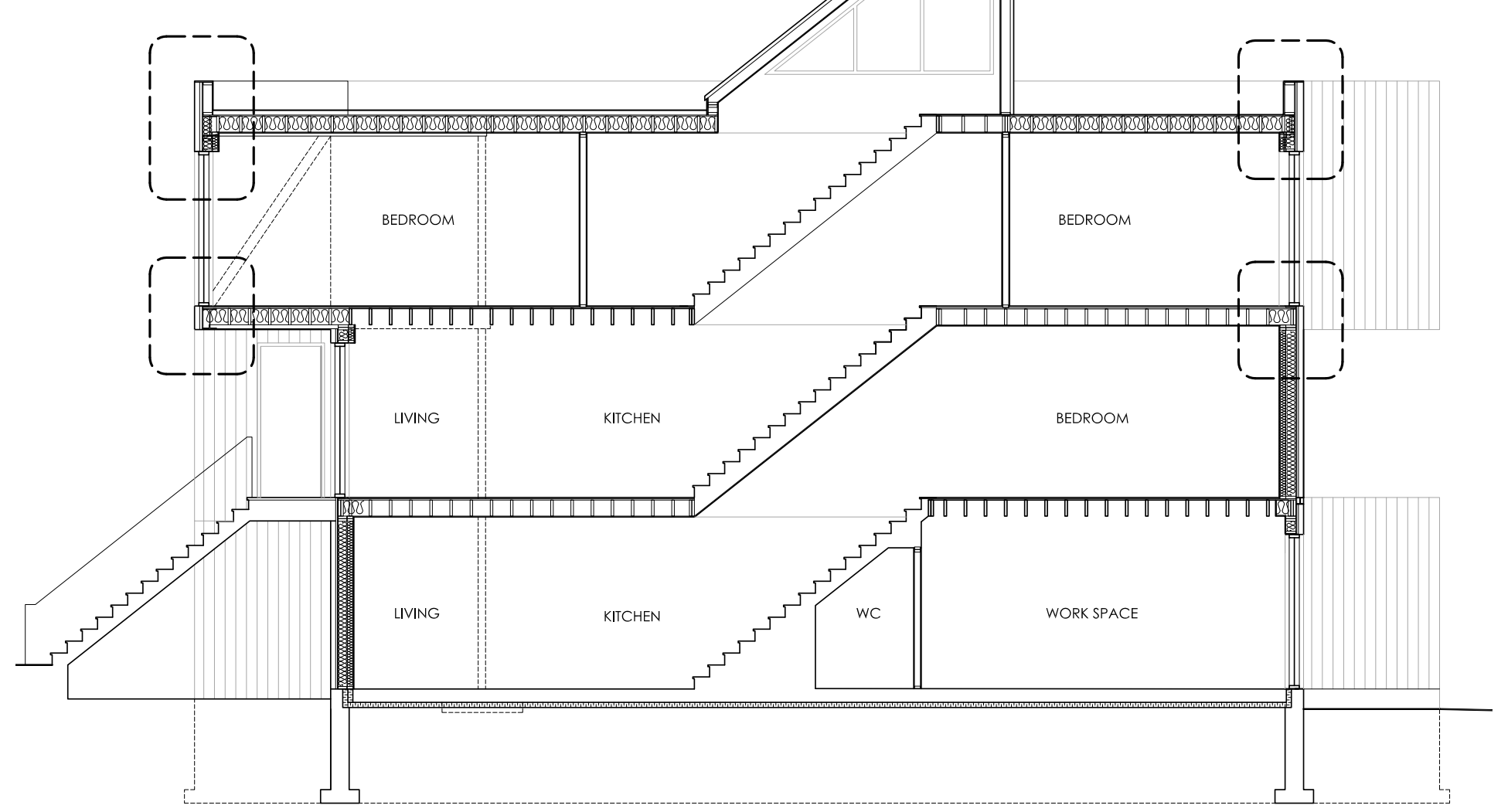

The party walls separating units and constructed of reclaimed concrete block. They serve both as fire separations and load bearing walls. The facade walls, therefore, are not load bearing and support thermal insulation and cladding only.

The external double walls are built of reclaimed $2 \times 4$ on $2 \times 6$ wood studs. 600 to $1800 \mathrm{~mm}$ studs are to be nailed together to achieve required length, this permits use of material that would otherwise be sent for reprocessing due to insufficient length. The studs of internal $(2 \times 4)$ and external $(2 \times 6)$ walls are not to be aligned in plan to minimize heat loss. The cavities are to be filled with R-13 (internal) and R-21 (external wall) recycled denim insulation, this provides thermal resistance of R-34 that exceeds current code regulations. Transportation of gypsum wall boards often results in damaging corners of the material. The double stud design permits use of undersized boards that otherwise would be sent to the manufacturer for recycling. The damaged boards are to be trimmed to $1100 \times 2150$ and fastened with exposed screws. Reveal trim will provide masking of the membrane beyond gypsum wall board.

The cantilever's steel components are to be covered with insulated sheathing to prevent thermal bridging. The product selected contains $80 \%$ post customer and has both insulation (R-5.5 per inch) and water-resistant properties.

Ceilings separating two different units are to be covered with continues fire resistant boards to meet the code requirements. Ceiling within one unit are to be exposed with visible structure and conduits.

The roof assembly is to be insulated with one layer of R-8 $(50 \mathrm{~mm})$ and one layer of R-30 (200mm) recycled denim insulation, as well as tapered polyisocyanurate insulation that at lowest point will provide thermal resistance of R-15. The internal layer of $50 \mathrm{~mm}$ insulation allows for electrical work (wiring, conduits) without affecting the outer $200 \mathrm{~mm}$ layer of insulation. The resistance of the roof assembly is estimated to be R-53. 


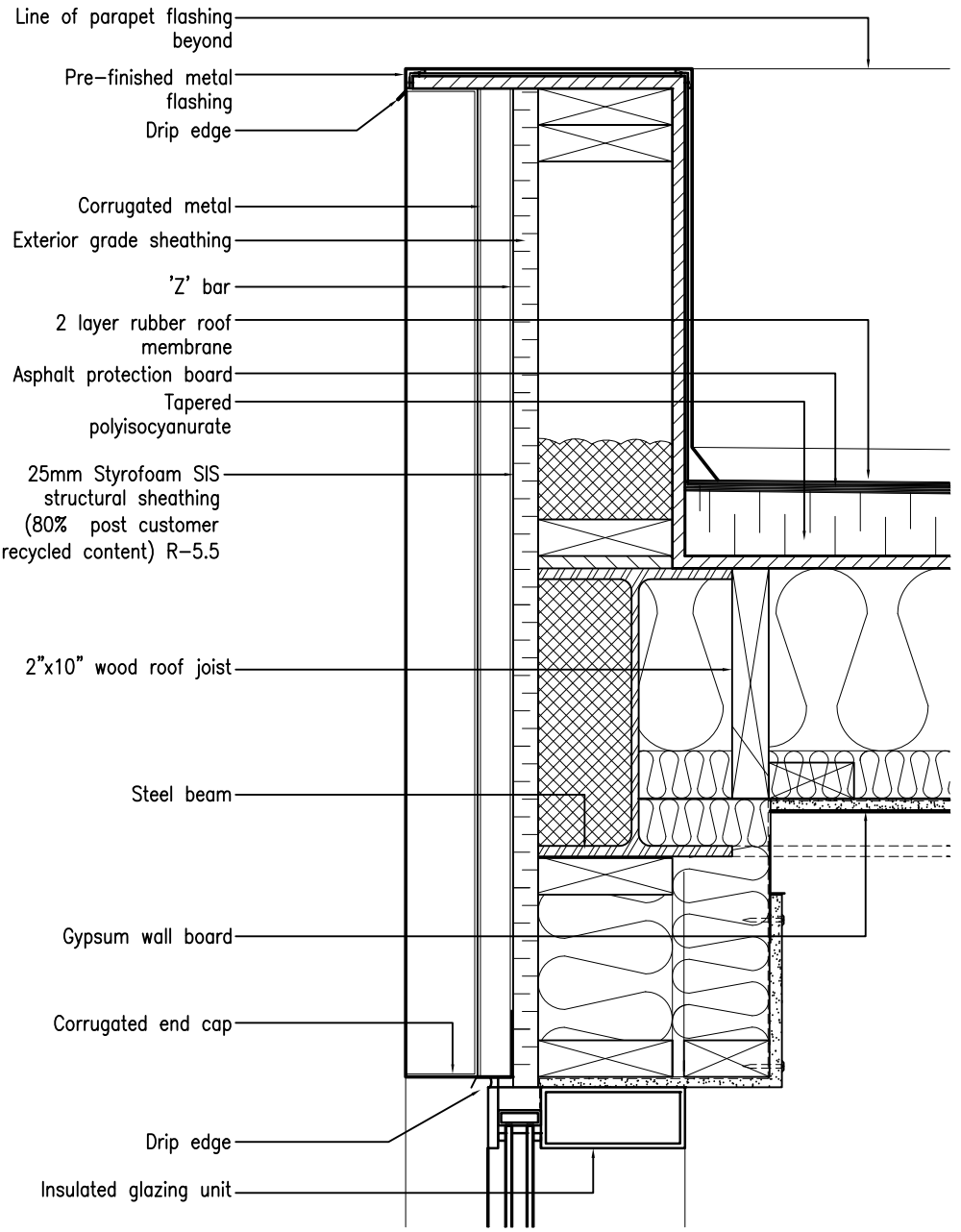

Fig 6.47 Parapet detail at cantilever

Fig 6.48 Soffit detail at cantilever

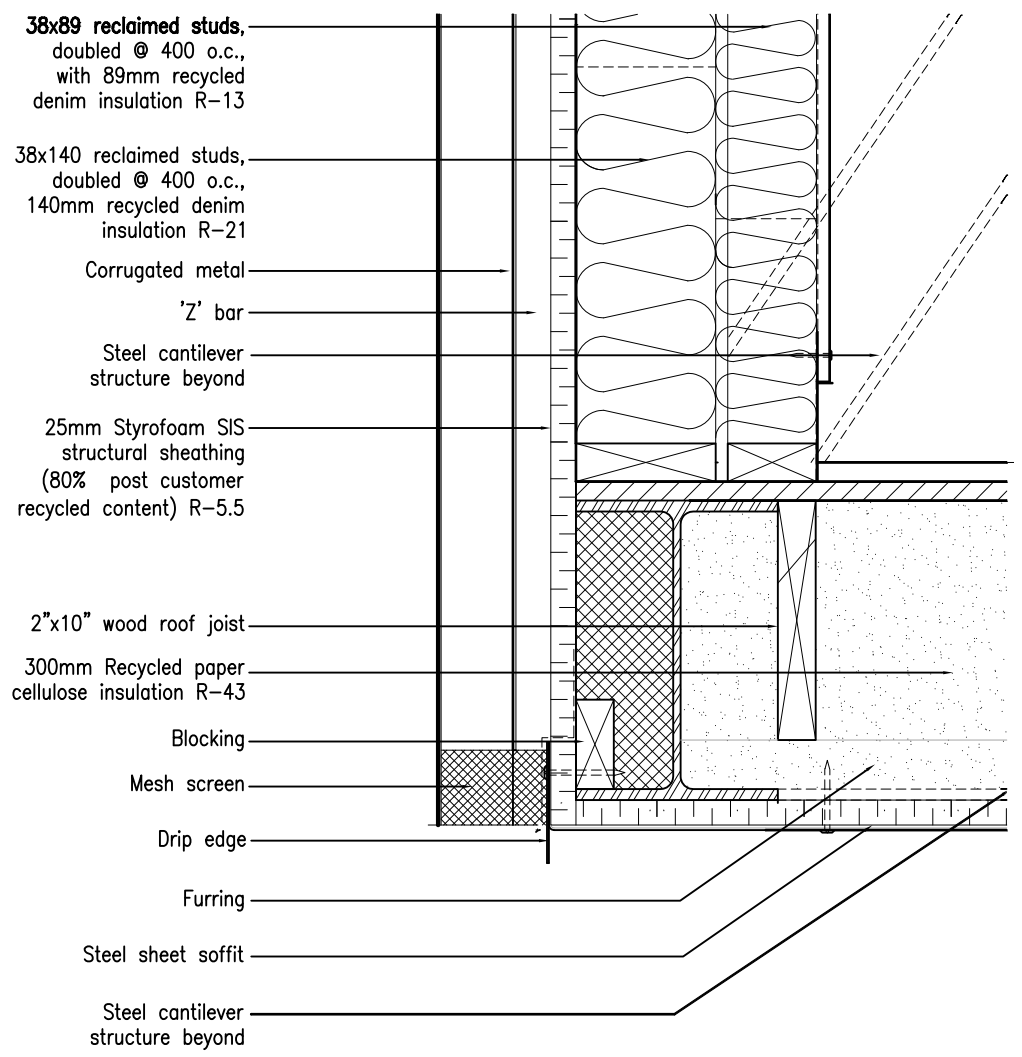

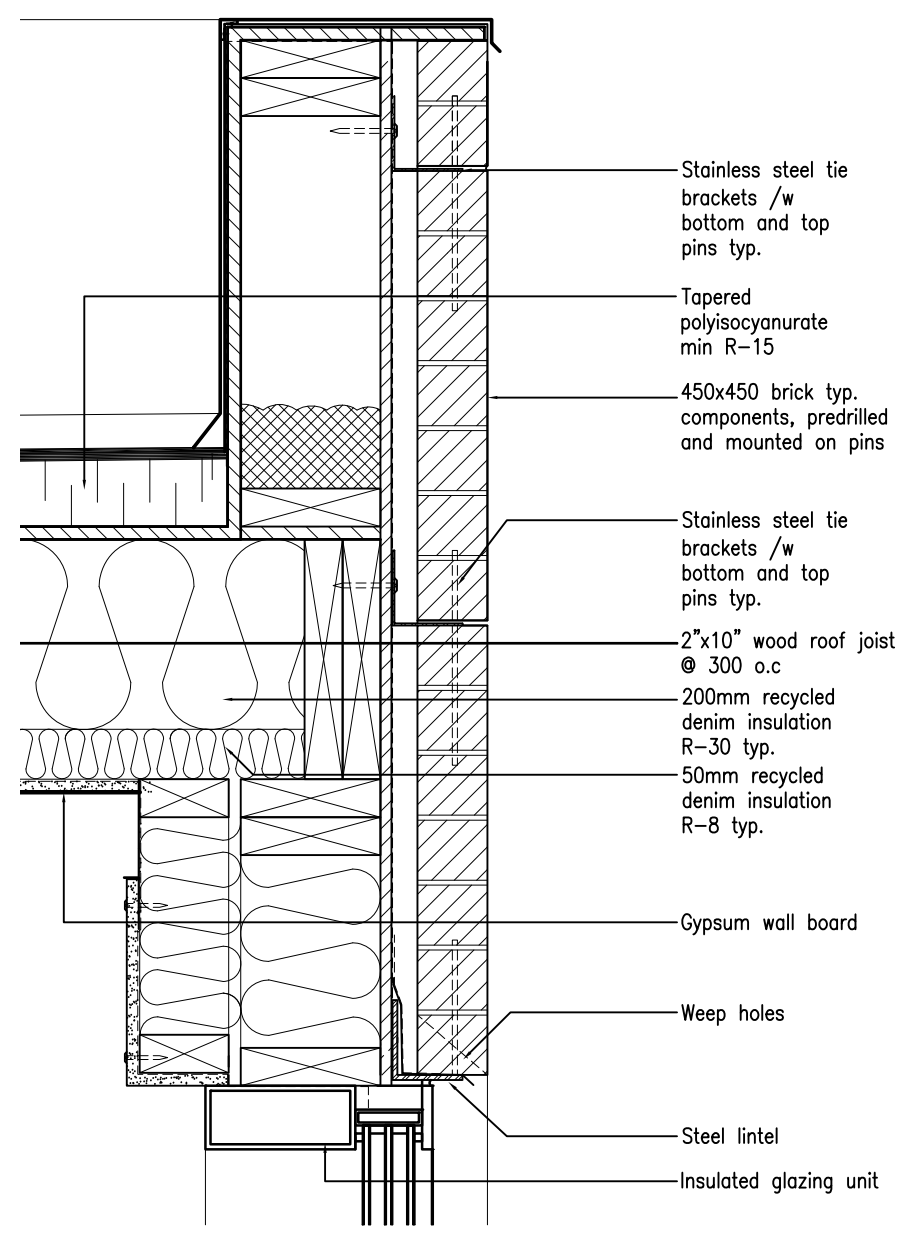

Fig 6.48 Parapet detail at brick component

Fig 6.49 Lintel detail

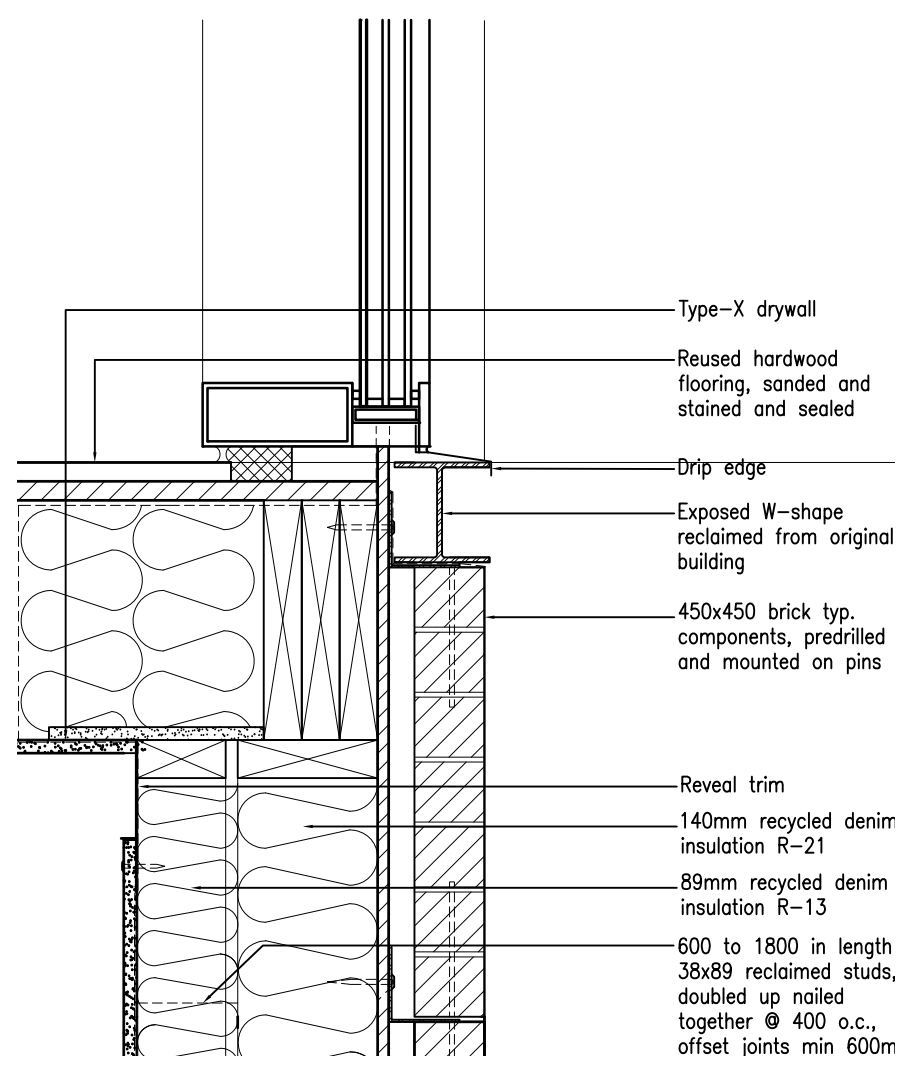




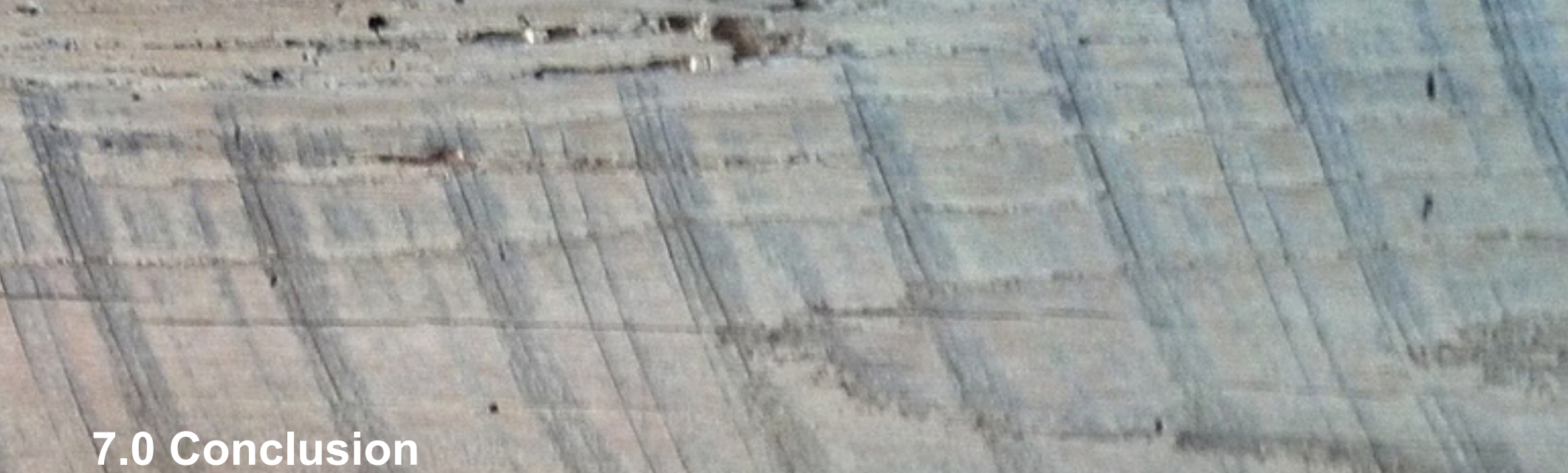

7.0 Conclusion

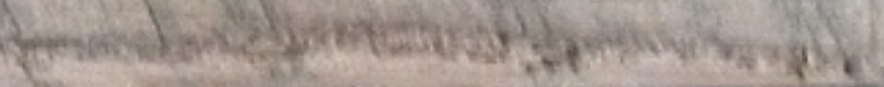

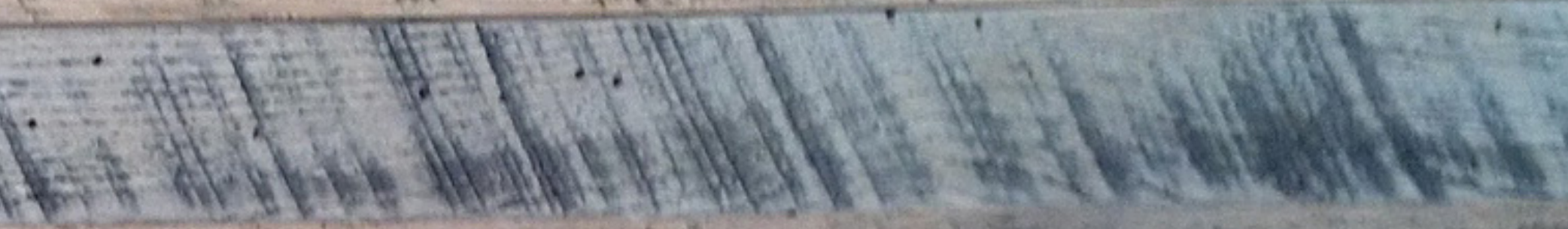

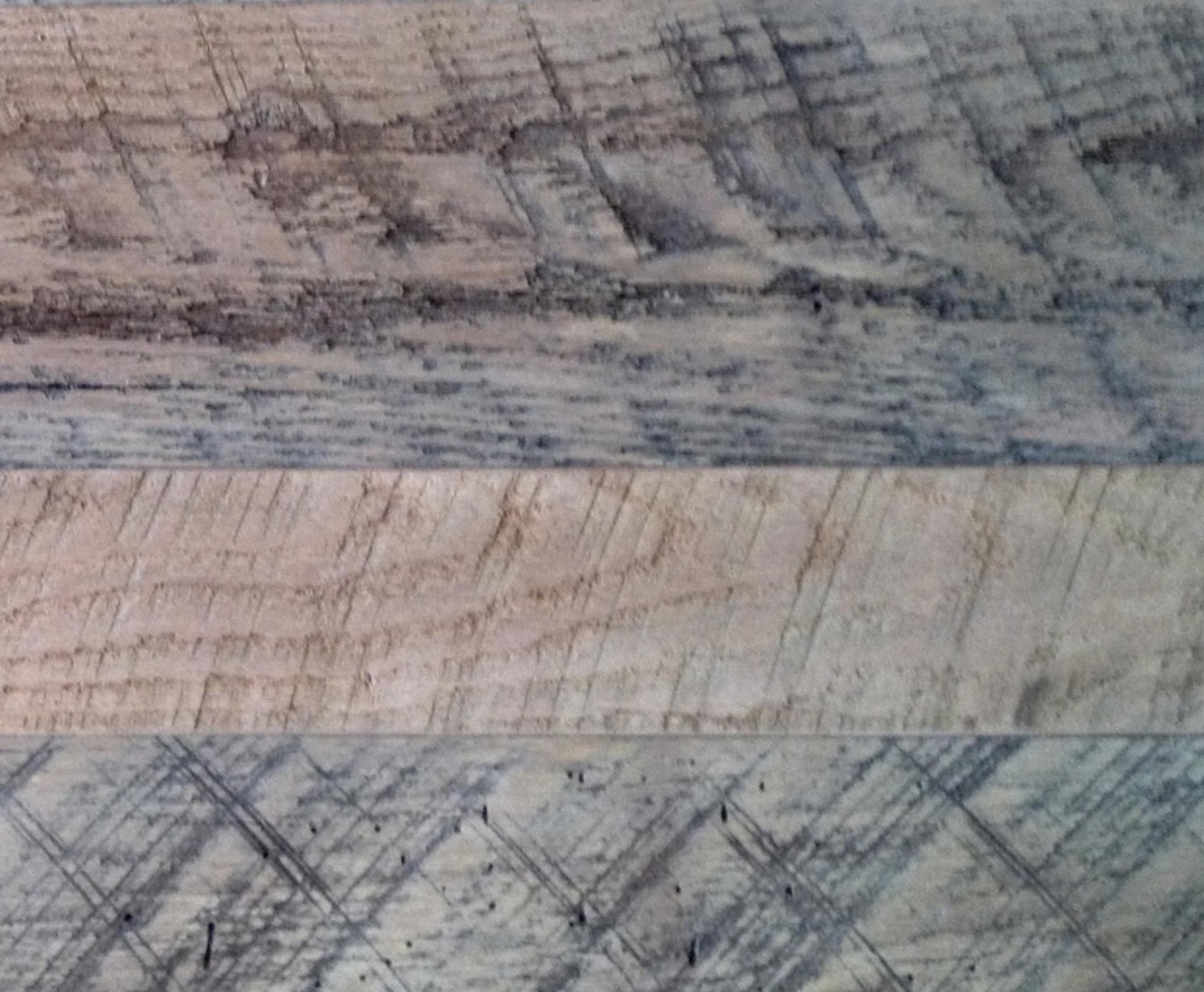


Fig 7.0 Old growth lumber

\subsection{Conclusion}

There are numerous impacts of designing with reused material on architectural practice. These can be noticed on every level from preliminary design to design development and contract management stage and include:

-Increases time required for design development stage

-If architect is required to survey for potential material source it might result in "non-billable" hours unless prior arrangement is made; as material organization (supplier, quantity and quality) is typically done by the contractor in Design Bid Build (DBB)

-Survey of an existing building for potential material is time consuming and samples for testing are difficult or impossible to obtain as the donor buildings are often still in use. (in case of well prospering cities)

-Increased time required for Design Development as multiple iterations are developed due to change in material quality and availability. For example a scenario where the specified reused material does not perform as desired during tests can result in mandatory redesign. (Ogbu L., 2010)

Involvement of all stakeholders at an early stage of the project is highly advisable. If DBB process is used, the architect can be assisted by a reused material consultant, thus externalizing the typical unknowns and challenges associated with the material. Although currently difficult to find, some consultants provide full spectrum of services: support with samples, specifications, and submittals; check for pricing and availability and quality of material; and coordinate purchase orders with the contractor. If the contractor is preselected by the owner and no reused material consultant is contracted, early involvement and dialogue between parties is recommended. This creates additional time investment in the early stage of the project, but externalizes material related problems to the contractor (material availability and quality and testing), thus reducing Design Development stage compared to typical DBB. It also eliminates possible extra costs associated with 'unknown methods' cited by contractors when working with reused materials. 
Designing with reused material creates a challenge from an architectural, engineering and construction stand point. The traditional design process has an added layer of working with the given components that put additional restraints on the designer. That restraint can have positive impacts by encouraging designers to conduct investigations with unconventional materials (in case of superuse) or with conventional materials in unusual fashion (pixelated elevation with material sourced from different buildings). Currently material reuse is not a common part of an architectural practice; however, with increasing cost of energy and non-linear relationship between energy and cost of building supplies, we will more often look at non-traditional sources of material. Such will allow for unusual aesthetics and experimentation to happen. My exploration was based on material sourced from current demolition trends with the goal typology matching current demands and was conservative in its form (to maximize the reapplication of material I was working with).

Success of reused material projects on large scale will have two results. One of those result is higher demand for reused material, material which otherwise would be a waste. The effect of that is treating waste as a commodity, thus making it less competitive with new materials in terms of cost. The second result of successful material reuse will be the end of designing with reused material as described in this thesis. As reused materials will have to compete with new materials the deconstruction will have to become more efficient, thus making deconstruction a high priority in the new designs. It can be considered that design with reused materials is only a step towards design for deconstruction, which seems to be an inevitable ultimate result of means oriented design. 


\section{List of figures}

Fig 1.0 Residential House Demolition, photographed by author 2013

Fig 1.1 Diminishing Resources, years remaining at rate of current use Future City Lab: Future in Progress. Please Do Disturb - Taymoore Bal baa et al. (2012), retrieved from http://www.blurb.co.uk/b/3210482-futurecity-lab-future-in-progress-please-do-distu, September 01, 2013.

Fig 1.2 Construction and demolition waste landfill. retrieved from http://www. ecy.wa.gov/programs/swfa/greenbuilding/images/CDLlandfill.jpg, Sep tember 01, 2013.

Fig 1.3 2009 Toronto Garbage Collection Srike. Temporary dump site, retrieved from http://wvs.topleftpixel.com/photos/2009/07/garbage_strike_queen_ sherbourne_01.jpg, September 01, 2013.

Fig 1.4 Recycling material prepared for processing, retrieved from http://www. facm.umn.edu/prod/groups/uservices/@pub/@uservices/@fm/@recy cling/documents/content/uservices_content_277453.jpg, September 01, 2013.

Fig 1.5 Current linear flow "cradle to grave", drawn by author

Fig $1.6 \quad$ Etobicoke building demolished, with steel components segregated for re cycling - reuse opportunity, photographed by author 2011

Fig 1.7 Reused material retailer in Ontario, photographed by author 2013

Fig 1.8 Salvaged and overstock materials offered at restores at fraction of the retail price, retrieved from $\mathrm{http} / / /$ media.syracuse.com/green/photo/201004-14-sdc-habitat6jpg-42c6aaba6aff1af8_large.jpg, September 01, 2013.

Fig 2.0 Abandoned steel structure, photographed by author 2012

Fig 2.1 Reused architectural elements from Pi-Ramesses, retrieved from http://4. bp.blogspot.com/-OaGo94Bz170/TcXW5CCBY4I/AAAAAAAAANI/mS GD0-bw4DY/s320/P4202144.JPG, September 01, 2013.

Fig 2.2 Ancient Rome stone reuse in later construction, retrieved from http://files. myopera.com/smclay/albums/7319262/DSC00147-Jewish\%20Ghetto. JPG, September 01, 2013.

Fig 2.3 Rebuilding Warsaw 1945, retrieved from http://1.bp.blogspot.com/-oZiorP diNsw/TmOBqOpjFCI/AAAAAAAAEIg/u8GfHu-rXI0/s400/IMG_8765. JPG, September 01, 2013.

Fig 2.4 Material Flow - alternatives to 'cradle to grave', diagram drawn by author

Fig 2.5 Hinte, E. v. (2007). In Peeren C., Jongert J. (Eds.), Superuse: Construct ing new architecture by shortcutting material flows. Rotterdam: 010 Pub lishers. 
Fig 2.6 Material Reuse Stages Diagram , drawn by author

Fig 2.7 Wikado Playground 2012 Architecten, Rotterdam, The Netherlands, retrieved from http://playgrounddesigns.blogspot.ca/2011/04/wikadoplayground-2012-architecture.html, September 01, 2013.

Fig 3.0 Reutilized materials, retrieved from http://www.archdaily.com/30050/bigdig-building-single-speed-design/inverset/, September 01, 2013.

Fig 3.1 Salvaged elements from Central Artery/Tunnel Project in Boston, retrieved from http://www.archdaily.com/24396/big-dig-house-singlespeed-design/1490218073_frame/, September 01, 2013.

Fig 3.2 Salvaged structural steel Central Artery/Tunnel Project in Boston, retrieved from http://www.archdaily.com/24396/big-dig-house-singlespeed-design/1059713129_columns/, September 01, 2013.

Fig 3.3 Salvaged invertset panels used in the Big Dig House, retrieved from http://www.archdaily.com/24396/big-dig-house-single-speed-de sign/840200782_inversets/, September 01, 2013.

Fig 3.4 Construction sequence and assembly of structural steel frame and in vertset floor/roof panels sourced from the Boston infrastructure project, retrieved from http://www.archdaily.com/24396/big-dig-house-singlespeed-design/\#, September 01, 2013.

Fig 3.5 From infrastructure to architecture, retrieved from http://www.ssdarchitec ture.com/works/residential/big-dig-building/, September 01, 2013.

Fig 3.6 Reuse of infrastructure elements - Big Dig Building, retrieved from http:// www.ssdarchitecture.com/works/residential/big-dig-building/, September 01, 2013.

Fig 3.7 Miele Space Station, retrieved from http://opendesignnow.org/index.php/ visual_index/recycling/, September 01, 2013.

Fig 3.8 From infrastructure to architecture, retrieved from http://opendesignnow. org/wp-content/uploads/2011/05/2012-miel-space-station-2-copy.

jpg, September 01, 2013.

Fig 3.9 Mountain Equipment Co-op Winnipeg is an example of material reuse

and adaptive reuse, retrieved from http://www.communitynewscommons. org/our-city/economy-business/grass-routes-2013-seeks-the-good-life/at tachment/mec-winnipeg/, September 01, 2013.

Fig 3.10 Construction Stages: two left buildings deconstructed for material reuse, retrieved from http://www.prairiearchitects.ca/commercial?project= Mountain-Equipment-Co-op\&id=15, September 01, 2013. 
Fig 3.11 MEC Winnipeg Material summary, Ogbu, L. (2010). Design for Reuse Primer: 15 Successful Reuse Projects Wihin Different Sectors Explored in-depth. Researched and edited by Public Architecture. Ver sion 2.0 Public Architecture

Fig 4.0 Bulk material wall - reclaim opportunity, photographed by author

Fig 4.1 Embodied energy of selected materials Hammond G., Jones C. Inventory of Carbon \& Energy (ICE) Version 1.6a, Sustainable Energy Research Team, University of Bath, UK. retrieved from http://www.bath.ac.uk/mecheng/sert/embodied/, September 01, 2013.

Fig 4.2 Materials reuse opportunities within a selected typology Calculation and table by author, unit values based on Hammond G., Jones C. Inventory of Carbon \& Energy (ICE) Version 1.6a, Sustainable Energy Research Team, University of Bath, UK. etrieved from http://www.bath.ac.uk/mecheng/sert/embodied/, September 01, 2013.

Fig 4.3 Wartime house - components breakdown materials reuse opportunities, exploded axonometric, image by author

Fig 5.0 Bulk material - brick, photograph by author

Fig 5.1 Unit material extraction, images by author

Fig 5.2 Component extraction, images by author

Fig 5.3 Small unit arrangements, images by author

Fig 5.4 Large unit extraction, images by author

Fig 5.5 Large unit arrangements, image by author

Fig 5.6 Stone fabrication saw, photographed by author

Fig 5.7 Settlement tank / Deposit collector, photographed by author

Fig 5.8 Harvest map for reuse and superuse, map by author, Images 1-3, 5-9 photographed by author, image 4 retrieved from http://www.bing.com/ maps/, September 1, 2013.

Fig 6.0 Oxidized metal surface Autodesk 3dmax map

Fig 6.1 Outline of the demolished industrial buildings, retrieved from http://www. bing.com/maps/, September 1, 2013.

Fig 6.2 Completed row housing development, retrieved https://www.google.ca/ maps/, September 1, 2013. 
Fig 6.3 South Etobicoke, maps by author

Fig 6.4 101 Portland St overview, retrieved http://www.bing.com/maps/ and https://www.google.ca/maps/, September 1, 2013.

Fig 6.5 Investigated building; well preserved structural components with bolted connection suitable for deconstruction, photographed by author

Fig 6.6 Investigated building; well preserved structural components with bolted connection suitable for deconstruction, drawings by author

Fig 6.7 Full take off of potential material to be reused including the material sizes and quantities, table by author

Fig 6.8 Steel structure with wood joists (open plan), drawings by author

Fig 6.9 Unit variations, image by author

Fig 6.10 Arrangements, image by author

Fig 6.11 Diagrams by author

Fig 6.15 Projected densification and laneway development, images by author

Fig 6.16 Detail site plan, drawing by author

Fig 6.17 Rendering looking west from Windsor St., image by author

Fig 6.18 Rendering looking west along Portland St., images by author

Fig 6.19 Rendering looking east along Portland St., images by author

Fig 6.20 Rendering looking north along proposed laneway, images by author

Fig 6.21 Cantilever cladding, elevation drawings by author

Fig 6.22 Large reclaimed component cladding system, sketches by author

Fig 6.23 Available materials, photographs by author

Fig 6.24 Initial material palette, sketches by author

Fig 6.25 Small component extraction, images by author

Fig 6.26 Small component cladding system using typical stone cladding brackets/ ties, drawing by author

Fig 6.27 Small component cladding system, elevations by author 
Fig 6.28 Floor Plans, drawings by author

Fig 6.29 Variations within one unit, non-permanent partitions, all electrical on exter nal walls for flexibility in space subdivision, drawings by author

Fig 6.30 Partition detail, mechanical fastening, no adhesive or plastering, all ele ments designed for fast erection and disassembly, drawings by author

Fig 6.31 Streel structure: greenhouses or pergola system, sketches by author

Fig 6.32 Roof arrangement access with hatches, image by author

Fig 6.33 Final roof design with full size stair access, model and photograph by au thor

Fig 6.34 Section, drawing by author

Fig 6.35 Interior, ground level, south (private) part of the unit, image by author

Fig 6.43 Greenhouse, West Elevation, model and photograph by author

Fig 6.44 South West Corner, model and photograph by author

Fig 6.45 North West Corner, model and photograph by author

Fig 6.46 Transverse Section, not to scale, drawing by author

Fig 6.47 Parapet detail at cantilever, scale 1:10, drawing by author

Fig 6.48 Soffit detail at cantilever, scale 1:10, drawing by author

Fig 6.48 Parapet detail at brick component, scale 1:10, drawing by author

Fig 6.49 Typical wall / lintel detail, scale 1:10, drawing by author

Fig 7.0 Old growth lumber retrieved from http://www.cmstatic1. com/17379/17379.140596.jpg, Spetember 1, 2013 


\section{References}

Bahamón, A. (2010). In Sanjinés M. C. (Ed.), Rematerial: From waste to architecture. New York: W.W. Norton \& Co.

Bill Addis.Building with reclaimed materials - A design handbook for reuse and recycling. London: Beta-Plus, 2007.

Brigitte Franzen et al. (2010). In Brigitte Franzen, Marc Gunnewig, Florian Heilmeyer (Ed.), West arch vol. 1: A new generation in architecture Jovis Verlag.

Borrow, C. (04/2010), Habitat for Humanity Toronto Inc. Financial Statements.

Botkin, D.B. (2010). Powering the Future: A Scientist's Guide to Energy Independence, New Jersey: Pearson Education.

Brundtland G. H. (1987) Our common future. In, World Commission on Environment and Development. (Eds.), . New York: Oxford University Press ;|aOxford.

Bums, B. (2008) Ecosuss. Ottawa: School of Industrial Design, Carleton University

Chini, A. R. \& Breuning, S. F. (2003). Deconstruction and Materials Reuse in the United States. The Future of Sustainable Construction, May 14th 2003.

Dantata, N., Touran, A. \& Wang, J. (2004). An Analysis of Cost and Duration of Deconstruction and Demolition of Residential Buildings in Massachusetts. Resources, Conservation and Recycling, 2005, Vol. 44, p. 1-15.

European Commission, Environment Sustainable Development (23.02.2012) http://ec.europa.eu/environment/eussd/

Fitzgerald, M. (2006, September). 'big dig' house makes case for 'precycling'. The newspaper for member of the American Society of Civil Engineers. Retrieved from http://www.asce.org/LandingPage. aspx?id=21889

Gorgolewski, M, Morettin L., The Process of Designing with Reused Building Components, Ryerson University

Gorgolewski, M., Straka, V., Edmonds, J. \& Sergio, S. 2006 Facilitating greater reuse and recycling of structural steel in the construction and demolition process, Ryerson University report to Natural Resources Canada, Ottawa. See http://www. reuse-steel.org/contact/

Habitat for Humanity, Restore (2012), retrieved from http://www.habitat.ca/restore-p7376.php, September 1, 2013 
Hammond G., Jones C. Inventory of Carbon \& Energy (ICE) Version 1.6a, Sustainable Energy Research Team, University of Bath, UK. See http://www.bath. ac.uk/mech-eng/sert/embodied/

Hinte, E. v. (2007). In Peeren C., Jongert J. (Eds.), Superuse: Constructing new architecture by shortcutting material flows. Rotterdam: 010 Publishers.

Hongbin Li, Lei Li, Binzhen Wu and Yanyan Xiong The End of Cheap Chinese Labor, The Journal of Economic Perspectives Vol. 26, No. 4 (Fall 2012), pp. 5774 Published by: American Economic Association, Stable URL: http://www.jstor. org/stable/23290280

Jongert, J., Nelson, N., \& Goosens, F. (11/2011). Recyclicity: A toolbox for Resource $\square$ Based design. Architectural Design, 81(6), 54-61.

McDonald, D. (07/2010). Undraded Lumber In Farm Buildings, Order No. 10-055 Minisry of Agricultural Food and Rural Affairs

McLear, K. MaryEllen C. Nobe (2011) Return on Investment for Non-Profit Deconstruction, 47th ASC Annual International Conference Proceedings.

National Center for Craftsmanship. (2010). Home. Retrieved September 29, 2010 from http://www.nccraftsmanship.org/.

National Center for Craftsmanship. (2010). Deconstruct Model. Retrieved October 20, 2010 from http://www.nccraftsmanship.org/documents/ ${ }^{* \star * \star *}{ }_{-}$Deconstruct_ Summary_11-9-09.pdf.

National Center for Craftsmanship. (2010). Deconstruct. Retrieved October 20, 2010 from http://www.nccraftsmanship.org/deconstruct.shtml.

Ogbu, L. (2010). Design for Reuse Primer: 15 Successful Reuse Projects Wihin Different Sectors Explored in-depth. Researched and edited by Public Architecture. Version 2.0 Public Architecture

Ontario. Ministry of Municipal Affairs and Housing. Building and Development Branch. (2006). 2006 building code compendium. (OBC) Toronto: Ontario Ministry of Municipal Affairs and Housing, Building and Development Branch.

Prairie Architects Inc. (2002) Mountain Equipment Co-op New Retail Facilities Summary of LEED Green Building Compliance. Winnipeg, Manitoba.

Rovers, R. (2008). In Klinckenberg F. (Ed.), Sustainable housing projects: Imple- 
menting a conceptual approach. Amsterdam: Techne Press.

Rovers, R. (2010) Material-Neutral Building: Closed Cycle Accounting for Buildings Construction A new practical way to measure improvements in creating a balanced resource use for construction, International Journal of Sustainable Building Technology and Urban Development , Vol. 1, Iss. 2, 152-159

Revenue Canada Agency, Determining fair market value (2011), retrieved September 1, 2013, from http://www.cra-arc.gc.ca/chrts-gvng/chrts/prtng/rcpts/dtrmnfmv-eng.html

Revenue Canada Agency, Charitable donation tax credit calculator (2013), retrieved September 1, 2013, from http://www.cra-arc.gc.ca/chrts-gvng/dnrs/svngs/ clmng1b2-eng.html

Saotome, T. (08/2007) Development of Construction and Demolition Waste Recycling in Ontario McMaster University, See http://msep.eng.mcmaster.ca/epp/ publications/student/Development_of_C\&D_recycling_in_Ontario.pdf

Single Speed Design (2006) retrieved from http://www.ssdarchitecture.com/ works/residential/big-dig-house/

Thorton, G. (05/2011) Financial Statements, Habitat for Humanity Toronto Inc.

Turgut, P. (2007). Cement composites with limestone dust and different grades of wood sawdust. Building and Environment, 42(11), 3801-3807. doi: 10.1016/j. buildenv.2006.11.008

U.S. Green Building Council (2001). LEED Green Building Rating System Version 2.0 retrieved September 1, 2013 http://www.usgbc.org/Docs/LEEDdocs/3.4x LEEDRatingSystemJune01.pdf.

United States Environmental Protection Agency (EPA), Lifecycle Building Challenge (12.19.2012)

http://www.epa.gov/greenbuilding/pubs/lbc.html

Wang, W.(2003) Sustainability is a Cultural Problem, Harvard Design Magazine 18 Spring/Summer 2003

Yeo, D., \& Gabbai, R. D. (2011). Sustainable design of reinforced concrete structures through embodied energy optimization. Energy and Buildings, 43(8), 20282033. doi: 10.1016/j.enbuild.2011.04.014 
